DEVELOPMENT AND VALIDATION OF A RADTHERM MODEL TO PREDICT EXHAUST SYSTEM BEHAVIOR FOR A HYBRID XM1124 HMMWV

Souman Haldar

Michigan Technological University

Follow this and additional works at: https://digitalcommons.mtu.edu/etds

Part of the Mechanical Engineering Commons

Copyright 2015 Souman Haldar

Recommended Citation

Haldar, Souman, "DEVELOPMENT AND VALIDATION OF A RADTHERM MODEL TO PREDICT EXHAUST SYSTEM BEHAVIOR FOR A HYBRID XM1124 HMMWV", Master's report, Michigan Technological University, 2015.

https://doi.org/10.37099/mtu.dc.etds/960

Follow this and additional works at: https://digitalcommons.mtu.edu/etds

Part of the Mechanical Engineering Commons 


\section{DEVELOPMENT AND VALIDATION OF A RADTHERM MODEL TO PREDICT EXHAUST SYSTEM BEHAVIOR FOR A HYBRID XM1124 HMMWV}

By

Souman Haldar

A REPORT

Submitted in partial fulfillment of the requirements for the degree of MASTER OF SCIENCE

In Mechanical Engineering

MICHIGAN TECHNOLOGICAL UNIVERSITY

2015

(C) 2015 Souman Haldar 
This report has been approved in partial fulfillment of the requirements for the Degree of MASTER OF SCIENCE in Mechanical Engineering.

Department of Mechanical Engineering-Engineering Mechanics

\author{
Advisor: Jeremy. J. Worm
}

Committee Member: Dr. Scott Miers

Committee Member: $\quad$ Dr. Stephen Hackney

Committee Member: Dr. Lucia Gauchia

Department Chair: $\quad$ Dr. William W. Predebon 


\section{Table of Contents}

List of Figures.....................................................................1 1

Acknowledgements .............................................................. 2

List of Abbreviations ........................................................... 3

Abstract ................................................................................... 4

1. Introduction...........................................................................5

2. Modeling of the Exhaust System ..................................... 6

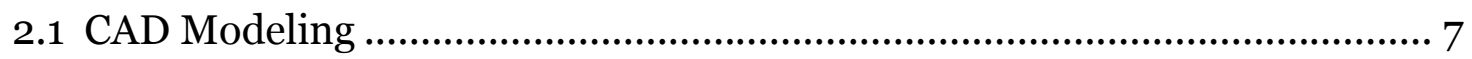

2.2 Mesh Of the Geometry...........................................................................

2.3 Thermal Modeling in RadTherm..................................................................15

2.3.1 Flowchart For RadTherm Model Development ..........................................17

2.3.2 Heat Transfer Mechanism between exhaust gases and exhaust pipe ......19

2.3.3 Steps for RadTherm Modeling ..................................................................21

3. Calibration \& Validation of the RadTherm Model...........35

3.1 Experimental Setup................................................................................... 35

3.1.1. Measuring Mass Flow Rate Of The Exhaust Gases................................... 36

3.1.2. Temperature Of The Exhaust Gases Through The Exhaust System ....... 43

3.1.3 Surface temperature Of The Exhaust System And Vehicle Underbody ... 45

3.1.4. Surface Properties for the Outer Surface of Exhaust System ................... 49

3.1.5. Data Acquisition (DAQ) System................................................................5 51

3.2 Model Calibration ...................................................................................... 53

4. Results And Discusion ............................................. 60

4.1. Exhaust Gas Temperature Profile .................................................................6 60

4.2. Surface Temperature Profile for the Exhaust System ...................................61

4.3. Surface Temperature for the Underbody of HMMWV ............................... 62

4.4. In-Cabin Floor Temperature of HMMWV ................................................... 63

5. Conclusion ........................................................... 64

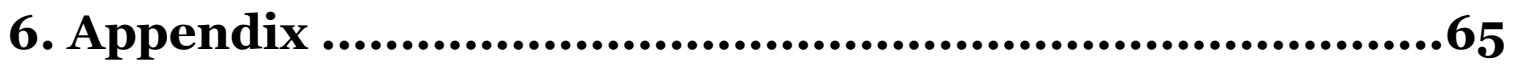

6.1. Energy conversion efficiencies for different powerplants.......................... 65

7. References ......................................................... 66

UNCLASSIFIED - Distribution Statement A. Approved for public release. 


\section{List of Figures}

FIGURE 1 PROCESS FLOW CHART USED IN MODELING THE EXHAUST SYSTEM THERMAL BEHAVIOR ...................................

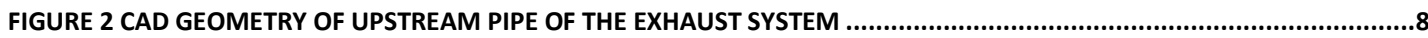

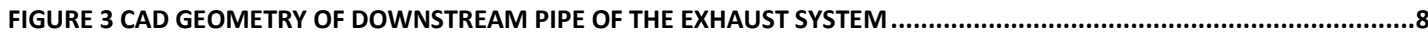

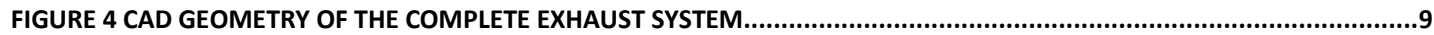
FIGURE 5 MESH OF THE UPSTREAM PIPE OF THE EXHAUST SYSTEM DEVELOPED USING HYPERMESH .................................11 FIGURE 6 MESH OF THE DOWNSTREAM PIPE OF THE EXHAUST SYSTEM DEVELOPED USING HYPERMESH ...........................11 FIGURE 7 MESH OF THE COMPLETE EXHAUST SYSTEM DEVELOPED USING HYPERMESH ...................................................12

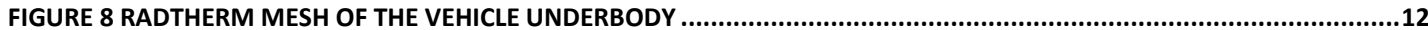
FIGURE 9 SIDE VIEW OF RADTHERM MODEL OF THE EXHAUST SYSTEM AND VEHICLE UNDERBODY....................................13 FIGURE 10 BOTTOM VIEW OF RADTHERM MODEL OF THE EXHAUST SYSTEM AND VEHICLE UNDERBODY............................13 FIGURE 11 RADTHERM MODEL OF THE EXHAUST SYSTEM AND VEHICLE UNDERBODY ....................................................14 FIGURE 12 OVERVIEW FOR THE HEAT TRANSFER MECHANISM FOR EXHAUST SYSTEM ....................................................17

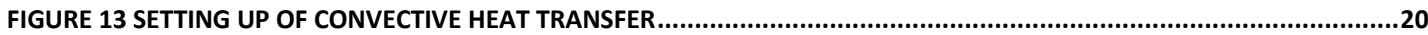
FIGURE 14 EXHAUST FLUID STREAMS ALONG WITH THE CATALYTIC FLUID NODE IN THE EXHAUST SYSTEM........................22

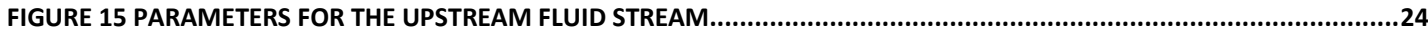

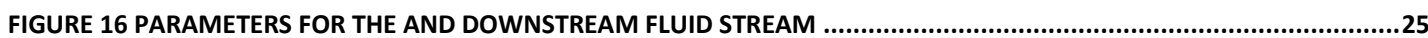
FIGURE 17 EXHAUST FLUID NODE IN RADTHERM

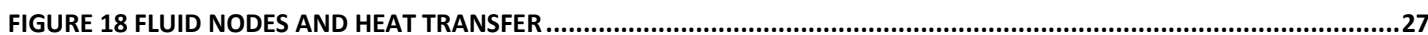

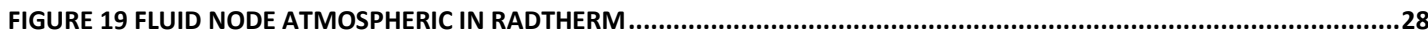

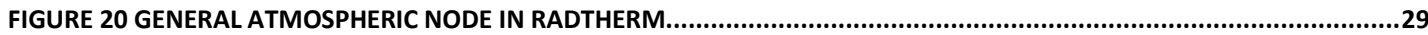
FIGURE 21 LIBRARY FUNCTION FOR GENERAL ATMOSPHERIC NODE IN RADTHERM ...................................................30

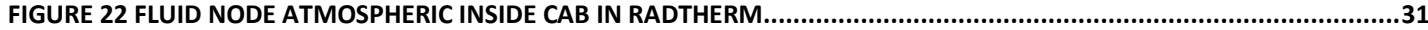
FIGURE 23 EXPERIMENTAL SETUP FOR MEASURING MASS FLOW RATE OF AIR USING MAF SENSOR .................................37

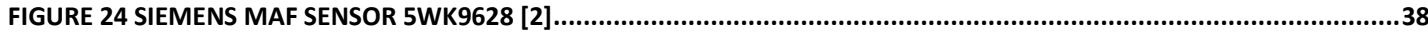

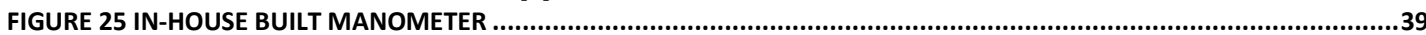
FIGURE 26 EXPERIMENTAL SETUP FOR CALIBRATING THE MANOMETER TO MEASURE FLOW RATE OF AIR .........................40 FIGURE 27 CALIBRATION CURVE SHOWING THE RELATIONSHIP BETWEEN AIRFLOW RATE AND PRESSURE DROP. AIR FLOW RATE (CFM) V/S PRESSURE DROP (CMS OF WATER). LINEAR CURVE FIT ................................40 FIGURE 28 CALIBRATION CURVE SHOWING THE RELATIONSHIP BETWEEN AIRFLOW RATE AND PRESSURE DROP. AIR FLOW RATE (CFM) V/S PRESSURE DROP (CMS OF WATER). SECOND ORDER CURVE FIT .....................41 FIGURE 29 CALIBRATION CURVE SHOWING THE RELATIONSHIP BETWEEN AIRFLOW RATE AND PRESSURE DROP. AIR FLOW RATE (CFM) V/S PRESSURE DROP (CMS OF WATER). THIRD ORDER CURVE FIT ........................41 FIGURE 30 ON VEHICLE INSTALLATION OF THE MANOMETER TO MEASURE INTAKE PRESSURE DROP .................................42 FIGURE 31 LOCATION OF THERMOCOUPLES TO MEASURE TEMPERATURE OF EXHAUST GASES ..........................................44 FIGURE 32 INSTALLATION OF THERMOCOUPLE IN EXHAUST SYSTEM …...........................................................................4

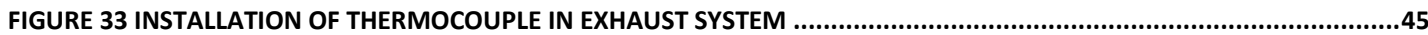
FIGURE 34 LOCATION OF THERMOCOUPLES TO MEASURE TEMPERATURE OF EXHAUST GASES AND SURFACE TEMPERATURE OF THE EXHAUST SYSTEM

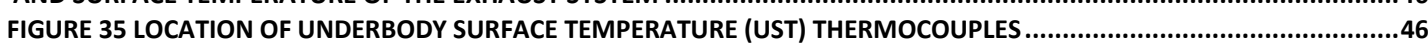

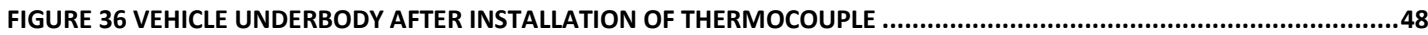

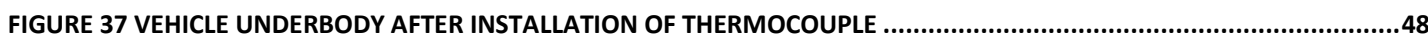

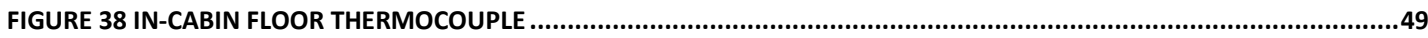

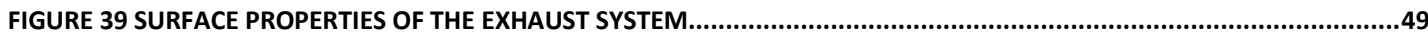
FIGURE 40 LABVIEW INTERFACE TO MONITOR TEMPERATURE AND ENGINE PARAMETERS ............................................52

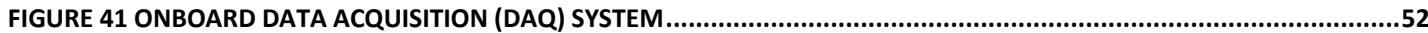
FIGURE 42 BATTERY SOC AND THE EXHAUST GAS TEMPERATURE WITH RESPECT TO TIME ...........................................53

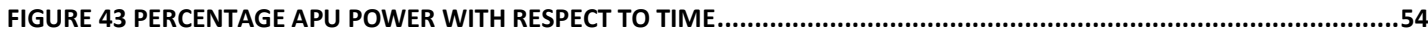
FIGURE 44 EXHAUST GAS TEMPERATURE PROFILE THROUGH THE EXHAUST SYSTEM FOR EXPERIMENTAL AND SIMULATION RESULTS.. FIGURE 45 SURFACE TEMPERATURE PROFILE FOR EXHAUST SYSTEM FOR EXPERIMENTAL

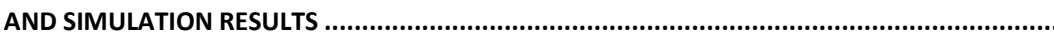
FIGURE 46 SURFACE TEMPERATURE FOR THE UNDERBODY OF HMMWV FOR EXPERIMENTAL AND SIMULATION RESULTS FIGURE 47 ENERGY CONVERSION EFFICIENCIES FOR DIFFERENT POWERPLANTS [SOURCE: HTTPS://WWW.DIESELNET.COM/TECH/DIESEL_POWERPLANTS.PHP]. 


\section{Acknowledgements}

I am thankful to my advisor Jeremy Worm for giving me the opportunity to work on this project. I'd like to express my sincere thanks for his constant support and guidance. This project would not have been possible without his help. His technical inputs and guidance have been of great help in completion of this research. I really appreciate Jeremy Worm's patience and his flexibility to accommodate my schedule. I would also like to thank Dr. Jeffrey Naber for his valuable guidance and inputs throughout the project. His expert technical advice helped in completion of the project on time. I would also like to thank Dr. Scott Miers, Dr. Stephen Hackney and Dr. Lucia Gauchia for sparing time from their busy schedule and serving on the committee for my defense.

I would like to extend my sincere thanks to the ThermoAnalytics team including Bobbi Wood, Katy Hickey, Tony Schwenn, Keith Johnson and Mark Klein, for their sponsorship of this project and support in developing the RadTherm model and also providing us with specialized tools required for measuring parameters on the vehicle like measuring surface properties and thermal imaging I.R. camera.

I would also like to thank Henry Schmidt and Chris Davis for their help and support in instrumenting the vehicle for experimental test. Their technical and logistical inputs from time to time were a valuable contribution to my learning experience.

I would also like to thank Michigan Tech Advanced Power Systems Research Center, for giving me an opportunity to conduct the research work in the lab.

I would also like to thank my friend Abhilash Marthi Somashankar and Alex Therakathu for providing his valuable inputs and helping me in developing the CAD model of the exhaust system and also in meshing.

Finally, my deepest thanks to my family and friends back in India. They have always motivated and encouraged me throughout my Masters journey. I would take this opportunity to thank my parents for who have always had their faith on my ambitions.

\section{Thank You}

Souman Haldar 


\section{List of Abbreviations}

\begin{tabular}{|c|c|}
\hline AFR & Air to Fuel Ratio \\
\hline AIS & Air Induction System \\
\hline APU & Auxiliary Power Unit \\
\hline CAD & Computer Aided Design \\
\hline CAE & Computer Aided Engineering \\
\hline CAF & Convective Augmentation Factor \\
\hline CAN & Controller Area Network \\
\hline cDAQ & Compact Data Acquisition System \\
\hline ECM & Engine Control Module \\
\hline ECU & Engine Control Unit \\
\hline FEA & Finite Element Analysis \\
\hline HDI & High Pressure Diesel Injection \\
\hline HMMWV & High Mobility Multipurpose Wheeled Vehicle \\
\hline IR & Infrared \\
\hline $\mathrm{Kg}$ & Kilogram \\
\hline $\mathrm{kJ}$ & Kilojoule \\
\hline $\mathrm{kPa}$ & Kilopascal \\
\hline kW & Kilowatt \\
\hline LHV & Lower Heating Value \\
\hline MAF & Mass Air Flow \\
\hline MTU & Michigan Technological University \\
\hline $\mathrm{NI}$ & National Instruments \\
\hline SOC & State of Charge \\
\hline VDC & Voltage - Direct Current \\
\hline${ }^{\circ} \mathrm{C}$ & Degrees Celsius \\
\hline 1-D & 1- Dimensional \\
\hline
\end{tabular}

UNCLASSIFIED - Distribution Statement A. Approved for public release. Page 3 of 64 


\begin{abstract}
Accurately predicting component temperatures, and the influence various subsystems have on each other prior to hardware development and testing is an important aspect of the vehicle development process. In this report, a 1-D thermal model is used for predicting the behavior of the exhaust system and underbody area of prototype Hybrid Electric HMMWV XM1124. This prototype vehicle is designed to be capable of exporting up to $15 \mathrm{~kW}$ of electrical power to a micro-grid or similar operation. However, in this project instead of exporting power to a micro-grid, 6.5 $\mathrm{kW}$ of power was used to charge the batteries and increase the SOC of the battery in standstill condition. This usage scenario results in moderately high engine loads with zero air velocity under the vehicle, leading to potentially extreme underbody temperatures. The thermal modeling of the exhaust system and the vehicle underbody is done using the RadTherm software by ThermoAnalytics Inc.

The 1-D thermal modeling tool was used to predict the surface temperature of the exhaust system, underbody surface temperature, and in-cabin floor temperature. The model was calibrated with experimental data providing the appropriate boundary conditions. Validation of the RadTherm model is done by instrumenting the vehicle with thermocouples and measuring temperatures at various points along the exhaust system and vehicle underbody sheet metal. These experimental values are then compared with the values predicted by RadTherm. The calibrated and validated model can be used as a tool to identify potential hot spots in the system to strategically design and place heat shields. This report will describe the details around the development, calibration, and experimental validation of the model.
\end{abstract}




\section{Introduction}

In recent years, the focus of product development has shifted from building prototype models to simulation which has drastically reduced the development time and cost. The case has been especially true in the case of 0-D and 1-D model based design where complex processes like combustion and mass flow can be modeled accurately and predictively.

The current project attempts the development of a 1-D model of the exhaust system for a diesel electric series hybrid HMMVW. The vehicle which has primarily military applications apart from the obvious transportation function has also the important application of power export by being an electric power generator whereby it is capable of exporting power to a camp. So the project aims at accurately modeling the exhaust system of the HMMVW when the vehicle is operating at a standstill condition as a power generation unit. Since the vehicle will be stationary during the power export process there are constraints to be considered like the lack of moving air over the external boundary of the exhaust system and the vehicle underbody which could lead to high temperatures in the exhaust system and on the vehicle underbody. The simulation results could be used as a predictive tool to identify hot spots in the exhaust system and the vehicle underbody and to design appropriate heat shielding to minimize heat transfer into the cabin. The model also provides us with the flexibility to test and experiment with different types of heat shields without any prototype development thereby saving cost and valuable time.

Hence, the study aims at conducting an accurate thermal analysis of the exhaust system of the vehicle using RadTherm. The approach of study will include finding the dimensional details of the exhaust system and vehicle underbody by physical measurement and then developing a 3-D CAD model. The CAD geometry is then imported into RadTherm and a thermal model of the exhaust system is developed in RadTherm. The RadTherm model is validated by collecting of experimental thermal data by running the engine over a range of load conditions. The thermal data is collected through strategically placed thermocouples along the exhaust system and the underbody of the vehicle to accurately capture the temperature conditions at various points. The model is calibrated to match closely to the experimental data and further it is made predictive to obtain thermal results of the system for conditions other than experimental setup. 


\section{Modeling of the Exhaust System}

The overall process of modeling the exhaust system consist of two major components. The first part consist of developing the CAD geometry of the exhaust system, meshing the CAD geometry and then exporting the CAD geometry in the required Nastran format ${ }^{1}$ which is required as input for RadTherm. The second part of the modeling consisted of developing the RadTherm model which includes setting the exhaust flow rate, defining the inlet exhaust temperature for the exhaust system and defining the boundary conditions such as convective heat transfer coefficient, wind velocity, surface emissivity values, etc. Figure-1 shows a flowchart of the steps followed in the modeling of the exhaust system.

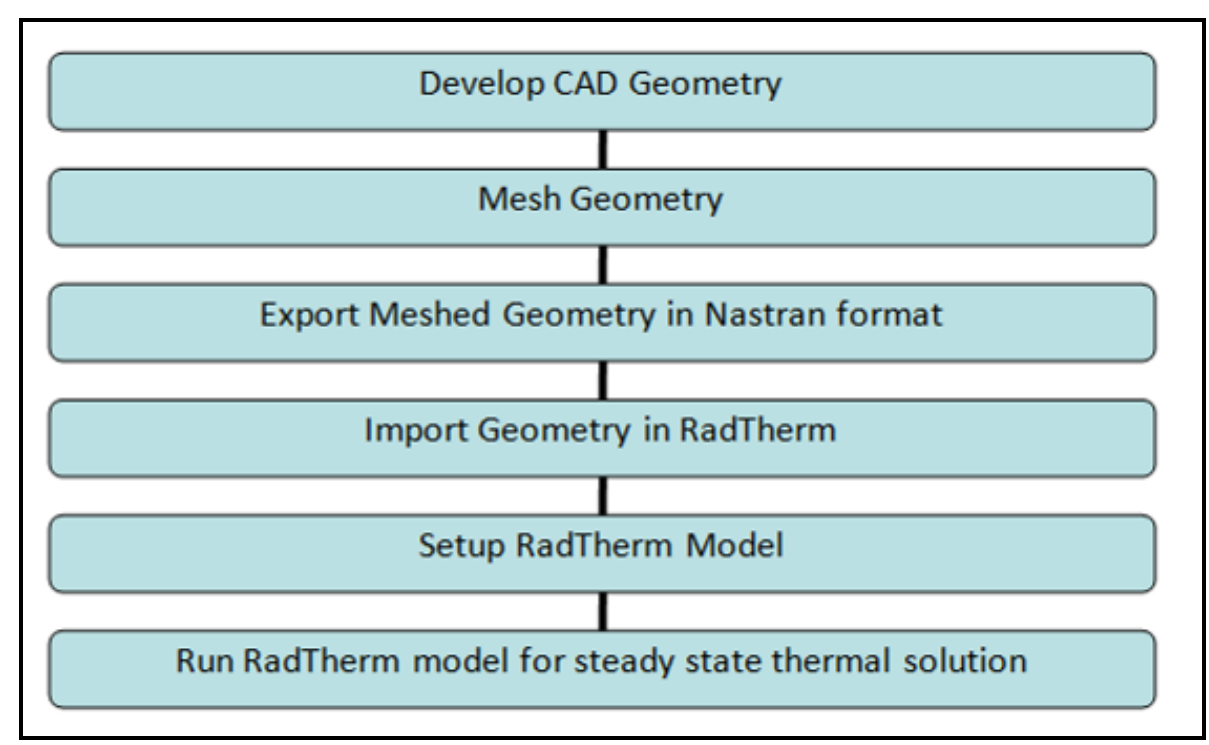

Figure 1 Process flow chart used in modeling the exhaust system thermal behavior

The accuracy of the CAD geometry and the quality of mesh is extremely critical for any FEA analysis. The CAD geometry was developed in CATIA V5 and the geometry was meshed using Hypermesh which ensured an accurate and good quality mesh.

\footnotetext{
${ }^{1}$ For analyzing complex geometry in RadTherm, the CAD geometry along with the mesh is required to be imported in RadTherm because of limited capability of RadTherm to mesh complex geometry. RadTherm can accept meshed components in few specific formats only and Nastran is one of those formats. So the mesh from the Hypermesh was exported in Nastran format so that it can be imported in RadTherm.
} 


\subsection{CAD Modeling}

The CAD geometry for the exhaust system was developed in CATIA V5. The first step in development of the CAD model was to obtain the dimensions of the exhaust system and vehicle underbody accurately. The dimensions of the exhaust system were obtained by removing the exhaust system from the vehicle and taking dimensions on the workbench using measuring tape and a vernier caliper. The pipe wall thickness was measured using vernier caliper and the thicknesses at the intermediate positions of the exhaust system were measured when the holes were drilled for installing the thermocouples. Based on the dimensions obtained, the CAD geometry on a 1:1 scale was developed in CATIA V5 and the dimensions of the CAD model were validated against the physical components on the vehicle to ensure measurement accuracy. The dimensions of the vehicle underbody were measured directly on the vehicle.

For thermal analysis, RadTherm requires the CAD geometry to be a shell type so the CAD geometry of the exhaust system and the vehicle underbody was developed as shell type without any thickness associated with them. The thickness for the individual parts in the geometry is defined in RadTherm.

The CAD geometry of the vehicle consists of the following three components:

1. Exhaust System

2. Vehicle Underbody

3. Vehicle Frame Rail

These three components are assembled together to form the final system which is used for the thermal modeling of the exhaust system. The CAD geometry of the exhaust system further consists of two sub-components. These two sub-components are assembled in CATIA V5 to obtain the complete exhaust system.

The following are the two sub-components of exhaust system:

1. Upstream pipe

2. Downstream Pipe

The first part of the exhaust system is called the Upstream Pipe. It starts from the exhaust manifold of the engine and continues to the inlet of the exhaust aftertreatment. Figure 2 shows a 3-D model of the Upstream Pipe. 


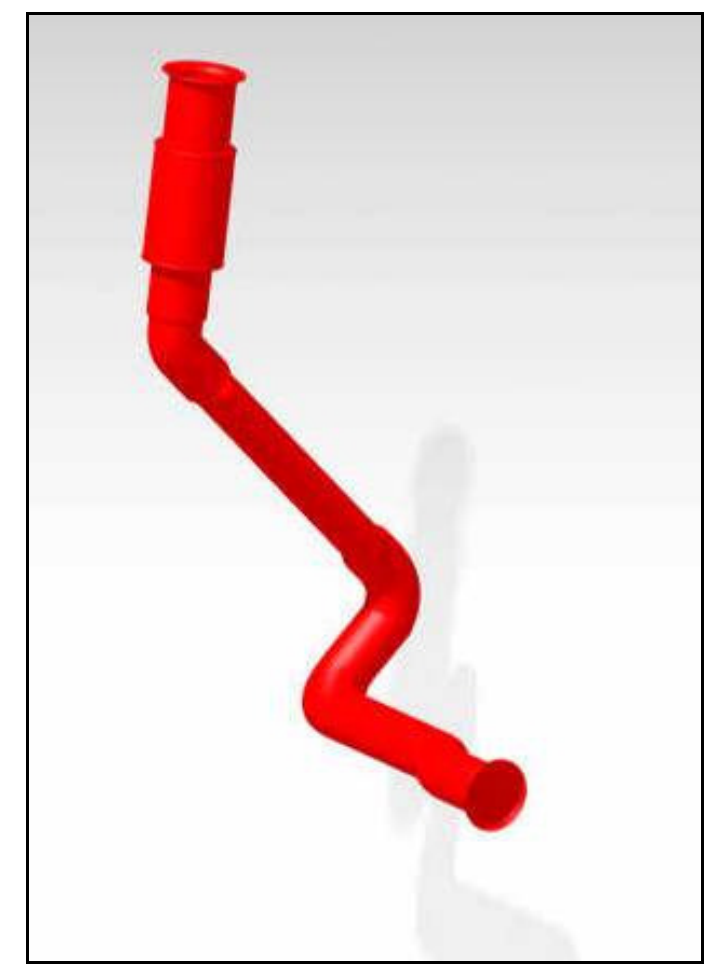

Figure 2 CAD geometry of Upstream Pipe of the Exhaust System

The second part of the exhaust system is called the Downstream Pipe. It starts from the after-treatment to the exhaust tail pipe. Figure 3 shows a 3-D model of the Downstream Pipe.

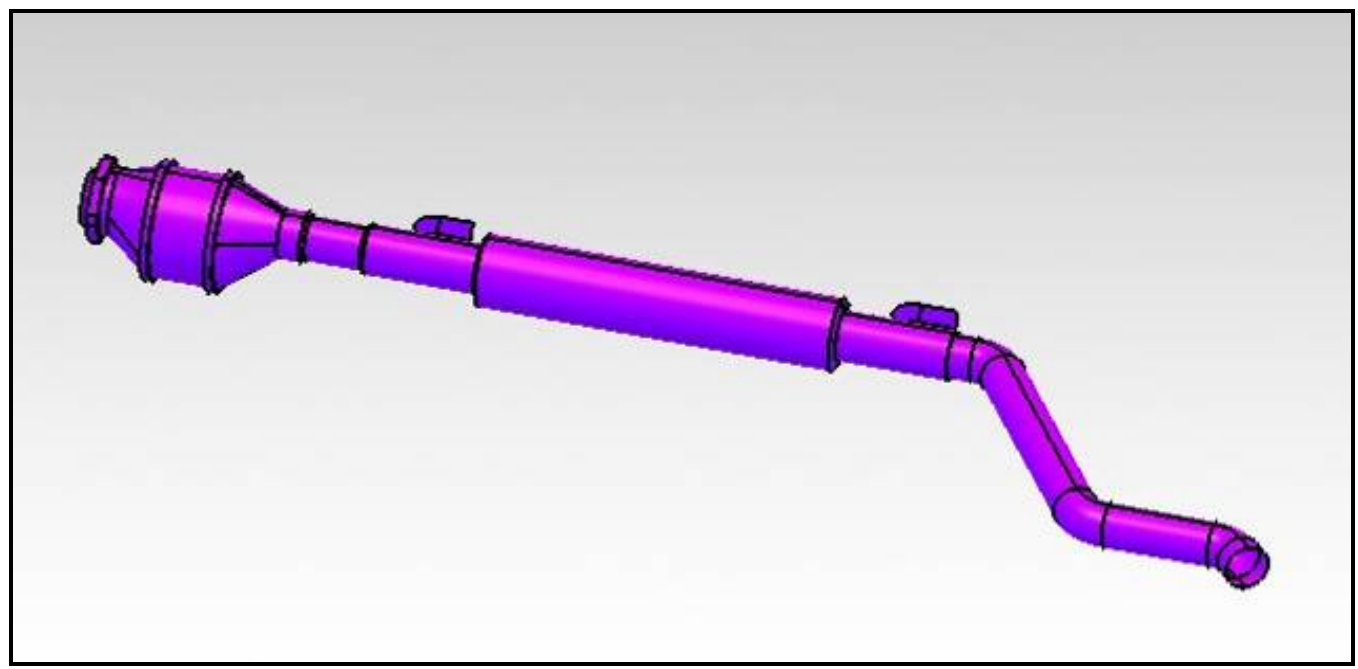

Figure 3 CAD geometry of Downstream Pipe of the Exhaust System 
The final exhaust system is obtained by assembling the Upstream and the Downstream pipe. Figure 4 shows a 3-D model of the complete exhaust system. The dimensions of the final CAD model of the exhaust system were validated by comparing the dimensions with the physical dimensions of the exhaust system.

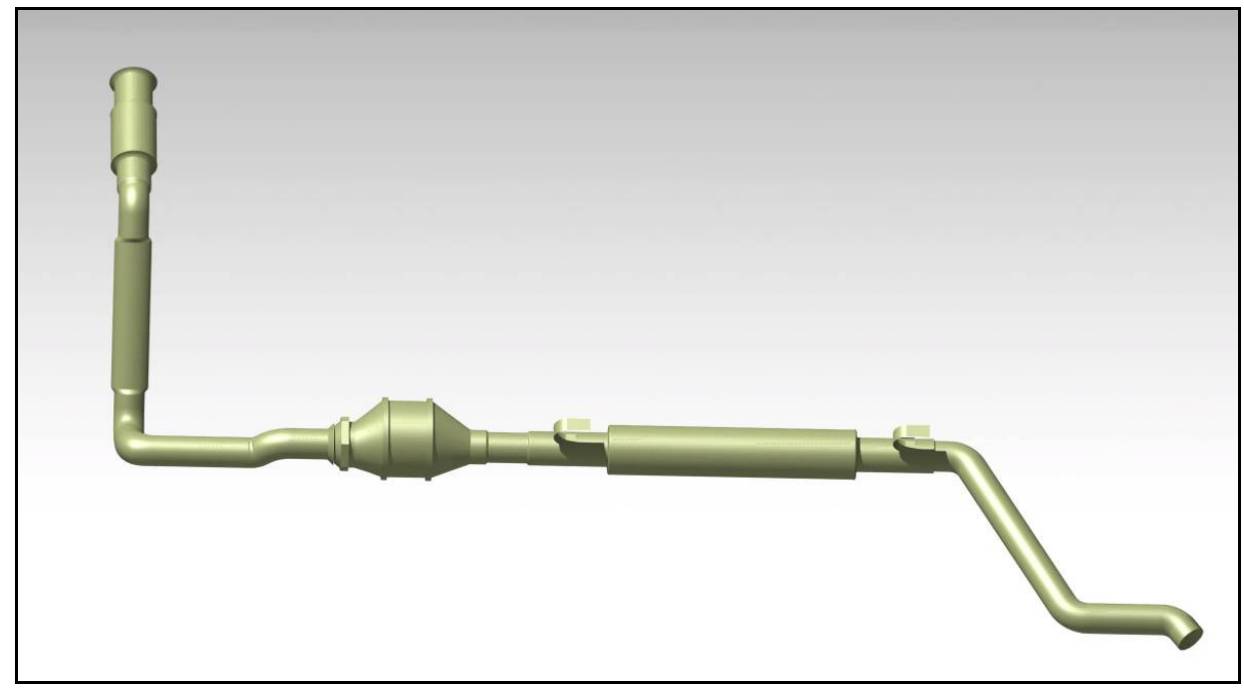

Figure 4 CAD geometry of the complete Exhaust System

\subsection{Mesh Of the Geometry}

Once the CAD geometry was developed the next step was to mesh the geometry using a meshing tool so that the meshed geometry could be imported into RadTherm for thermal analysis. A high quality ${ }^{2}$ of mesh is critical for FEA analysis. Hypermesh was used as the meshing tool. Hypermesh was selected as meshing tool because it could easily export the mesh model to Nastran format which is the required input for RadTherm. A good mesh is defined based on how closely the mesh captures the geometry of the CAD model, solution convergence and the accuracy of the results. This depends on few parameters like the size of the mesh element and the type of the mesh element. Generally a small element size is preferred as it captures the geometry more closely. However, too small element size tremendously increases the simulation time. So there is always a tradeoff between the size of the elements and simulation time.

\footnotetext{
${ }^{2}$ High quality of mesh is defined based on how closely the mesh captures the geometry of the CAD model, solution convergence and the accuracy of the results.. This depends on the parameters like the size of the mesh element and the type of the mesh element. Generally a small element size are preferred as it captures the geometry more closely.
} 
The CAD files for the exhaust system were exported to IGS format in CATIA. This was done so that these files could be imported to Hypermesh. The CAD geometry was imported in Hypermesh and then the surface meshed. The size of the elements is set as $10 \mathrm{~mm}$ and the element type selected was Mixed type. Mixed element type includes both Quads and Triads. Table 1 shows the summary of the element type used for meshing. Meshing of the geometry was tried with element size of $0.1 \mathrm{~mm}$ and $1 \mathrm{~mm}$ also but due to large number of elements, meshing failed and Hypermesh crashed. So the element size was kept as $10 \mathrm{~mm}$ to reduce the number of elements in Hypermesh and complete the mesh. Reducing the number of the elements also reduced the simulation time in meshing and in RadTherm.

The RadTherm model was also simulated with smaller element size $(3 \mathrm{~mm}$ element size) but then the simulation took approximately 1 hour to complete, which was very high. This led us to increase the element size and in turn reduce the time required for simulation.

Table 1 - Summary of the element type for Meshing

\begin{tabular}{|c|c|c|c|}
\hline Srl. No. & Element Type & $\begin{array}{c}\text { Number of } \\
\text { Nodes }\end{array}$ \\
\hline 1. & TRIADS & 3 & Image \\
\hline 2. & QUADS & 4 & \\
\hline
\end{tabular}


Figure 5 shows the mesh for the Upstream pipe of the exhaust system developed in Hypermesh.

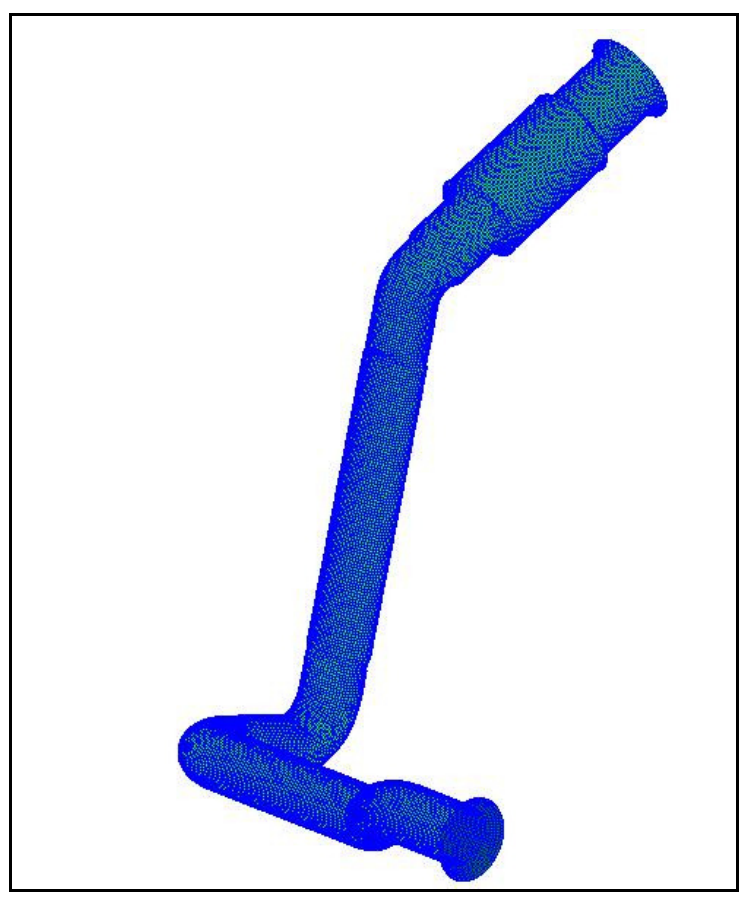

Figure 5 Mesh of the Upstream pipe of the Exhaust System developed using Hypermesh

Figure 6 shows the mesh for the Downstream pipe of the exhaust system developed in Hypermesh.

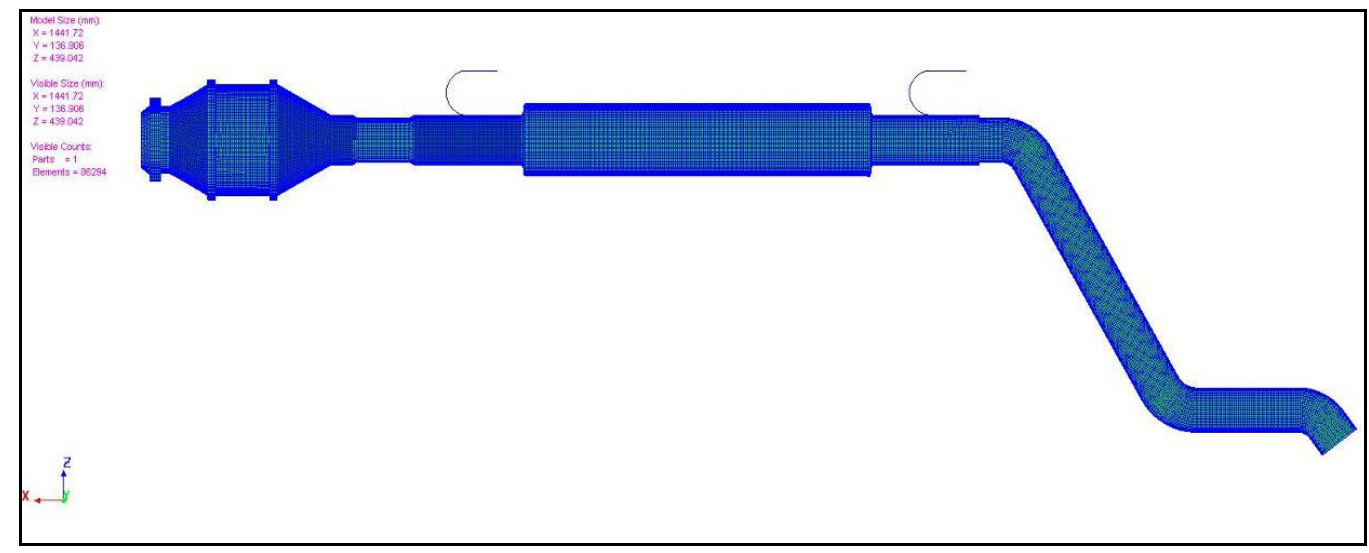

Figure 6 Mesh of the Downstream pipe of the Exhaust System developed using Hypermesh 
Figure 7 shows the mesh for the complete geometry of the exhaust system.

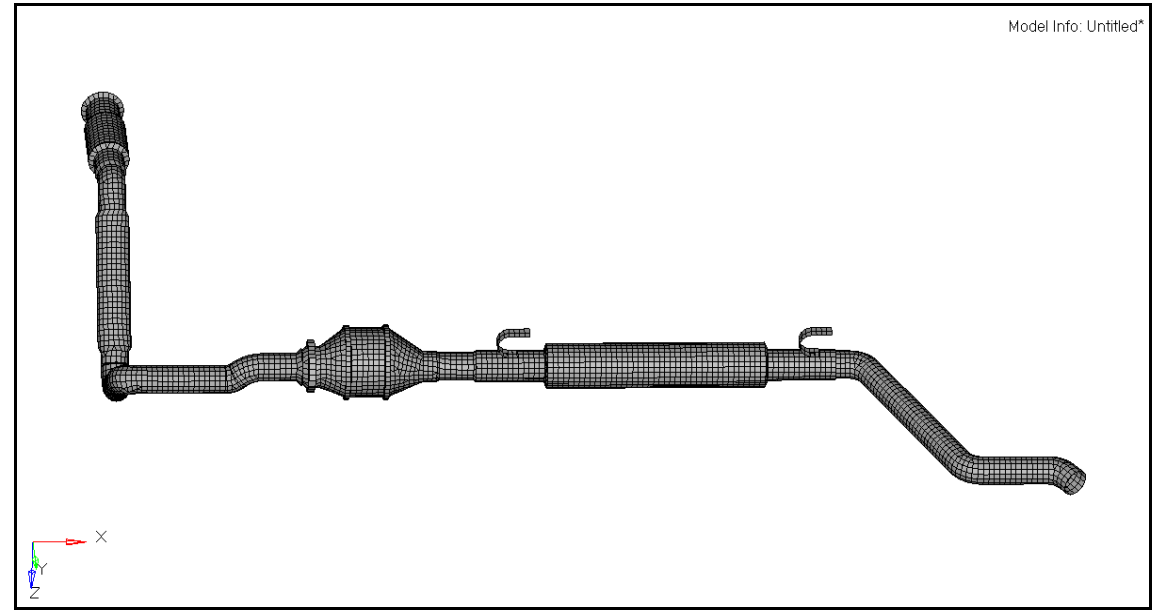

Figure 7 Mesh of the complete Exhaust System developed using Hypermesh

The meshed component of the exhaust system is exported in Nastran (*.nas). This was done because RadTherm can accept meshed component in few specific formats only and Nastran is one of the accepted formats.

Some of the less complex parts are modeled directly in RadTherm. RadTherm is capable of modeling and meshing simple components. The simpler components like the vehicle underbody, the heat shield and the chassis rail are modeled accurately and directly in RadTherm. This reduces the model development time. Figure 8 shows the vehicle underbody which is directly modeled in RadTherm.

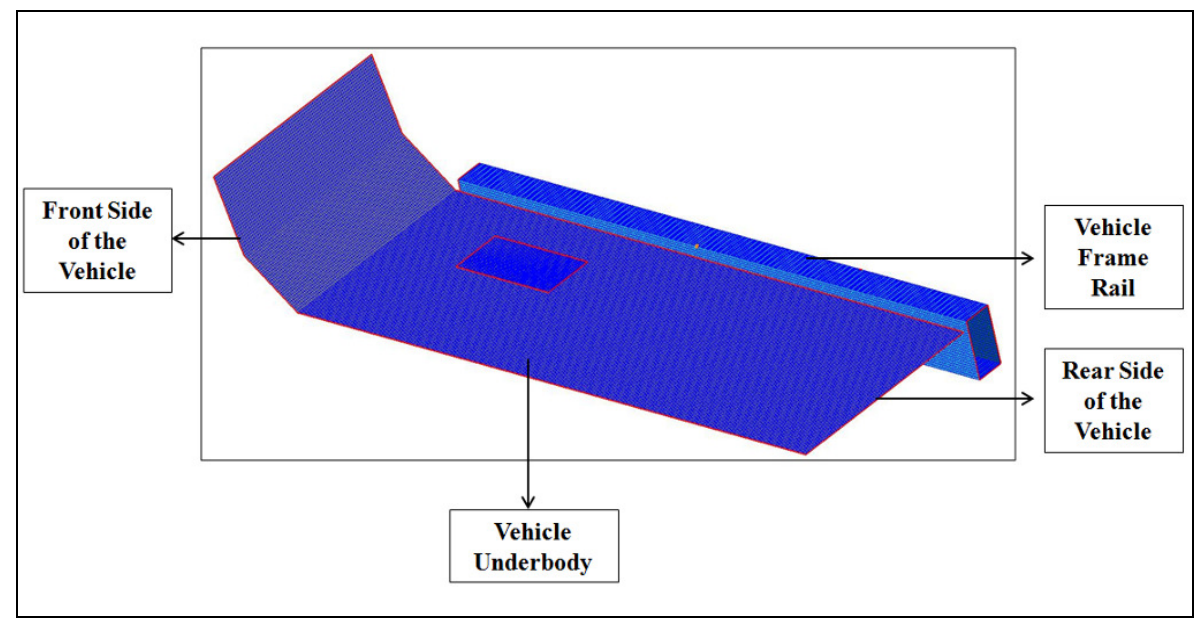

Figure 8 RadTherm Mesh of the Vehicle Underbody 
The final geometry for thermal analysis was developed by assembling all the three sub-components including the exhaust system, the chassis rail and vehicle underbody in RadTherm. The exhaust system is connected to the vehicle underbody using two hooks as present in the actual vehicle. In RadTherm, a conductive thermal link was established between the exhaust system and the vehicle underbody through the two hooks. Figures 9 and 10 shows the exhaust system after it has been assembled in RadTherm.

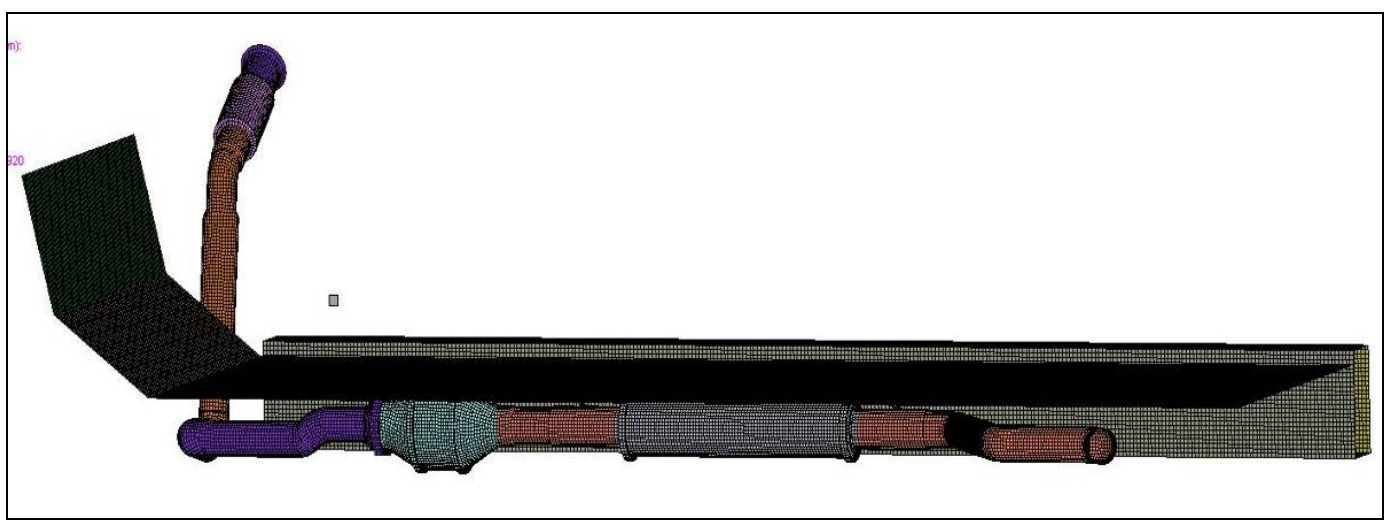

Figure 9 Side View of RadTherm model of the exhaust system and vehicle Underbody

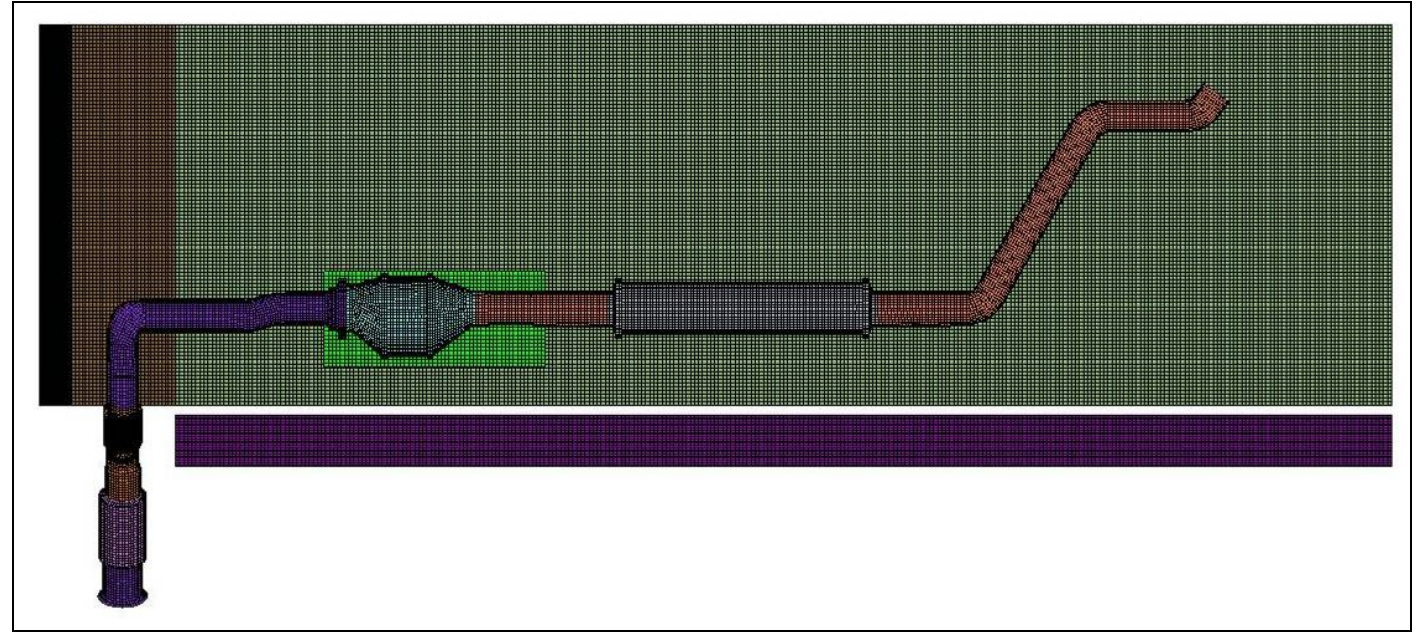

Figure 10 Bottom View of RadTherm model of the exhaust system and vehicle Underbody 
In order to accurately model the system, a heat shield was also added in the vehicle underbody just above the after-treatment. The heat shield is used in the HMMWV to reduce heat transfer into the cabin thus maintaining lower temperature inside the cabin. Table 2 shows the details of the mesh for the complete system.

Table 2 Summary of the mesh for the exhaust system

\begin{tabular}{|l|l|}
\hline \multicolumn{1}{|c|}{ Detail } & \multicolumn{1}{c|}{ Value } \\
\hline Mesh Type & Shell Type \\
\hline Total Number of Elements & 89920 \\
\hline Type of elements & Triads and Quads \\
\hline Number of Triad Elements & 468 \\
\hline Number of Quad Elements & 89452 \\
\hline
\end{tabular}

Figure 11 shows the RadTherm model of the exhaust system along with the vehicle underbody and vehicle frame.

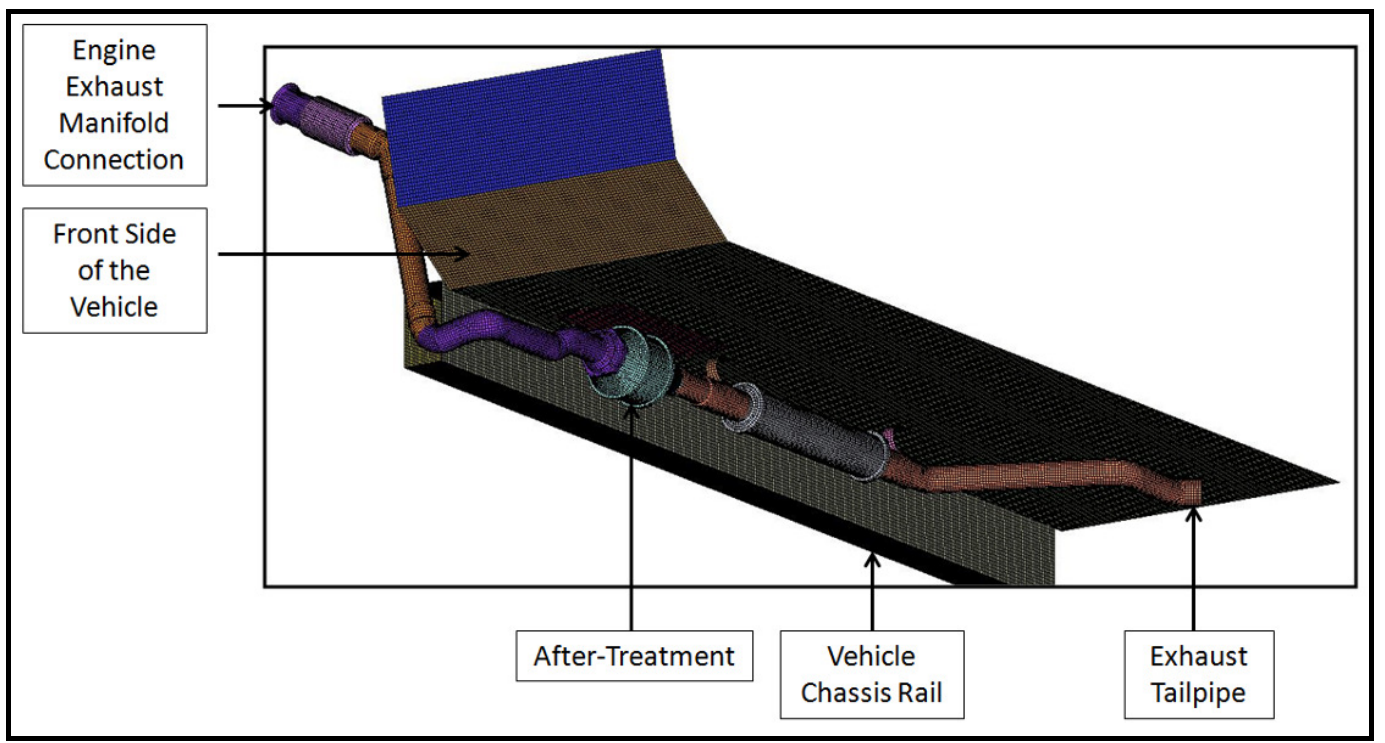

Figure 11 RadTherm model of the exhaust system and vehicle Underbody

\footnotetext{
${ }^{3}$ Shell type mesh is used for meshing models which are developed as shell type. A shell CAD model is a model which does not have thickness associated with it. RadTherm requires that the model imported in RadTherm be shell type. So the CAD model developed was developed as shell type and then meshed as Shell type before importing it into RadTherm.
} 


\subsection{Thermal Modeling in RadTherm}

The thermal modeling of the exhaust system was done in a thermal simulation tool called RadTherm. RadTherm is a tool from ThermoAnalytics for comprehensive Computer Aided Engineering (CAE) thermal analysis.

The process of developing the RadTherm model consists of importing the meshed geometry of the exhaust system into RadTherm, defining thermal links between different components of the model, setting up of the convective heat transfer coefficient, surface emissivity values, wind velocity and mass flow rate of exhaust.

One of the important parameters in RadTherm is accurately modeling how heat is transferred from one point to the next. Heat transfer from one point to the next is simulated by applying one or more of the three fundamental modes of heat transfer, as will be briefly reviewed next.

\section{Conduction}

In conduction, heat is transferred from a higher temperature region to a lower temperature region within an object or between objects that are in physical contact. In solids, conduction is governed by the collision and vibration of the molecules and atoms of the object. In liquids and gases, conduction is due to collision and diffusion of the particles during their random motion. Conduction is governed by Fourier's Law of Heat Transfer.

Equation 1, represents the Fourier's Law of Heat Transfer.

$$
\frac{d Q}{d t}=-\frac{\kappa \cdot A \cdot \Delta T}{\Delta x}
$$

where,

$\frac{d Q}{d t}$ is the rate of heat transfer $(\mathrm{W})$

$A$ is the cross-sectional area $\left(\mathrm{m}^{2}\right)$,

$\Delta T$ is the temperature difference between the ends $(\mathrm{K})$,

$\Delta x$ is the distance between the ends $(\mathrm{m})$

$\mathrm{k}=\mathrm{is}$ the thermal conductivity of the material $(\mathrm{W} / \mathrm{m}-\mathrm{k})$ 


\section{Convection}

In convection, heat is transferred from one point to another by movement of the fluid. Convection heat transfer involves combination of conduction (heat diffusion) and advection (heat transfer by bulk fluid flow only). The transfer of heat from the surface of the body to the fluid not only consists of heat transfer by advection (by movement of the fluid only) but also conduction and diffusion near the boundary layer of the object. Convection heat transfer is governed by Newton's Law of Cooling. Equation 2, represents the Newton's Law of Cooling.

$$
\begin{gathered}
\qquad \frac{d Q}{d T}=h \cdot A \cdot \Delta T \\
\text { where, } \\
\frac{d Q}{d T}=\text { Rate of heat transfer }(\mathrm{W}) \\
\mathrm{h}=\text { Convective heat transfer coefficient }\left(\mathrm{W} / \mathrm{m}^{2}-\mathrm{K}\right) \\
\mathrm{A}=\text { heat transfer area }\left(\mathrm{m}^{2}\right) \\
\Delta T=\text { Thermal gradient between environment and the surface }(\mathrm{K})
\end{gathered}
$$

\section{Radiation}

Transfer of heat through radiation does not require any medium unlike conduction and convection. Heat is transferred in the form of electromagnetic waves. Heat transfer through radiation is governed by the Stefan-Boltzmann Law. Equation 3, represents the Stefan-Boltzmann Law.

$$
\begin{aligned}
& \frac{d Q}{d T}=q=\varepsilon \cdot \sigma T^{4} A \\
& \text { where, } \\
& q=\text { heat transfer per unit time }(W) \\
& \sigma=5.670310^{-8}\left(\mathrm{~W} / \mathrm{m}^{2} \mathrm{~K}^{4}\right) \text { - Stefan-Boltzmann Constant } \\
& T=\text { absolute temperature Kelvin }(K) \\
& A=\text { area of the emitting body }\left(\mathrm{m}^{2}\right) \\
& \varepsilon=\text { emissivity of the object (one for a black body) }
\end{aligned}
$$




\subsubsection{Flowchart For RadTherm Model Development}

Figure 12 shows the flow chart for the model development in RadTherm. This flowchart gives an overview of the heat transfer mechanism for the exhaust system.

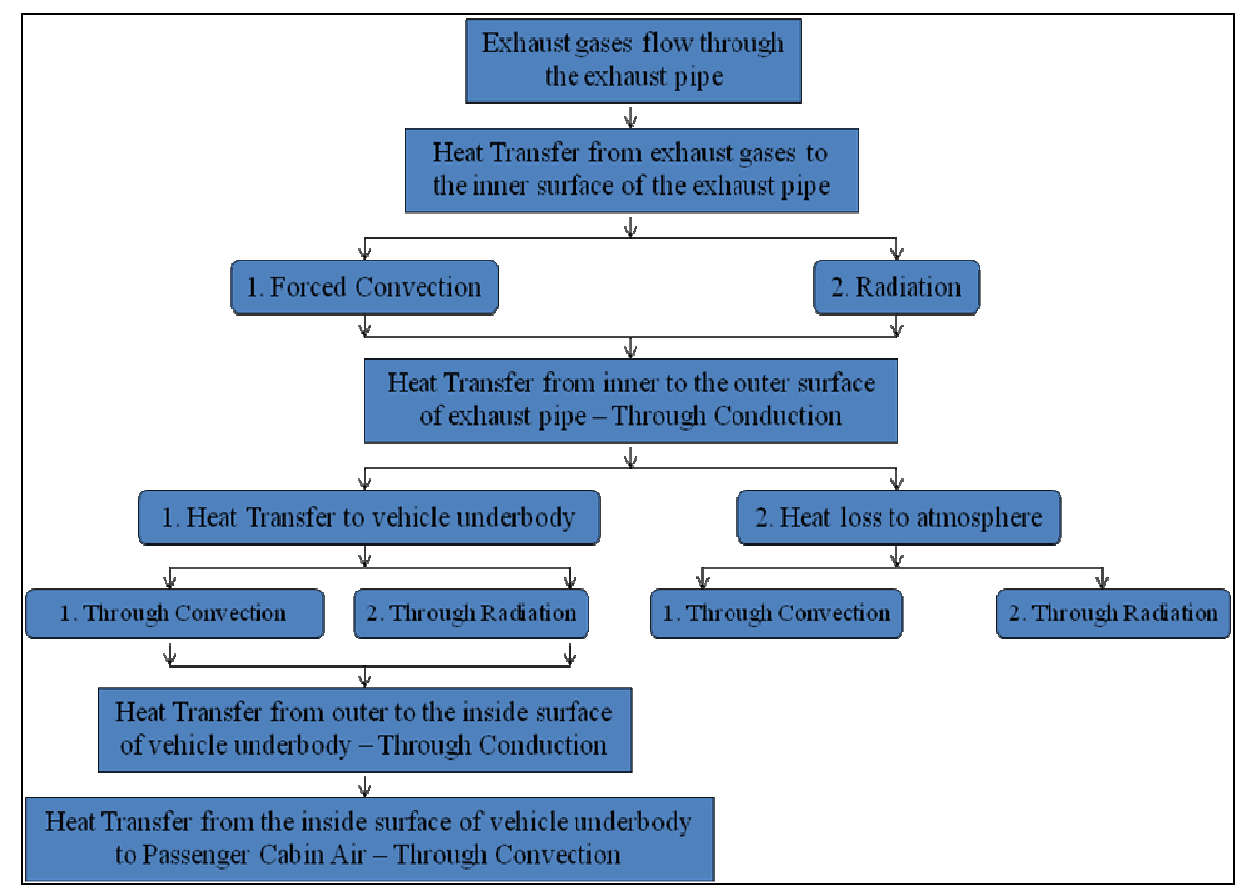

Figure 12 Overview for the heat transfer mechanism for exhaust system

The hot gases flowing through the exhaust system transfers heat to the inner surface of the exhaust pipe through convection and radiation. The parameters like the mass flow rate of the hot gases ${ }^{4}$, the initial temperature of the exhaust gases at the entry of the exhaust system and forced convective heat transfer coefficient are defined in the RadTherm which are required for convective and radiative heat transfer. Heat is then transferred from the inner surface of the exhaust pipe to outer surface of the exhaust pipe through conduction. The conductive heat transfer properties like thermal conductivity of the material and specific heat are defined in the RadTherm. Once heat is transferred to the surface of the exhaust pipe two things happen, first heat is lost to the environment through convection and radiation and second heat is transferred to the vehicle underbody through convection and radiation. Next heat is transferred from the outer surface of the underbody to the inner surface of the vehicle underbody through conduction.

4 The calculations for the mass flow rate of exhaust gases are explained in the section 3.1.1 
Table 3 Summary of the Parameters for Heat Transfer

\begin{tabular}{|c|c|c|c|c|}
\hline $\begin{array}{c}\text { Heat } \\
\text { Transferred } \\
\text { From }\end{array}$ & $\begin{array}{c}\text { Heat } \\
\text { Transferred } \\
\text { To }\end{array}$ & $\begin{array}{l}\text { Modes of } \\
\text { Heat } \\
\text { Transfer }\end{array}$ & $\begin{array}{c}\text { Heat Transfer } \\
\text { Parameters Required }\end{array}$ & $\begin{array}{l}\text { Parameters } \\
\text { defined in } \\
\text { RadTherm }\end{array}$ \\
\hline \multirow{4}{*}{$\begin{array}{l}\text { Hot gases } \\
\text { flowing through } \\
\text { the exhaust } \\
\text { system }\end{array}$} & \multirow{4}{*}{$\begin{array}{c}\text { Inner Surface } \\
\text { of the Exhaust } \\
\text { Pipe }\end{array}$} & \multirow{2}{*}{ Convection } & $\begin{array}{c}\text { Mass flow rate of exhaust } \\
\text { gases }\end{array}$ & $\begin{array}{c}\text { Mass flow rate of } \\
\text { exhaust gases }\end{array}$ \\
\hline & & & $\begin{array}{c}\text { Convective heat transfer } \\
\text { coefficient }\end{array}$ & $\begin{array}{l}\text { Calculated by } \\
\text { RadTherm }\end{array}$ \\
\hline & & \multirow{2}{*}{ Radiation } & $\begin{array}{c}\text { Emissivity values for the } \\
\text { inner surface of the exhaust } \\
\text { pipe }\end{array}$ & Emissivity Values \\
\hline & & & $\begin{array}{c}\text { Absorptivity values for the } \\
\text { inner surface of the exhaust } \\
\text { pipe }\end{array}$ & Absorptivity Values \\
\hline $\begin{array}{l}\text { Inner Surface of } \\
\text { the Exhaust Pipe }\end{array}$ & $\begin{array}{c}\text { Outer Surface } \\
\text { of the Exhaust } \\
\text { Pipe }\end{array}$ & Conduction & $\begin{array}{c}\text { Thermal conductivity of } \\
\text { material }\end{array}$ & $\begin{array}{c}\text { Defined in RadTherm } \\
\text { based on material } \\
\text { selected }\end{array}$ \\
\hline \multirow{5}{*}{$\begin{array}{l}\text { Outer Surface of } \\
\text { the Exhaust Pipe }\end{array}$} & \multirow{3}{*}{$\begin{array}{c}\text { Outer surface } \\
\text { of vehicle } \\
\text { underbody }\end{array}$} & Convection & $\begin{array}{c}\text { Convective heat transfer } \\
\text { coefficient }\end{array}$ & $\begin{array}{l}\text { Calculated by } \\
\text { RadTherm using } \\
\text { ambient wind } \\
\text { velocity. }\end{array}$ \\
\hline & & \multirow{2}{*}{ Radiation } & $\begin{array}{l}\text { Emissivity values for the } \\
\text { Outer surface of the exhaust } \\
\text { pipe and vehicle underbody }\end{array}$ & Emissivity Values \\
\hline & & & $\begin{array}{l}\text { Absorptivity values for the } \\
\text { Outer surface of the exhaust } \\
\text { pipe and vehicle underbody }\end{array}$ & Absorptivity Values \\
\hline & \multirow[t]{2}{*}{$\begin{array}{l}\text { Heat loss to } \\
\text { atmosphere }\end{array}$} & Convection & $\begin{array}{c}\text { Convective heat transfer } \\
\text { coefficient }\end{array}$ & $\begin{array}{l}\text { Calculated by } \\
\text { RadTherm using } \\
\text { ambient wind } \\
\text { velocity. }\end{array}$ \\
\hline & & Radiation & $\begin{array}{c}\text { Emissivity values for the } \\
\text { Outer surface of the exhaust } \\
\text { pipe }\end{array}$ & Emissivity Values \\
\hline
\end{tabular}

UNCLASSIFIED - Distribution Statement A. Approved for public release. Page 18 of 64 


\begin{tabular}{|c|c|l|c|c|}
\hline & & $\begin{array}{c}\text { Absorptivity values for the } \\
\text { Outer surface of the exhaust } \\
\text { pipe }\end{array}$ & Absorptivity Values \\
\hline $\begin{array}{c}\text { Outer surface of } \\
\text { vehicle } \\
\text { underbody }\end{array}$ & $\begin{array}{c}\text { Inside surface } \\
\text { of vehicle } \\
\text { underbody }\end{array}$ & Conduction & $\begin{array}{c}\text { Thermal conductivity of } \\
\text { material }\end{array}$ & $\begin{array}{c}\text { Defined in RadTherm } \\
\text { based on material } \\
\text { selected }\end{array}$ \\
\hline
\end{tabular}

\subsubsection{Heat Transfer Mechanism between exhaust gases and exhaust pipe}

As shown in Figure 12, heat from the hot exhaust gases are transferred to the inner surface of the exhaust system through two modes

1. Heat transfer through convection

2. Heat transfer through radiation

\section{Through Convection}

Heat transfer through convection is the transfer of heat from one point to another by movement of the fluid. The equation 2 gives the relation between the rate of heat transfer through convection and the different parameters on which it depends

$$
\begin{aligned}
& \frac{d Q}{d T}=h \cdot A \cdot \Delta T \\
& \text { Where, } \\
& \frac{d Q}{d T}=\text { Rate of heat transfer }(\mathrm{W}) \\
& \mathrm{h}=\text { Convective heat transfer coefficient } \\
& \mathrm{A}=\text { heat transfer surface area ( } \mathrm{m}^{2} \text { ) } \\
& \Delta T=\text { Time-dependent thermal gradient between } \\
& \quad \text { environment and the surface }
\end{aligned}
$$


The convective heat transfer coefficient $(\mathrm{h})$ is calculated by RadTherm based on the type of flow (laminar/turbulent), velocity of flow and the mass flow rate of the exhaust gases. The flow type is decided by RadTherm by calculating the Reynold's Number (Re). In RadTherm, the inner surface of the exhaust system is referred as the Back surface. For convective heat transfer on the inner side of the exhaust pipe, the convection type is set as Fluid stream. Setting the convection type as fluid stream ensures that RadTherm considers the flowing exhaust gases inside the pipe as the fluid with which is involved in the convective heat transfer. A convective heat transfer multiplier known as Convective Augmentation Factor (CAF) is used. CAF is used to account for the pulsating flow of the exhaust gases. Figure 13 shows the setting up of the convective heat transfer for the inner surface of the upstream pipe.

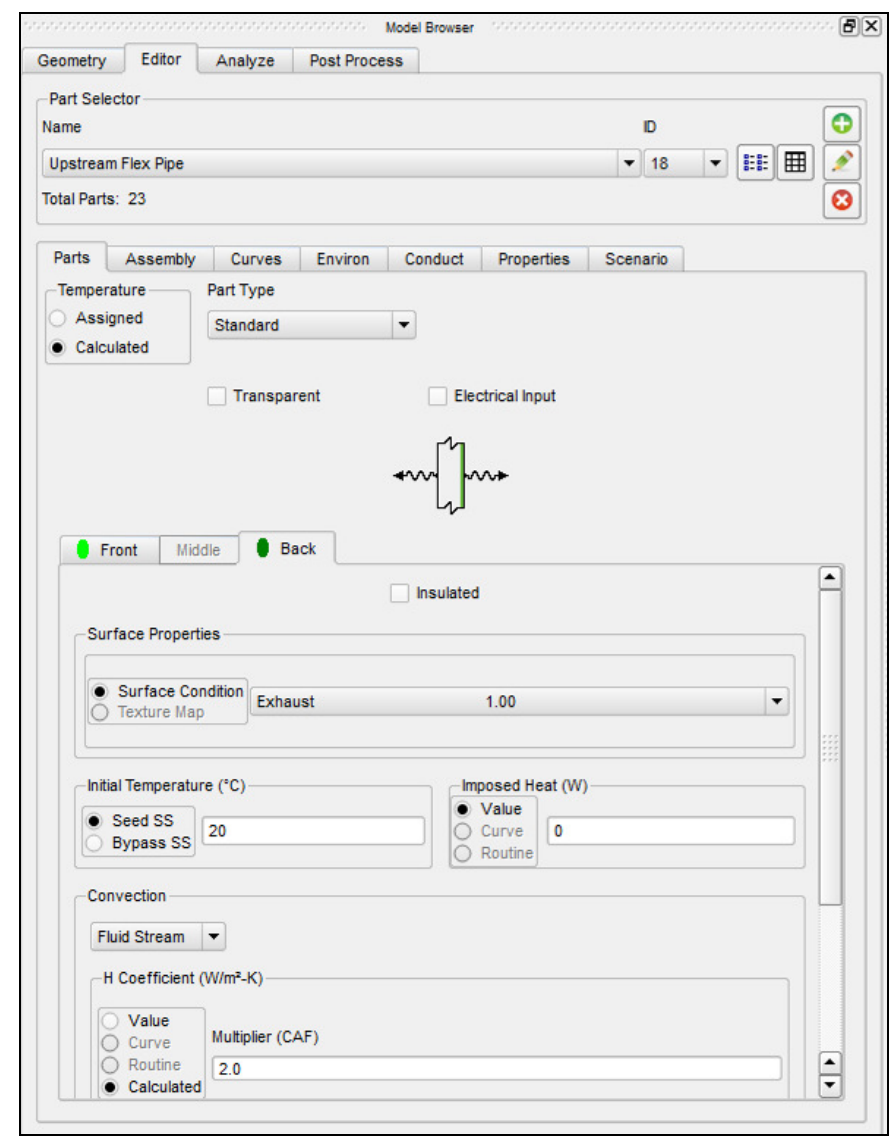

Figure 13 Setting up of convective heat transfer 


\section{Through Radiation}

Heat is also transferred from the gases to the inner surface of the exhaust pipe through radiation. The surface properties for the inner surface of the exhaust pipe are defined in RadTherm. These properties are assigned through the emissivity and absorptivity values. The surface properties for the inner surface of the exhaust system is set as "Exhaust", which is a predefined surface property for the inner surface of exhaust pipes. The inner surface of the exhaust system was set to a default value as it was difficult to measure the surface properties for the inner surface. The surface properties for the inner surface were considered uniform throughout the exhaust system.

Table 4 Radiation heat transfer properties for the Inner surface of the Exhaust Pipe

\begin{tabular}{|c|c|c|c|}
\hline Srl. No. & Part & Emissivity & Absorptivity \\
\hline 1. & Inner Surface of Exhaust Pipe & 1.0 & 0.9 \\
\hline
\end{tabular}

\subsubsection{Steps for RadTherm Modeling}

The following steps were identified and completed for developing the RadTherm model of the exhaust system.

A. Setting up of the exhaust mass flow rate in RadTherm

B. Defining Exhaust Gas Inlet Temperature for the Exhaust System

C. Defining Fluid Nodes ${ }^{5}$ for setting up thermal links for convective heat transfer between different parts

D. Defining Parameters for Heat Transfer by Radiation

E. Defining a heat generation element for the after-treatment part and thermally connecting it to the model.

These steps are explained in detail in the following section.

\footnotetext{
${ }^{5}$ In RadTherm, a fluid node is used to setup a convective heat transfer between two components or to connect two fluid nodes thermally. A fluid node is a fluid particle with no dimension or mass associated with it. It is used as an intermediate medium through which heat is transferred.
} 


\section{A. Setting up of the exhaust mass flow rate in RadTherm}

For thermal analysis of the exhaust flow through the exhaust system, the exhaust mass flow rate of the exhaust gasses are required. This was done in RadTherm by defining a fluid stream with the value of the mass flow rate in $\mathrm{kg} / \mathrm{s}$. The fluid stream was defined in RadTherm by providing a start and end point for the fluid stream and defining the number of fluid nodes in between the two end points.

The exhaust fluid stream was divided in two parts:

\section{Fluid Stream Upstream}

\section{Fluid Stream Downstream}

The Fluid Stream Upstream represents the exhaust gases from the engine exhaust manifold to the after-treatment. The Fluid Stream Downstream represents the exhaust gases flowing from the after-treatment to the exhaust tailpipe. Each of the two fluid streams had 25 fluid nodes to precisely track the temperature of the exhaust gases flowing through the exhaust system. The fluid stream was divided in two parts so that a fluid node with heat generation can be added between the two fluid streams to represent the exothermic reaction in the after-treatment. Figure 14 shows the overview of the two fluid streams and the fluid node which is used to connect both the fluid streams. The mass flow rate of exhaust gases are computed experimentally from the mass flow rate of the intake air and mass flow rate of the fuel. This value is then entered into the RadTherm model. This is explained in detail in the section Experimental Setup.

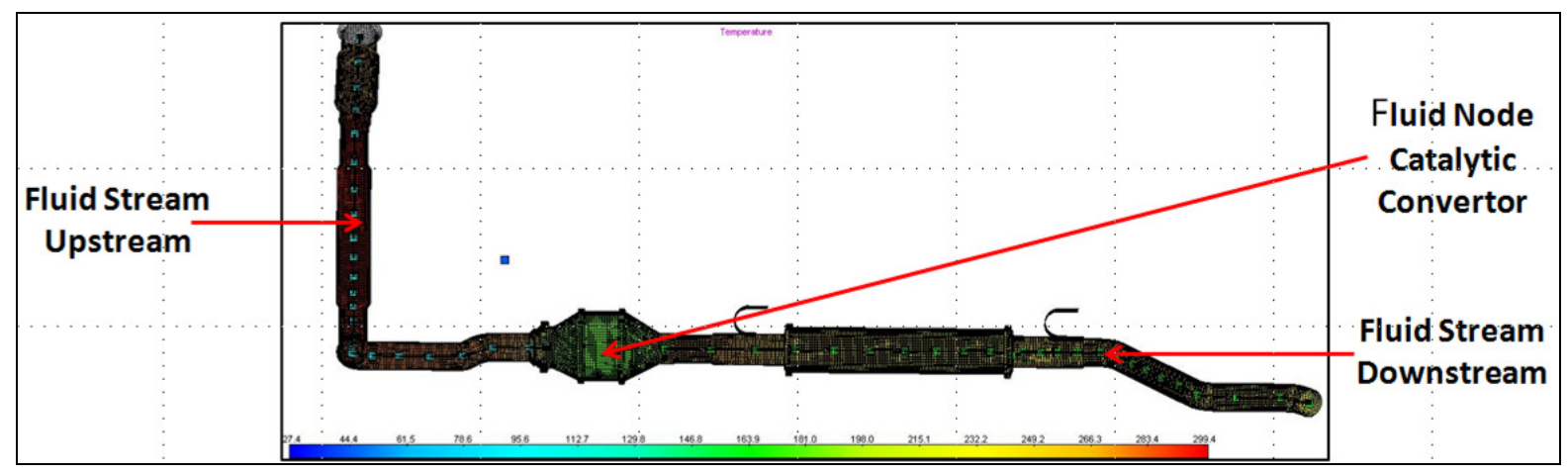

Figure 14 Exhaust fluid streams along with the Catalytic fluid node in the exhaust system

UNCLASSIFIED - Distribution Statement A. Approved for public release. $\quad$ Page 22 of 64 
Table 5 lists the various parameters for both the fluid streams.

Table 5 Fluid Stream Properties in RadTherm

\begin{tabular}{|c|c|c|c|}
\hline Srl. No. & Fluid Stream & Parameter & Value \\
\hline 1. & & Number of fluid nodes & 25 \\
\hline 2. & & $\begin{array}{l}\text { Upstream exhaust gas mass flow } \\
\text { rate }(\mathrm{kg} / \mathrm{s})\end{array}$ & $\begin{array}{l}\text { As obtained from } \\
\text { experimental test }\end{array}$ \\
\hline 3. & & Temperature $\left({ }^{\circ} \mathrm{C}\right)$ & Calculated \\
\hline 4. & $\begin{array}{l}\text { Upstream } \\
\text { Fluid Stream }\end{array}$ & Material of exhaust gases & Standard Air \\
\hline 5. & & $\begin{array}{l}\text { Initial temperature of fluid stream } \\
\left({ }^{\circ} \mathrm{C}\right)\end{array}$ & $25^{\circ} \mathrm{C}$ \\
\hline 6. & & Heat Imposed on fluid stream (W) & 0 Watts \\
\hline 7. & & Upstream Part & Exhaust Fluid Node \\
\hline 8. & \multirow{7}{*}{$\begin{array}{l}\text { Downstream } \\
\text { Fluid Stream }\end{array}$} & Number of fluid nodes & 25 \\
\hline 9. & & $\begin{array}{l}\text { Downstream exhaust gas mass flow } \\
\text { rate }(\mathrm{kg} / \mathrm{s})\end{array}$ & $\begin{array}{l}\text { Same as Upstream exhaust } \\
\text { gas mass flow rate }\end{array}$ \\
\hline 10. & & Temperature $\left({ }^{\circ} \mathrm{C}\right)$ & Calculated \\
\hline 11. & & Material of exhaust gases & Standard Air ${ }^{6}$ \\
\hline 12. & & $\begin{array}{l}\text { Initial temperature of fluid stream } \\
\left({ }^{\circ} \mathrm{C}\right)\end{array}$ & $25^{\circ} \mathrm{C}$ \\
\hline 13. & & Heat Imposed on fluid stream (W) & 0 Watts \\
\hline 14. & & Upstream Part & $\begin{array}{l}\text { Fluid Node Catalytic } \\
\text { Converter }\end{array}$ \\
\hline
\end{tabular}

${ }^{6}$ The effect of using actual exhaust gas properties in RadTherm for the exhaust gases will increase the overall gamma value for the exhaust gases. With the increase in the gamma value the specific heat for the exhaust gases will increase which will lead to higher exhaust gas temperature because of slower rate of cooling.

UNCLASSIFIED - Distribution Statement A. Approved for public release. Page 23 of 64 
Setting the temperature parameter for the exhaust gas (fluid stream) to "Calculated" allows RadTherm to calculate the temperature of the exhaust gas as it flows through the exhaust pipe. RadTherm calculates the heat transferred to the vehicle underbody and also the heat loss to the surrounding environment through convection and radiation and then calculates the temperature of the exhaust gases.

Figure 15 and 16 show the various parameters for the Upstream Fluid Stream and Downstream Fluid Stream.

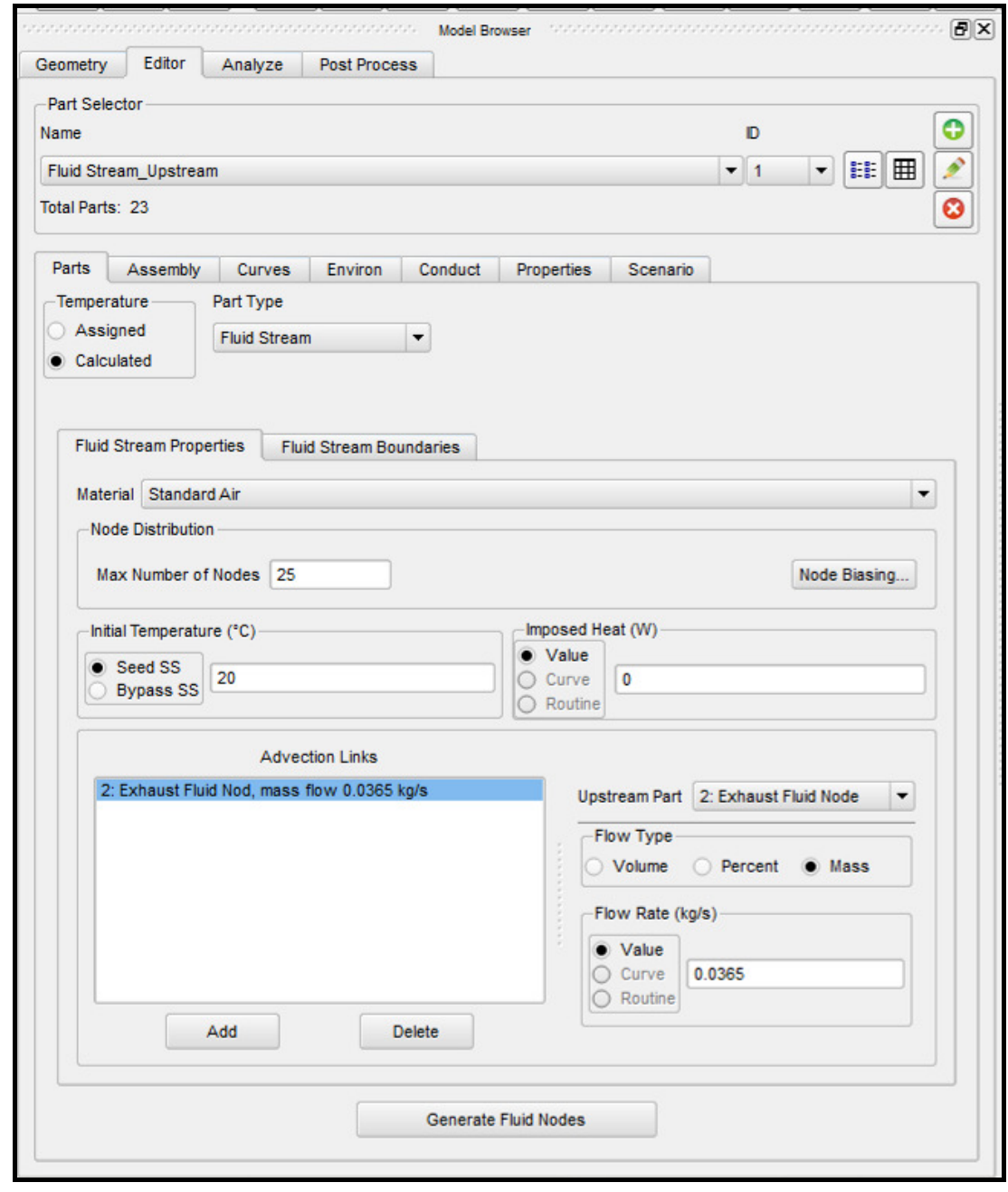

Figure 15 Parameters for the Upstream Fluid Stream 


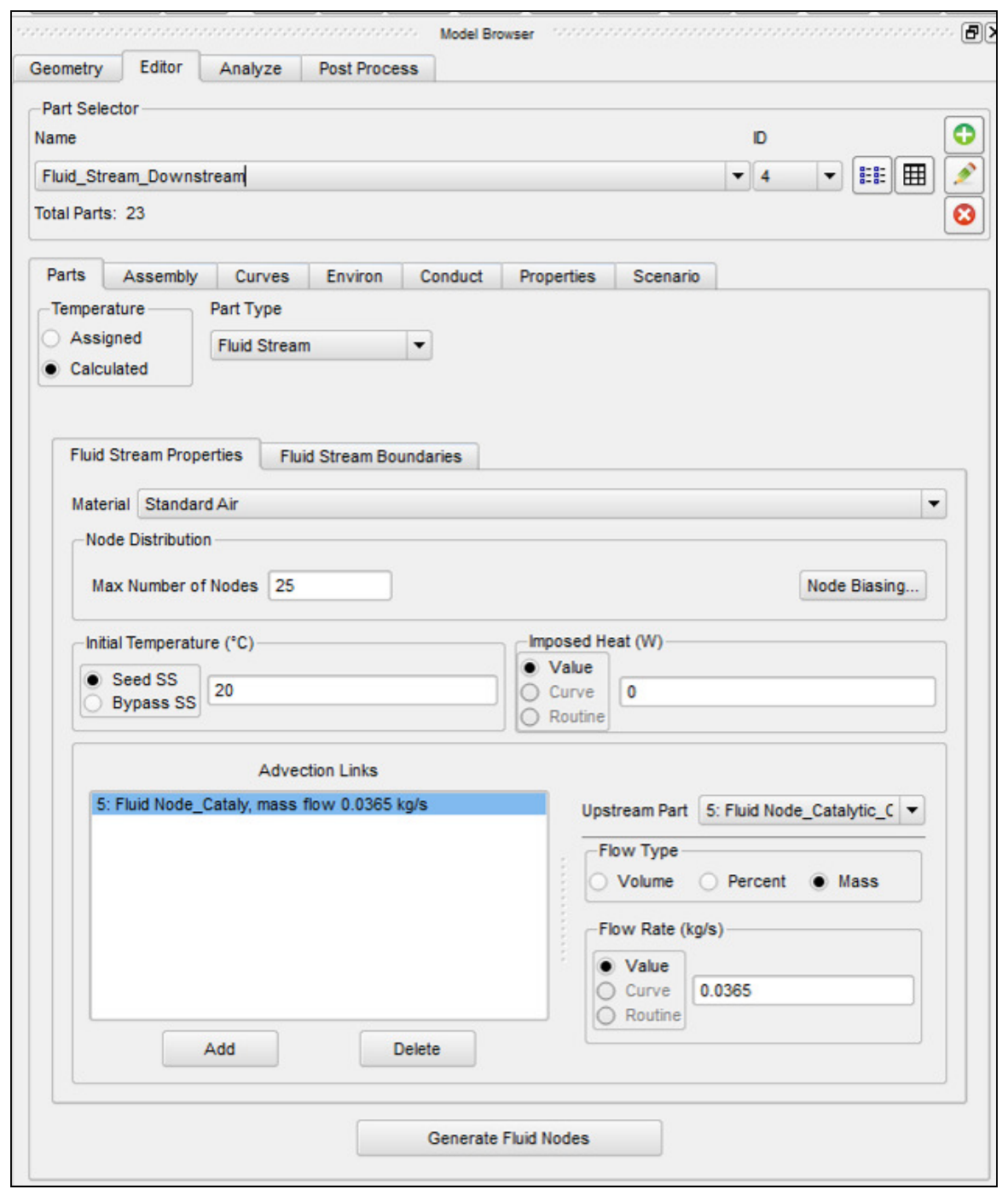

Figure 16 Parameters for the and Downstream Fluid Stream

UNCLASSIFIED - Distribution Statement A. Approved for public release. Page 25 of 64 


\section{B. Defining Exhaust Gas Inlet Temperature for the Exhaust System}

The temperature of the exhaust gases at the inlet of the exhaust system was measured directly on the vehicle using a thermocouple. This temperature was provided as input in the RadTherm model. In RadTherm, an exhaust fluid node is defined to represent the exhaust gases coming out of the engine exhaust manifold. This exhaust fluid node is provided as the starting fluid particle for the Upstream fluid stream. So exhaust gases enter the exhaust system at this temperature. Figure 17 shows the definition of the exhaust fluid node in RadTherm.

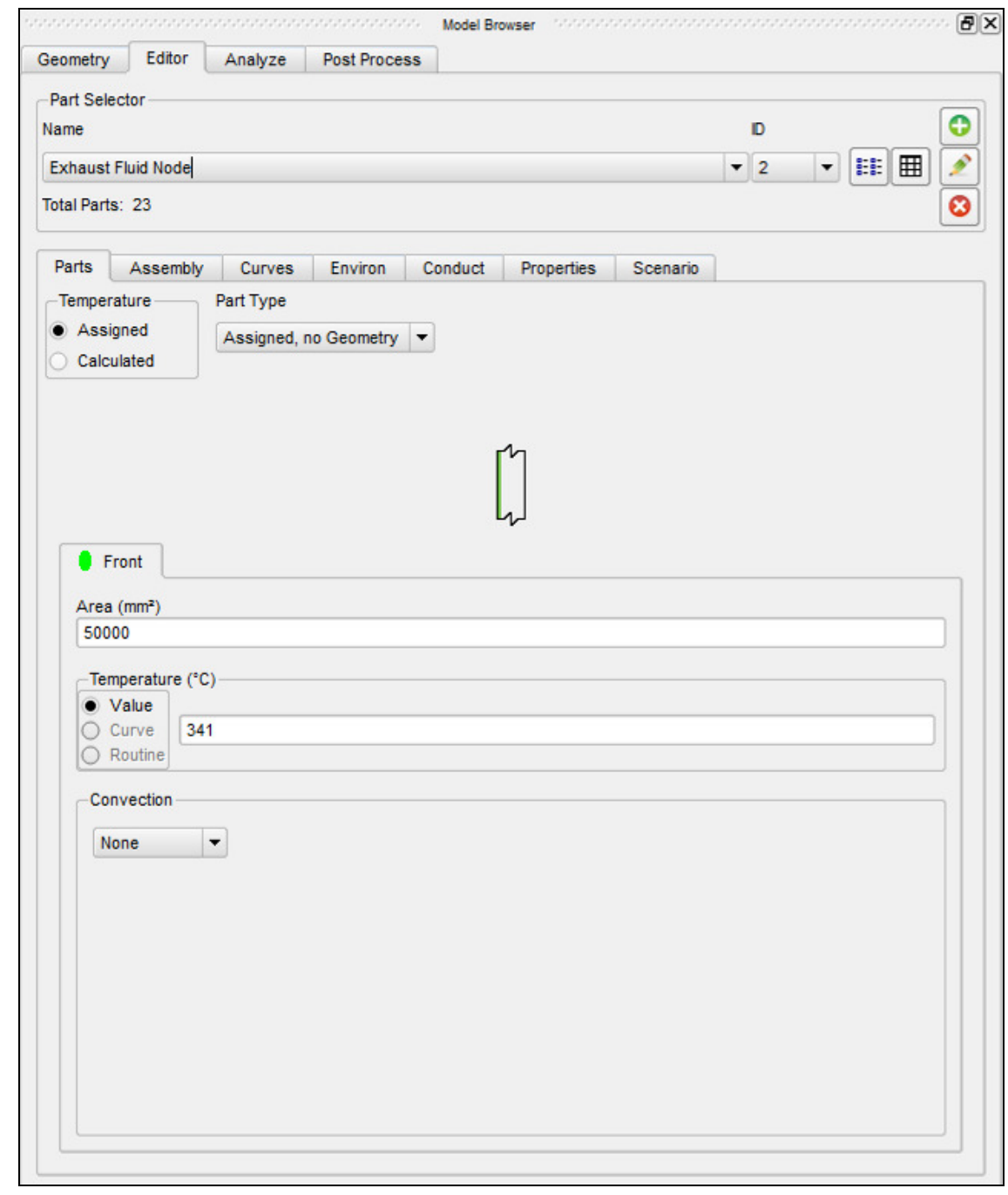

Figure 17 Exhaust fluid node in RadTherm 


\section{Defining Fluid Nodes for setting up thermal links for convection between different parts}

In order to set up convective heat transfer between the different components, fluid nodes are required to be defined in RadTherm. These fluid nodes are used as thermal links for connecting two parts which are involved in heat transfer. There are in total five fluid nodes used in the RadTherm model. One of the fluid nodes is the exhaust fluid node which has been described in the earlier section. The other four fluid nodes are used for creating thermal links between the different components. These fluid nodes are described below:

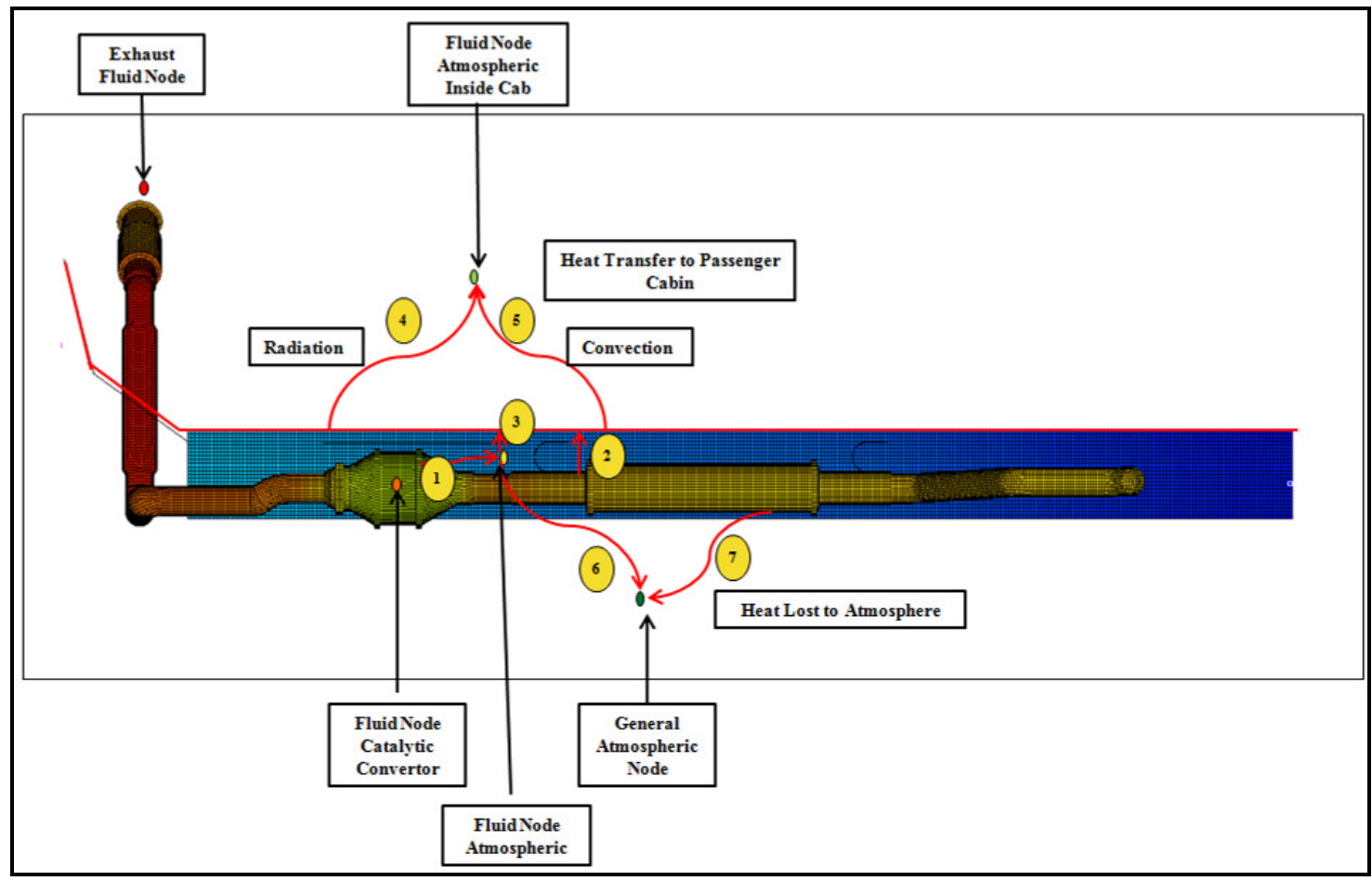

Figure 18 Fluid Nodes and Heat Transfer

As mentioned earlier, the exhaust gases in RadTherm are represented by two fluid streams. When a fluid stream is defined in RadTherm, it is automatically defined using fluid nodes. Each of the two fluid streams have 25 fluid nodes and these fluid nodes represent the fluid stream. However, these fluid nodes are not used for convective heat transfer between components as shown in the Figure 18. 


\section{C-I. Fluid Node Atmospheric}

This fluid node thermally connects the outer surface of the exhaust pipe to the vehicle underbody. This fluid node transfers heat from outer surface of the exhaust pipe to the vehicle underbody through convection. It represents the air particle between the exhaust pipe and the vehicle underbody. This fluid node also connects with the surrounding atmosphere (through the General Atmospheric Node) and losses heat to the environment. The temperature parameter for this fluid node is set to "Calculated" as RadTherm automatically calculates the temperature for this fluid node. Figure 19 shows the defining of node "Fluid Node Atmospheric" in RadTherm. Heat is also transferred from the outer surface of the exhaust pipe to the vehicle underbody through radiation but this fluid node does not take part in heat transfer through radiation. This is because heat transfer through radiation does not require any medium.

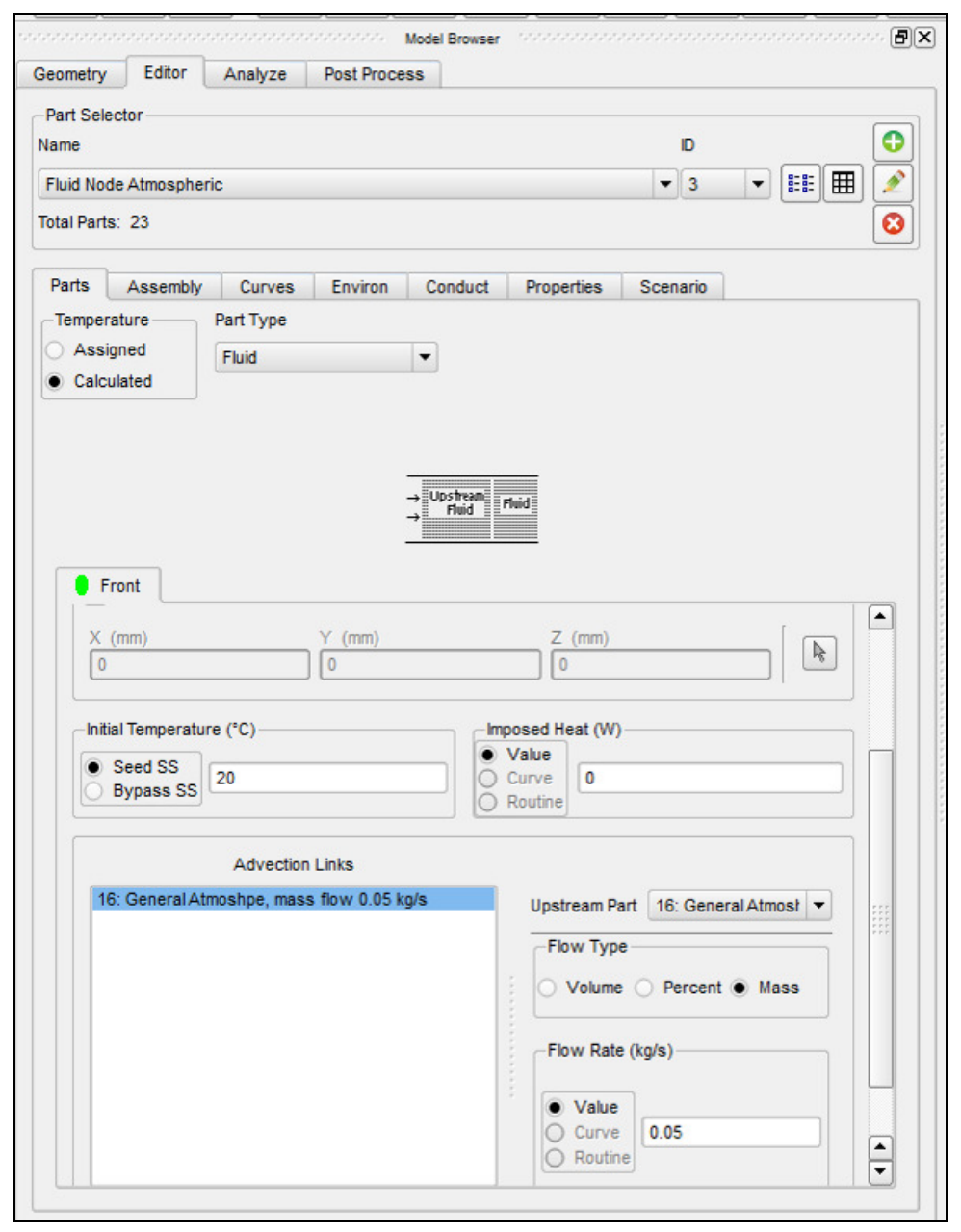

Figure 19 Fluid Node Atmospheric in RadTherm 


\section{C-II. General Atmospheric Node}

This fluid node represents the surrounding atmosphere to which heat is lost by convection and radiation. The temperature parameter for this fluid node is set to "Assigned" at a value of $20^{\circ} \mathrm{C}$ as the atmosphere acts as constant temperature heat sink. There is a convective heat transfer between "Fluid Node Atmospheric" and this fluid node representing the heat loss. Figure 20 and 21 shows the defining of this fluid node in RadTherm.

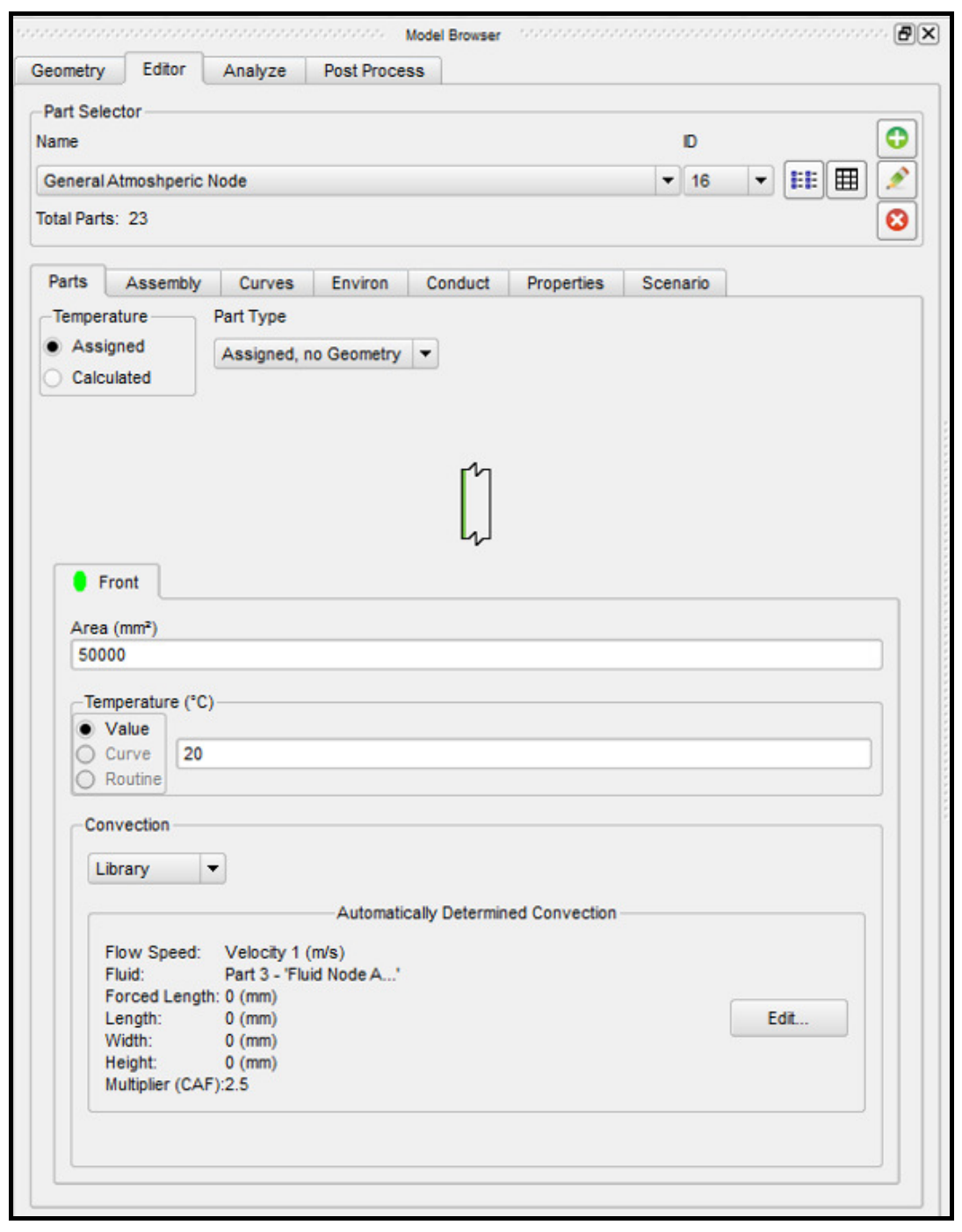

Figure 20 General Atmospheric Node in RadTherm 


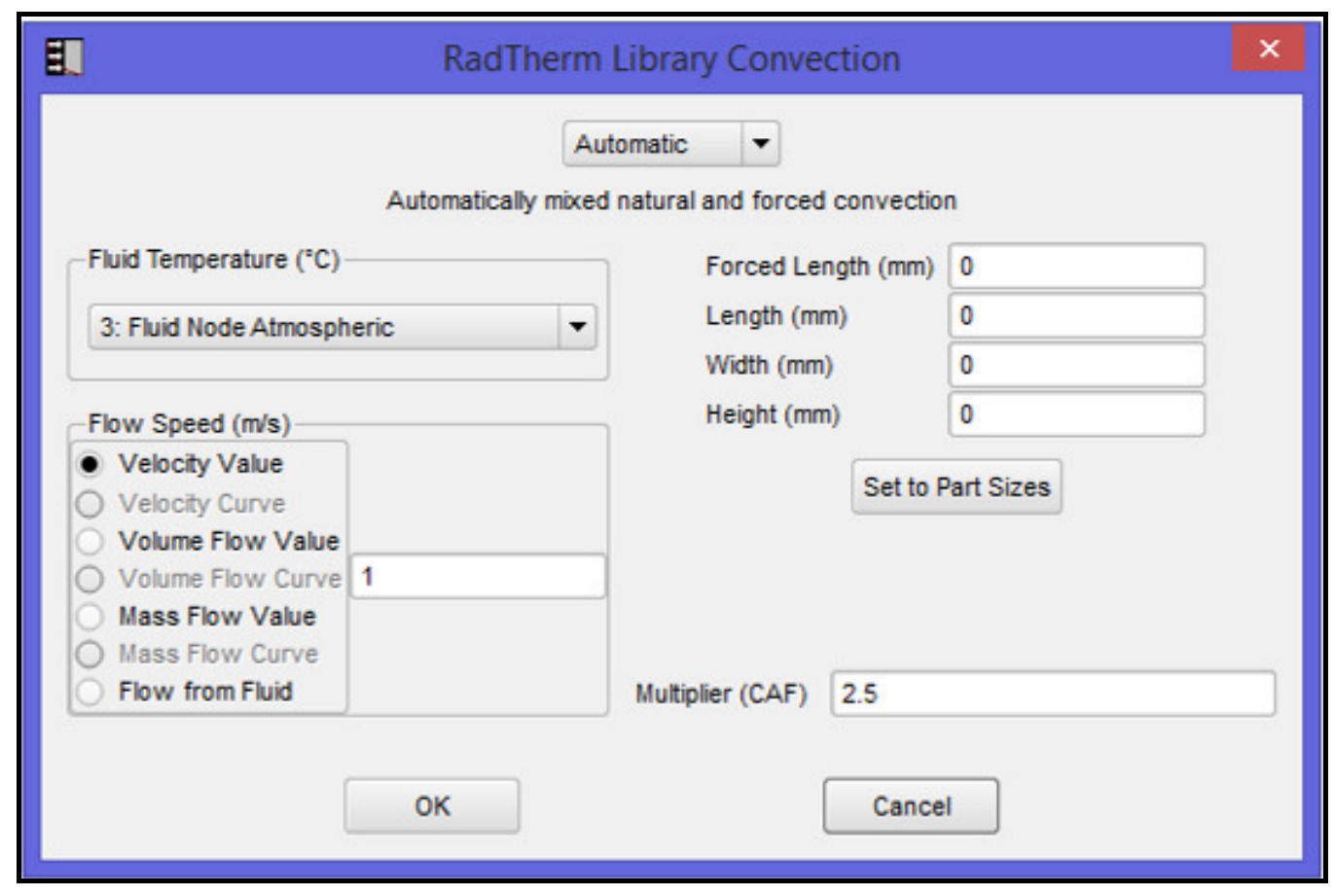

Figure 21 Library Function for General Atmospheric Node in RadTherm 


\section{C-III. Fluid Node Atmospheric Inside Cab}

This fluid node represents an air particle inside the passenger cabin. Heat is transferred from the floor of the vehicle to this fluid node through convection and radiation. The part type is "Fluid" and the Temperature is set as "Calculated". Figure 22 shows defining this fluid node in RadTherm.

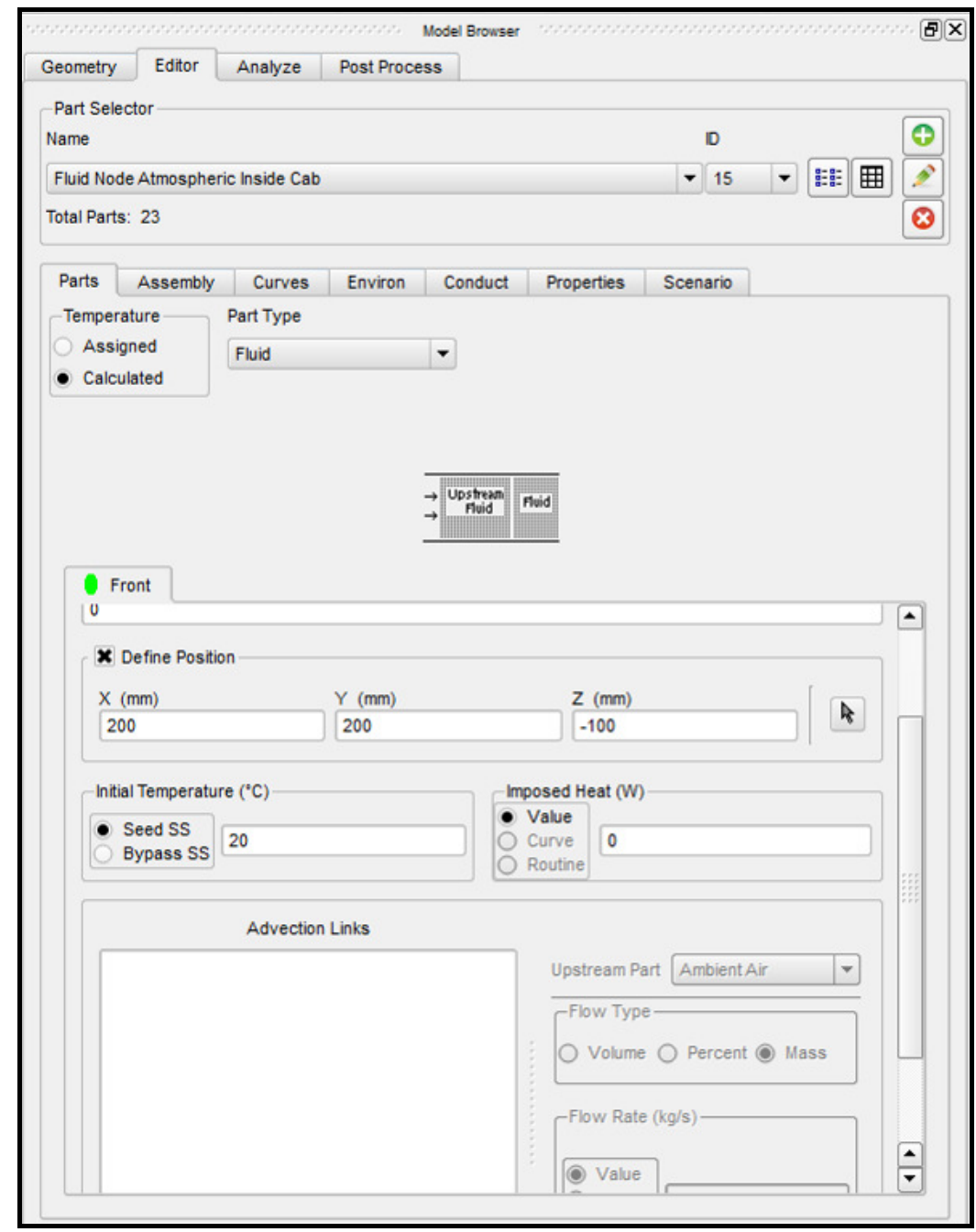

Figure 22 Fluid Node Atmospheric Inside Cab in RadTherm 
Table 6 lists all the parameters for the different Fluid Node particles.

Table 6 Parameters for the Fluid Node Particles

\begin{tabular}{|c|c|c|c|}
\hline $\begin{array}{l}\text { Srl. } \\
\text { No. }\end{array}$ & Fluid node & Parameter & Value \\
\hline \multirow{5}{*}{1.} & \multirow{5}{*}{$\begin{array}{l}\text { Fluid Node } \\
\text { Atmospheric }\end{array}$} & Temperature Type & Calculated \\
\hline & & Temperature & N/A \\
\hline & & Convection Type & $\begin{array}{l}\text { Advection link setup with } \\
\text { general surrounding } \\
\text { atmosphere (General } \\
\text { Atmospheric Node) }\end{array}$ \\
\hline & & Part Type & Fluid \\
\hline & & $\begin{array}{l}\text { Initial Temperature of } \\
\text { the fluid node }\end{array}$ & $20^{\circ} \mathrm{C}$ \\
\hline \multirow{4}{*}{2.} & \multirow{4}{*}{$\begin{array}{c}\text { General } \\
\text { Atmospheric } \\
\text { Node }\end{array}$} & Temperature Type & Assigned \\
\hline & & Temperature & $20^{\circ} \mathrm{C}$ \\
\hline & & Convection Type & Library Function \\
\hline & & Part Type & Assigned \\
\hline \multirow{5}{*}{3.} & \multirow{5}{*}{$\begin{array}{l}\text { Fluid Node } \\
\text { Atmospheric } \\
\text { Inside Cab }\end{array}$} & Temperature Type & Calculated \\
\hline & & Temperature & N/A \\
\hline & & Convection Type & None \\
\hline & & Part Type & Fluid \\
\hline & & $\begin{array}{l}\text { Initial Temperature of } \\
\text { the fluid node }\end{array}$ & $20^{\circ} \mathrm{C}$ \\
\hline 4. & Exhaust Fluid & Temperature Type & Assigned \\
\hline
\end{tabular}




\begin{tabular}{|c|c|c|c|}
\hline & \multirow[t]{3}{*}{ Node } & Temperature & $\begin{array}{l}\text { As obtained from } \\
\text { experimental data }\end{array}$ \\
\hline & & Convection Type & None \\
\hline & & Part Type & Assigned \\
\hline \multirow{5}{*}{5.} & \multirow{5}{*}{$\begin{array}{l}\text { Fluid Node } \\
\text { Catalytic } \\
\text { Converter }\end{array}$} & Temperature Type & Calculated \\
\hline & & Part Type & Fluid \\
\hline & & $\begin{array}{l}\text { Initial Temperature of } \\
\text { the fluid node }\end{array}$ & $20^{\circ} \mathrm{C}$ \\
\hline & & Heat Imposed & 300 Watts $^{7}$ \\
\hline & & Advection Links & $\begin{array}{l}\text { Advection with fluid stream } \\
\text { Upstream with a mass flow } \\
\text { rate of } 0.0365 \mathrm{~kg} / \mathrm{sec}\end{array}$ \\
\hline
\end{tabular}

\section{Defining Parameters for Heat Transfer by Radiation}

The thermal model of the exhaust system was developed by creating thermal links between the various components using the fluid nodes. These fluid nodes provide a thermal link between different components which is used for the convective heat transfer. As mentioned above there are 4 fluid nodes used in the model and three of them are used for creating the thermal links between various components.

The surface properties, namely the thermal emissivity and absorptivity values for the components of the exhaust system are defined in RadTherm. This enables RadTherm to compute the heat transfer and the heat loss to the environment using the StefanBoltzmann Law.

These surface properties were measured experimentally using a Directional Hemispherical Reflectometer, model number SOC410 built by Surface Optics Corporation. This device is used for measuring the thermal emissivity and solar

7 Heat was added at the after-treatment in order to account for the exothermic reaction at the after-treatment. The calculation for the heat addition is explained in the section 3.2 Model Calibration. 
absorptivity values for the surfaces of objects. The values of these surface property measurements are given in the experimental section.

\section{E. Defining heat generation element for the after-treatment part and thermally connecting it to the model}

The exhaust fluid stream is modeled as two different streams; - Fluid Stream Upstream and Fluid Stream Downstream. These two streams are connected by a fluid node called the "Fluid Node Catalytic Converter". This was done so that a heat generation element could be added to the model to represent the exothermic reaction taking place inside the after-treatment. The addition of heat increases the temperature of the exhaust gases as they pass through this fluid node. The amount of heat added was calculated based on the assumed combustion efficiency of the engine and the assumed conversion efficiency of the catalyst. This value of the heat addition is described in detail in the Section 3.2 Model Calibration. 


\section{Calibration \& Validation of the RadTherm Model}

Once the RadTherm model was developed and parameterized with known measurements, it was calibrated to experimental data. There were several parameters which were adjusted in this calibration process. Additional data was used for validation purposes.

An experimental setup was developed in order to calibrate the model and validate the results obtained from the modeling. The experimental setup is explained in detail in the following section.

\subsection{Experimental Setup}

The experimental setup for the calibration and validation of the RadTherm model was developed by instrumenting the existing HMMWV. Table 7 lists the parameters required for calibration and validation of the RadTherm model.

Table 7 Parameters required for Calibration and Validation of RadTherm model

\begin{tabular}{|c|l|}
\hline Classification of Parameter & \multicolumn{1}{|c|}{ Parameters } \\
\hline \multirow{4}{*}{ Parameters for Parameterization } & $\begin{array}{l}\text { Emissivity and Absorptivity } \\
\text { Properties for surfaces of the } \\
\text { exhaust system }\end{array}$ \\
\cline { 2 - 2 } & $\begin{array}{l}\text { Mass flow rate of the exhaust } \\
\text { gases }\end{array}$ \\
\hline \multirow{4}{*}{ Parameters for Calibration } & $\begin{array}{l}\text { Convective Augmentation } \\
\text { Factor (CAF) }\end{array}$ \\
\cline { 2 - 2 } & $\begin{array}{l}\text { Heat addition at after- } \\
\text { treatment }\end{array}$ \\
\hline \multirow{2}{*}{ Parameters for Validation } & $\begin{array}{l}\text { Exhaust Gas Temperature } \\
\text { Profile }\end{array}$ \\
\cline { 2 - 2 } & $\begin{array}{l}\text { Temperature profile for the } \\
\text { surface of the exhaust system } \\
\text { and vehicle underbody }\end{array}$ \\
\cline { 2 - 2 } & In-cabin floor temperature \\
\hline
\end{tabular}

UNCLASSIFIED - Distribution Statement A. Approved for public release. Page 35 of 64 


\subsubsection{Measuring Mass Flow Rate Of The Exhaust Gases}

Mass flow of the exhaust gases through the exhaust system had a considerable effect on the simulation results in RadTherm. Therefore, it was very important to accurately compute the mass flow rate of the exhaust gases. The Law of Conservation of Mass was used for calculating the mass flow of the exhaust gases. The mass flow rate of the exhaust gases was equal to the mass flow rate of the air at the intake manifold and the mass flow rate of the fuel.

$$
\mathrm{m}_{\text {exhaust }}=\mathrm{m}_{\text {intake_air }}+\mathrm{m}_{\text {fuel }}
$$

$$
\begin{aligned}
& \text { where, } \\
& \dot{m}_{\text {exhaust }}=\text { Mass flow rate of exhaust } \\
& \dot{m}_{\text {intake_air = Mass flow rate of intake air }} \\
& \dot{m}_{\text {fuel }}=\text { Mass flow rate of fuel }
\end{aligned}
$$

\section{Mass Flow Rate of Intake Air}

Three options were identified and analyzed to obtain the mass flow rate of the air through the intake manifold. Each of these methods had their own advantages and challenges.

\section{A. Obtain the mass flow rate of the air at the intake manifold using the existing Mass Air Flow (MAF) sensor.}

The prototype HMMWV has a mass air flow sensor in the Air Induction System to measure the mass flow rate for air into the engine.

The experimental setup for using the sensor to read the flow rate of the air is described in the following passage. The Air Induction System (AIS) from the vehicle was removed and connected to a Superflow Model 110 airflow bench. This was done 
so that the output of the sensor could be correlated to a known airflow. The MAF sensor was powered by providing an external 12 VDC supply. The signal pins of the MAF sensor were connected to a National Instruments MyDAQ Data Acquisition system to measure the output voltage from the sensor. Figure 23 shows experimental setup for measuring mass flow rate of air using the existing MAF sensor.

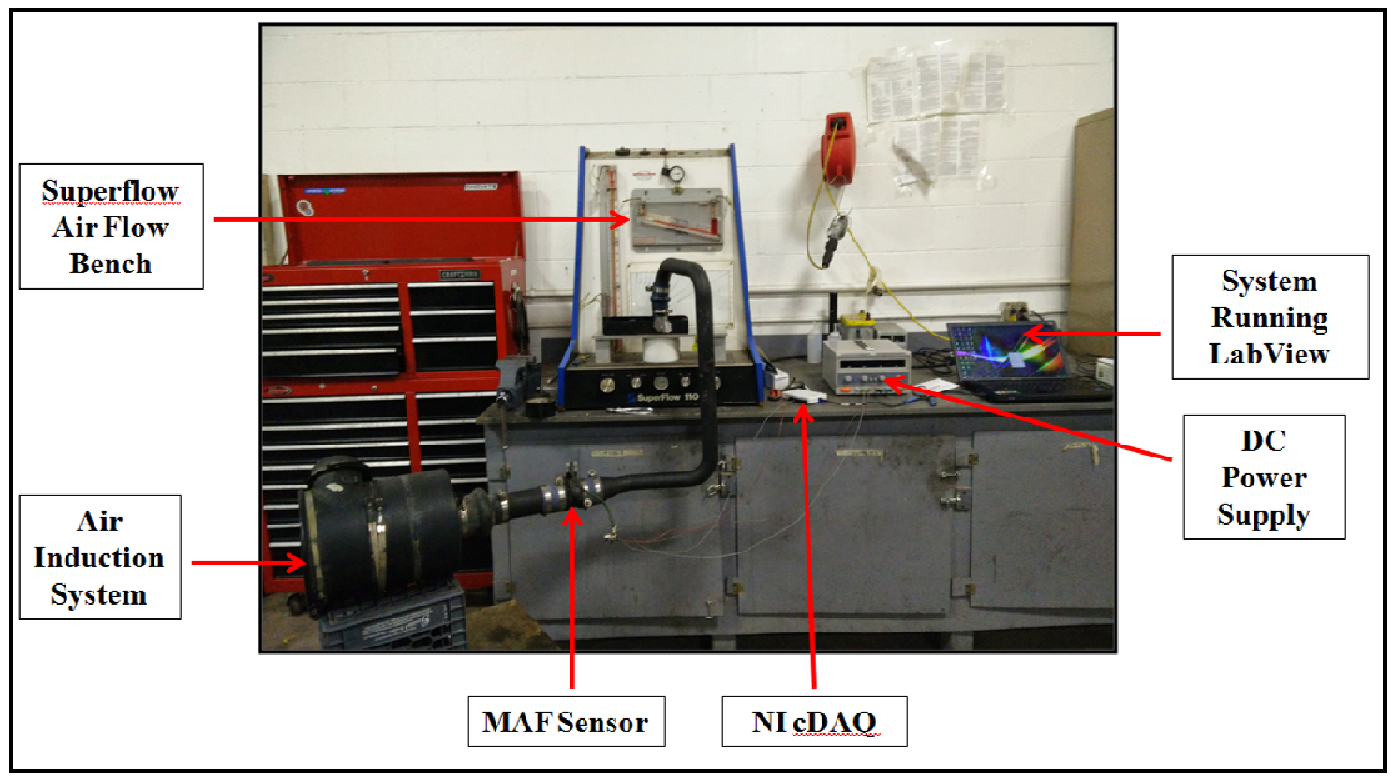

Figure 23 Experimental setup for measuring mass flow rate of air using MAF sensor

However, there were challenges faced while using this method. The MAF sensor used on the HMMWV had an integrated ambient air temperature sensor, which made it difficult to identify the pin configuration for the sensor. The prototype HMMWV has a DW12 TED4 CIROGEN 2.2 L diesel engine and a BOSCH ECU - EDC 15C2 for High pressure Diesel Injection (HDI) System [1]. The pin configuration and the expected output signal voltage $(0-5 \mathrm{~V})$ for the MAF sensor was obtained from the BOSCH ECU manual. However, even after sweeping the mass flow rate of air no change was observed in the output signal voltage from the MAF sensor. Also the input voltage from the DC power supply was swept from $5 \mathrm{~V}$ to $24 \mathrm{~V}$ but still no change was observed in the output signal. This could be because of the failure to power ON the sensor with external power supply or incorrect pin configuration. Since the sensor could not be calibrated on the bench this method could not be used. 


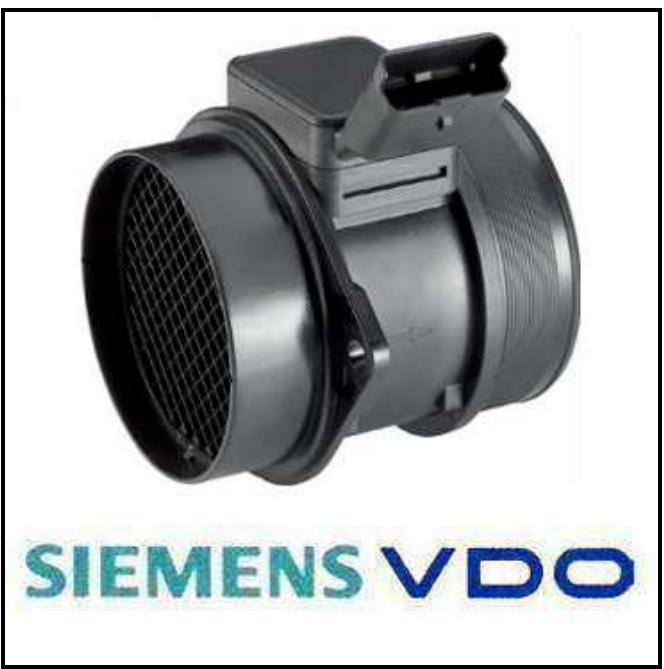

Figure 24 Siemens MAF sensor 5WK9628 [2]

Details for the MAF sensor shown in Figure 24 are obtained from the part :

Make : SIEMENS

Model \# : 5WK9628

\section{B. Obtain mass flow rate of the air at the intake over the vehicle CAN network}

The prototype HMMWV uses the J1939 protocol to communicate between different components over the CAN network. In general, most of the vehicle information is available over the CAN network but in case of the prototype HMMWV many of the messages are not in the standard but rather proprietary messages created by DRS, the company who built the prototype. As a result, this method to obtain the mass flow rate over the CAN network also failed.

\section{Determine the mass flow rate of the air from pressure drop measurements.}

The mass flow rate of the air was finally obtained by correlating the pressure drop across an induced restriction in the AIS with a known flow rate, then measuring the pressure drop during vehicle operation. A manometer was used to obtain the pressure drop, and thus correlate to a known mass flow rate. The manometer was connected after the air filter of the induction system so that a noticeable pressure drop could be observed. The pressure drop was calibrated on the SuperFlow 110 Airflow bench with the complete AIS setup identical to the in-vehicle geometry. The liquid used in the manometer was plain water with food color. The food color was 
added to improve visibility and enhance readability. Figure 25 shows the manometer which was built in-house.

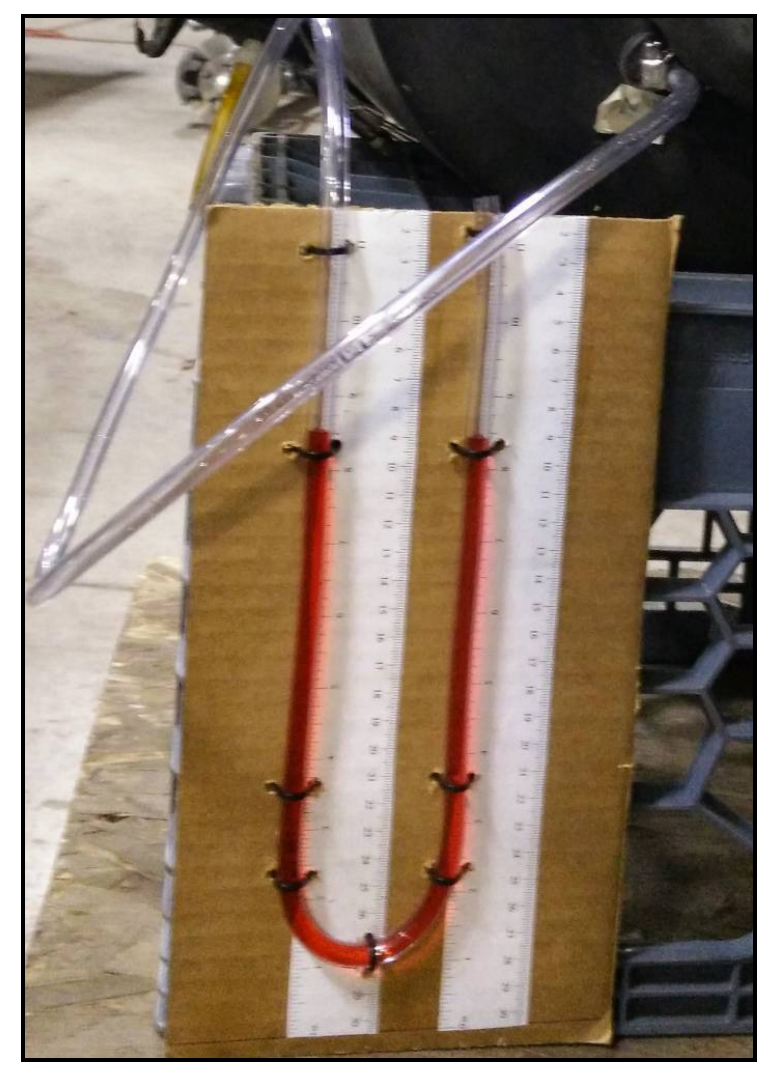

Figure 25 In-house built manometer

The manometer was calibrated on the flow bench along with the complete air induction system. Different flow rate of air was passed through the induction system and the pressure drop was measured across the filter using the manometer. Initially the pressure drop obtained across the filter was very less because of less restriction offered by the filter. In order to increase the sensitivity between the airflow rate and pressure drop in our test, $60 \%$ of the inlet of the Air Induction System (AIS) was covered with duct tape. However, the duct tape should be removed in case the engine and the APU are loaded further in order to let higher air flow into the system. Figure 26 shows the complete setup for calibrating the manometer on the air flow bench. A flow calibration curve was obtained for different flow rates. Figure 27,28 and 29 show the calibration curve for linear, second and third order polyfit for different flow rates of air. 


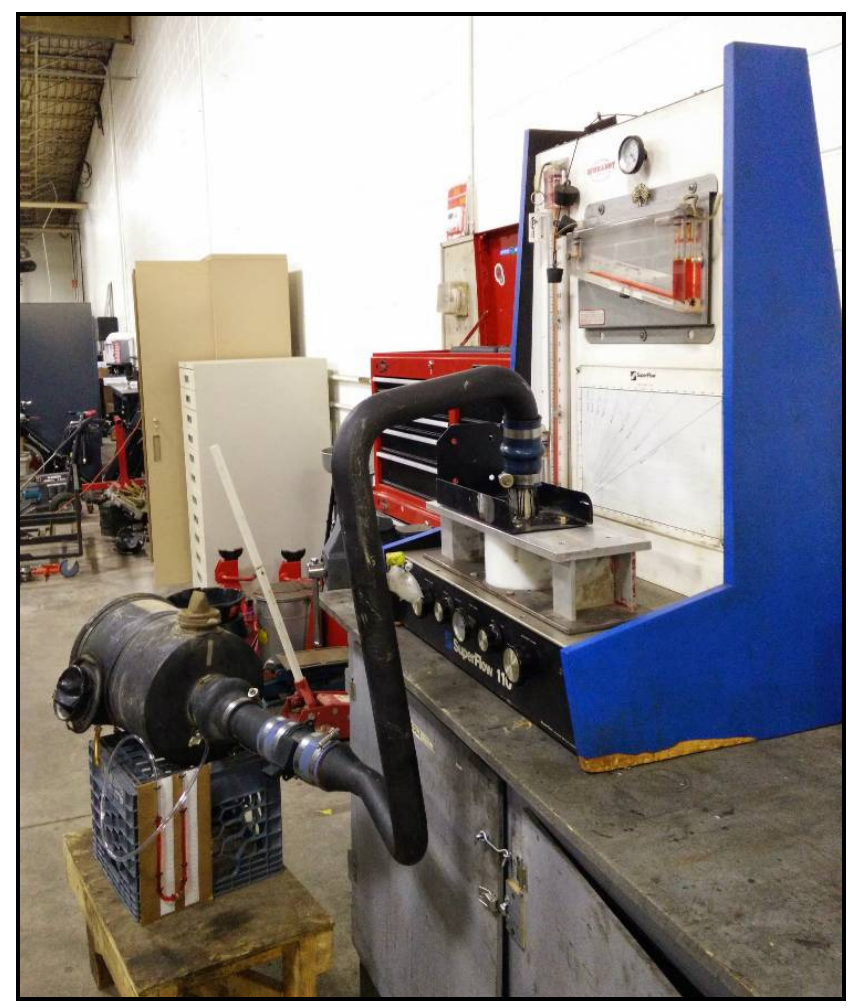

Figure 26 Experimental Setup for calibrating the manometer to measure flow rate of air

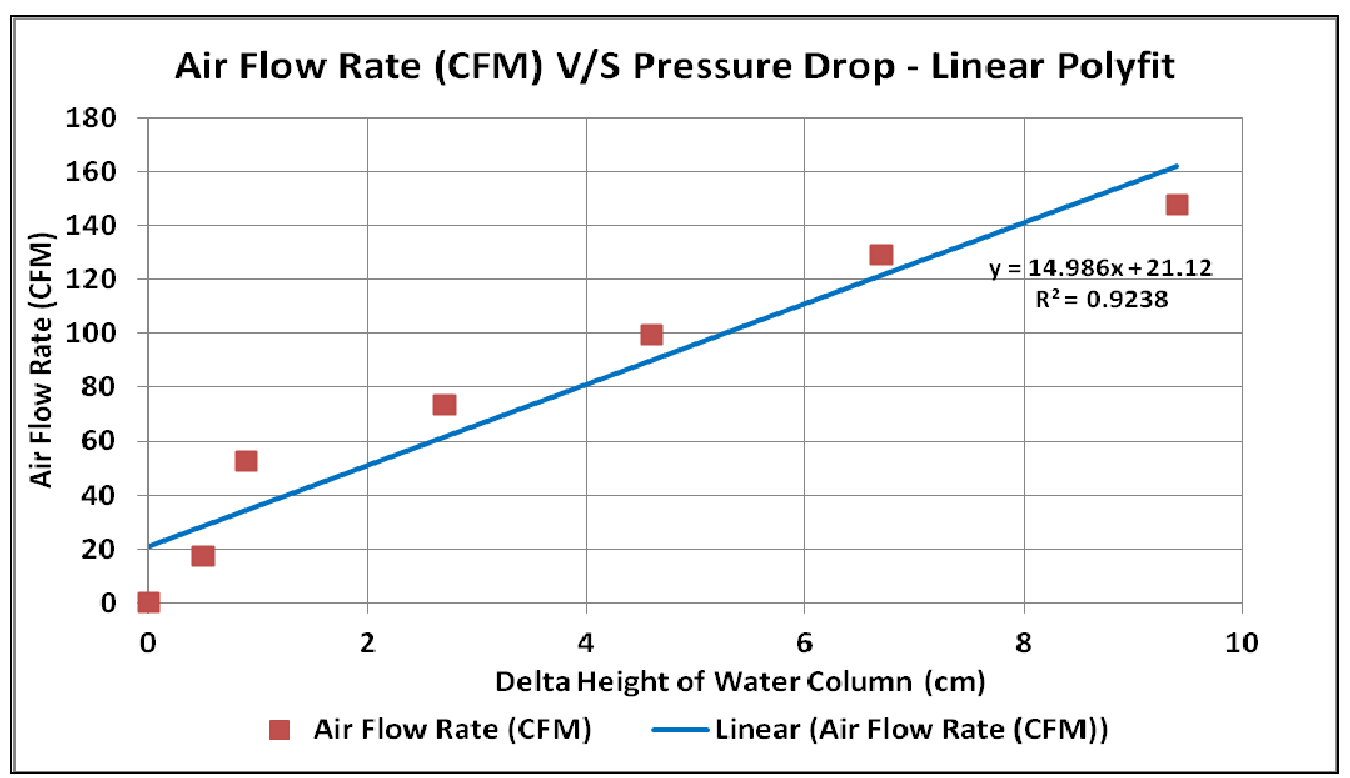

Figure 27 Calibration Curve showing the relationship between airflow rate and pressure drop. Air Flow Rate (CFM) V/s Pressure drop (Cms of Water). Linear Curve Fit 


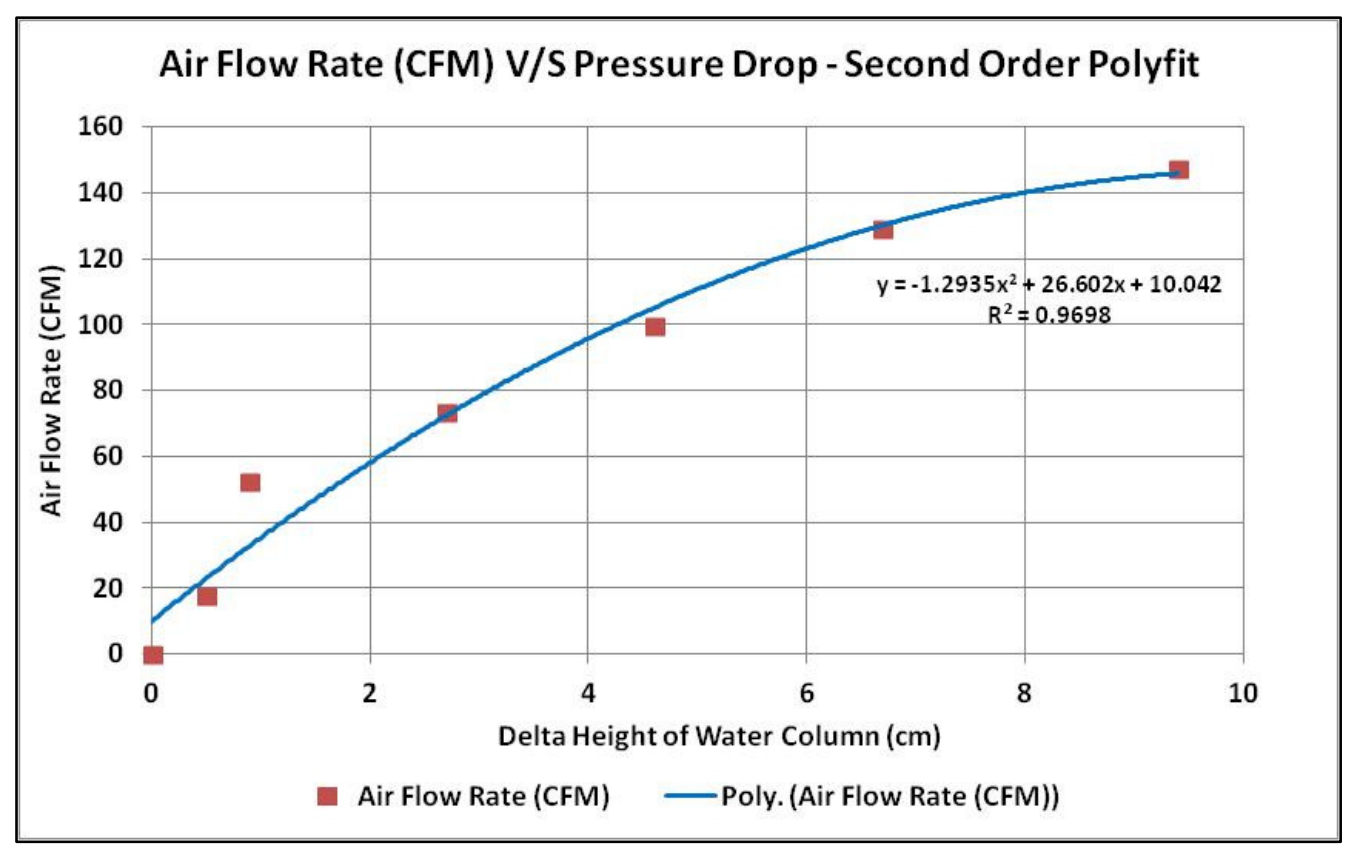

Figure 28 Calibration Curve showing the relationship between airflow rate and pressure drop. Air Flow Rate (CFM) V/s Pressure drop (Cms of Water). Second Order Curve Fit

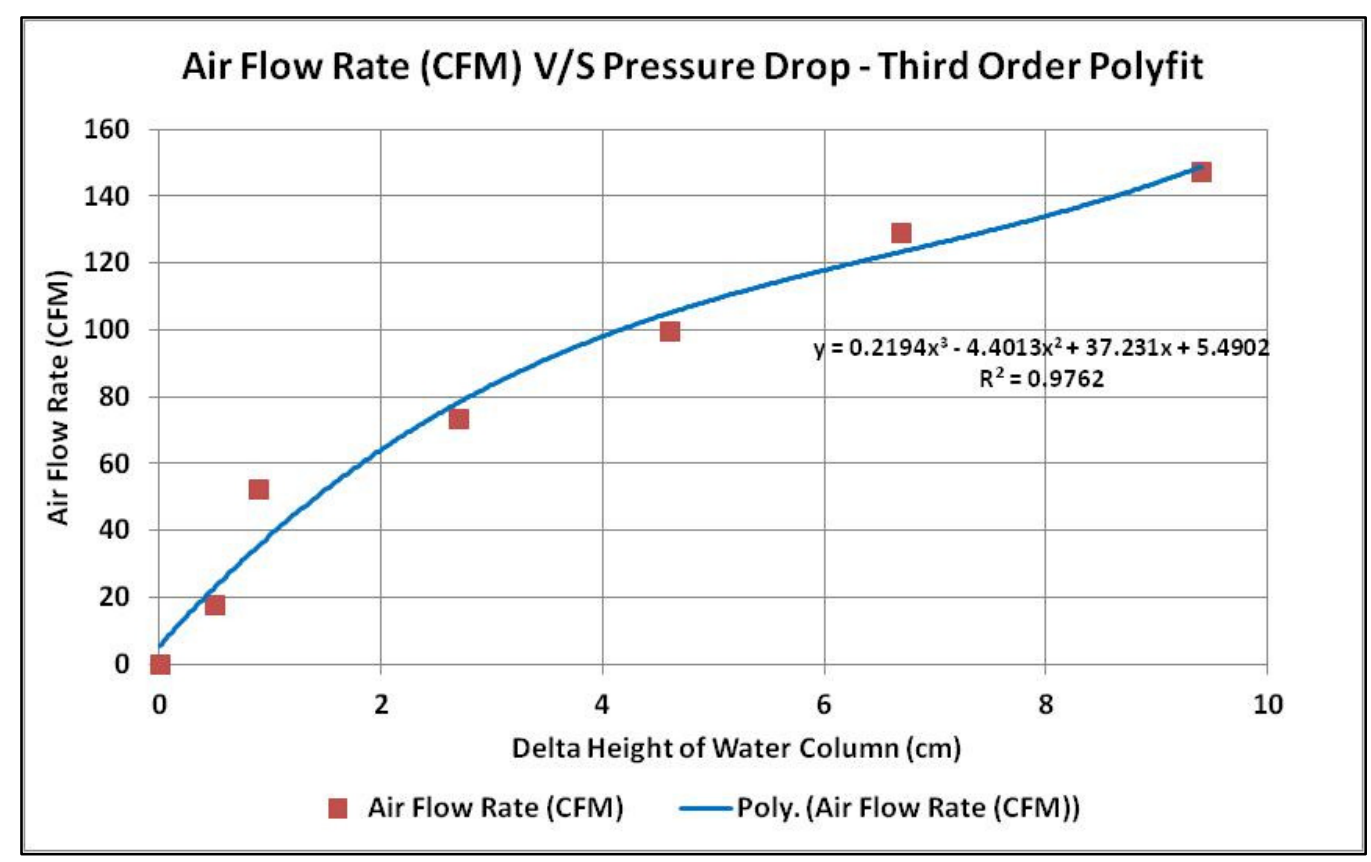

Figure 29 Calibration Curve showing the relationship between airflow rate and pressure drop. Air Flow Rate (CFM) V/s Pressure drop (Cms of Water). Third Order Curve Fit

UNCLASSIFIED - Distribution Statement A. Approved for public release. Page 41 of 64 
Experimental data was used to obtain a linear, a second order and a third order curve fits between the data points. For our testing we used the linear fit between the flow rate and the pressure drop. However, a third order curve fit would have given accurate results for the mass flow rate of the intake air. Once the flow restriction was calibrated it was then used directly on the vehicle to measure the flow rate of the air through the air induction system during the testing. Figure 30 shows the setup for measuring the pressure drop across the Air Induction System (AIS) as air flows through it.

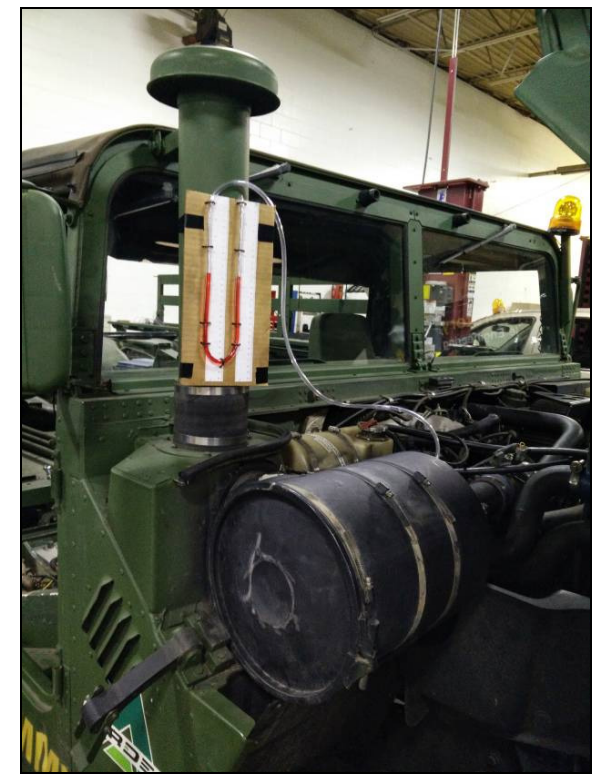

Figure 30 On Vehicle installation of the manometer to measure intake pressure drop

The pressure drop across the filter was recorded at different timestamps corresponding to the engine operating condition. The volumetric flow rate was obtained from the calibration shown in Figure 27. The mass flow rate of the air was calculated from the volumetric flow rate using the Ideal Gas equation of state.

$$
\mathbf{P V}=\mathbf{m R T}
$$

where,

$\mathrm{P}=$ Pressure $=$ (assumed to be standard atmosphere at $101325 \mathrm{~Pa}$ )

$V=$ Volume Flow rate obtained from the Calibration Curve in $\mathrm{m}^{3} / \mathrm{sec}$

$\mathrm{R}=$ Universal Gas Constant for air $=287.058 \mathrm{~J} / \mathrm{Kg}-\mathrm{K}$

$\mathrm{T}=$ temperature in Kelvin $=293 \mathrm{~K}$

$\mathrm{m}=$ Mass flow rate of the air in $\mathrm{Kg} / \mathrm{s}$ 


\section{Mass Flow Rate of the Fuel}

Mass flow rate of the fuel was obtained through calculation after measuring the generator load of the vehicle over the CAN and making a few assumptions. It was assumed that the APU unit in HMMWV consists of the engine and generator together and the operating load of the HMMWV is represented by the percent APU. APU percent is the percent electrical output of the rated generator output. As the rated power output and the percent APU for the generator was known we could calculate the output power from the generator. From the generator output power, a generator efficiency of $90 \%$ was considered based on the UQM PowerPhase specification sheet [3] to calculate the engine output power. In order to calculate the mass flow rate of the fuel, engine thermal efficiency of 30\% (Refer Appendix) and Lower Heating Value (LHV) of diesel was used.

The detailed calculation for mass flow rate of the fuel is shown in Section 3.2 Model Calibration.

The final mass flow rate of the exhaust was obtained by adding the mass flow of the intake air and the mass flow rate of the fuel. The detail calculation for mass flow rate of exhaust gases is shown in Section 3.2 under Model Calibration.

\subsubsection{Temperature Of The Exhaust Gases Through The Exhaust System}

The temperature of the exhaust gas flowing through the exhaust system was measured using k-type thermocouples. Holes were drilled and thermocouples were installed in the exhaust system to measure the temperature of the flowing gases. These thermocouples were connected to the National Instrument's cDAQ Data Acquisition System installed in the vehicle to record the temperatures (this system is also used to record CAN parameters and other data in the vehicle). The location and the number of thermocouples were decided so that the complete model of the exhaust system could be validated with the experimental results. There were five thermocouples used to measure the temperature of the gases flowing through the exhaust system. Figure 31 shows the location of the five thermocouples. 


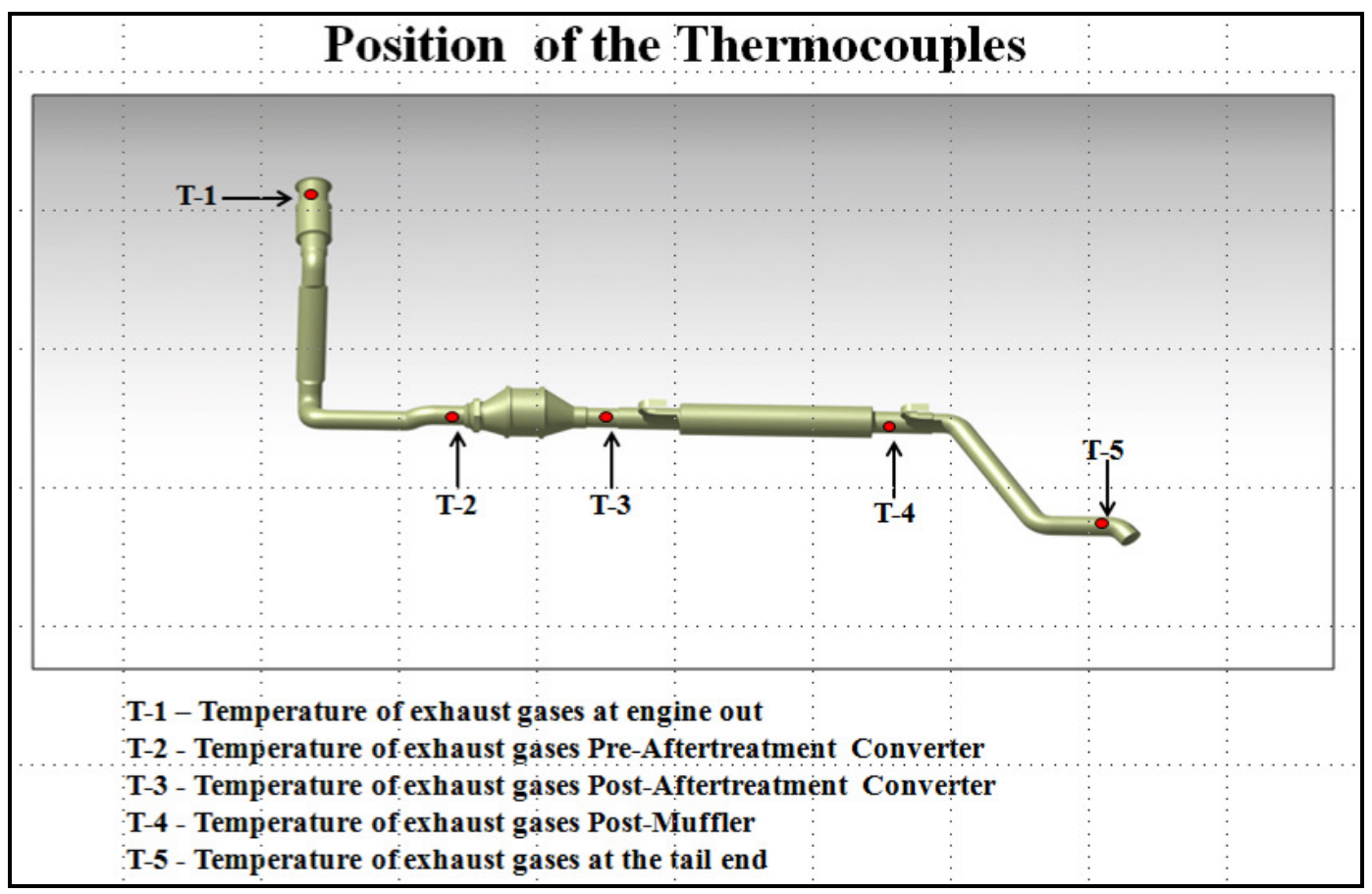

Figure 31 Location of thermocouples to measure temperature of exhaust gases

Figure 32 and 33 show the installation of the thermocouples in the exhaust system for measuring the temperature of the exhaust gases.

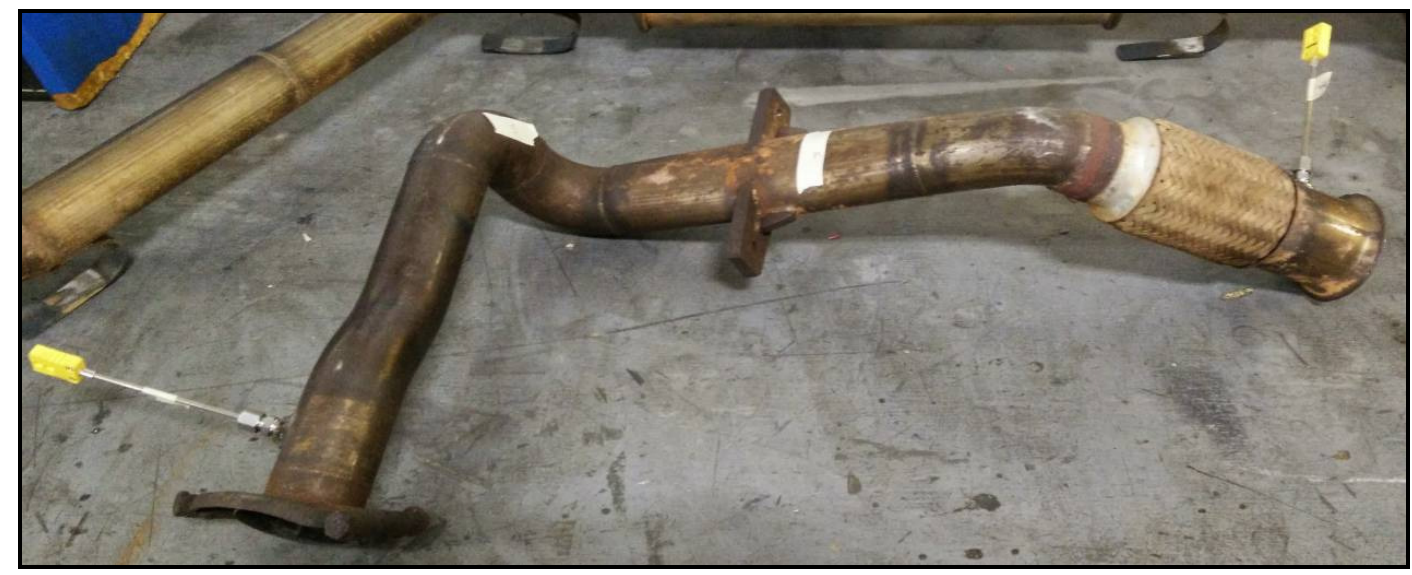

Figure 32 Installation of Thermocouple in Exhaust system 


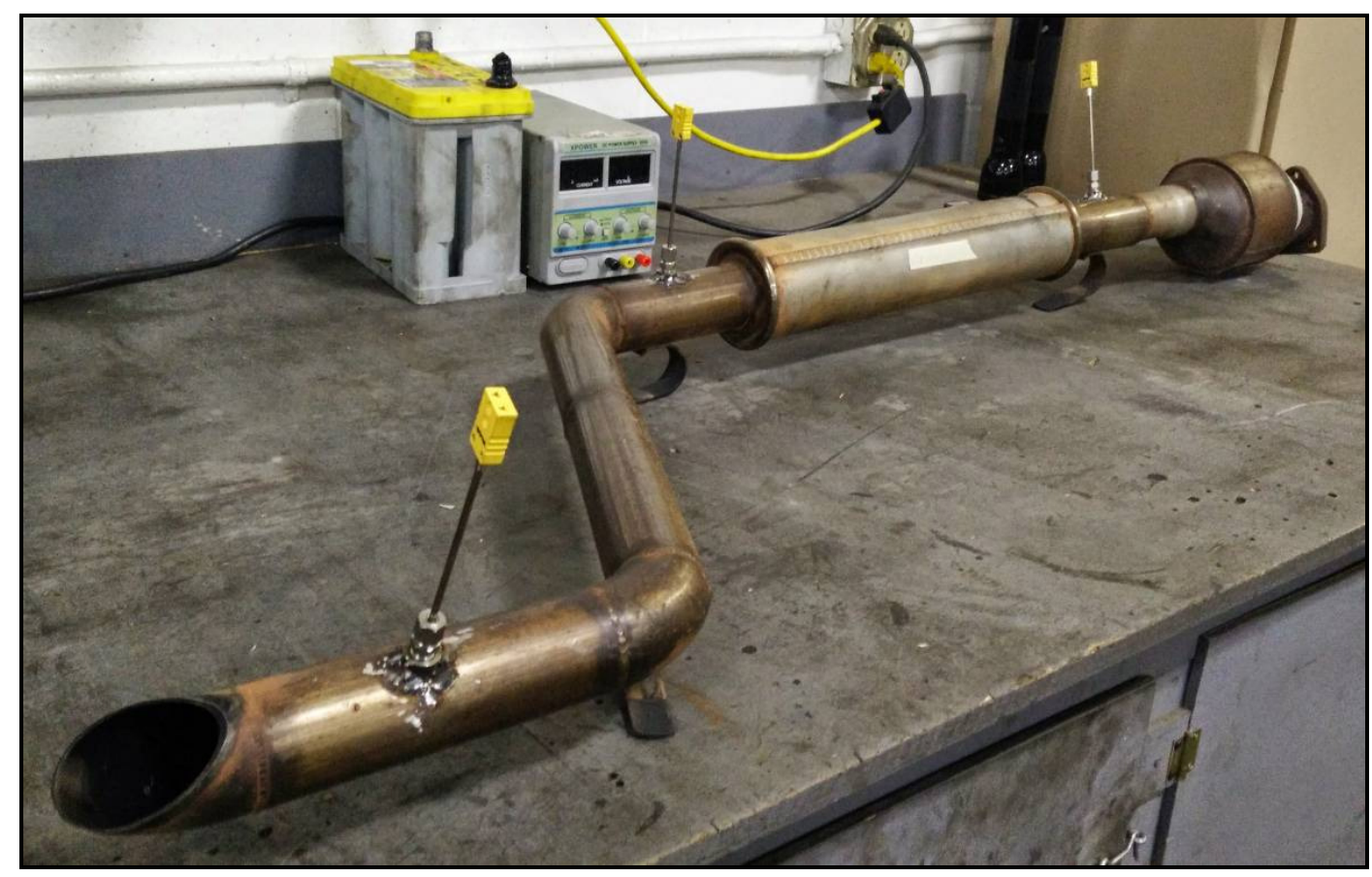

Figure 33 Installation of Thermocouple in Exhaust system

\subsubsection{Surface temperature Of The Exhaust System And Vehicle Underbody}

The surface temperature of the exhaust system and the vehicle underbody were obtained by using k-type thermocouple wire. In order to form a thermocouple, the insulation of the thermocouple wires were striped and the exposed ends were twisted together until the wires wound in a helix. The tip of the thermocouple wires was then glued to the surfaces using the Arctic Silver Thermal Adhesive. The thermal glue ensured that the tip of the thermocouple wires and the surface are in thermal contact with least thermal resistance between them. The thermocouple wires were connected to the $\mathrm{NI}$ CDAQ to record the temperatures. The location of the thermocouples for measuring surface temperature was kept closer to the exhaust system because of high thermal activity around them. There were 4 thermocouples which measured the surface temperature of the exhaust system. Figure 34 shows the location of the thermocouples on the surface of the exhaust system. 


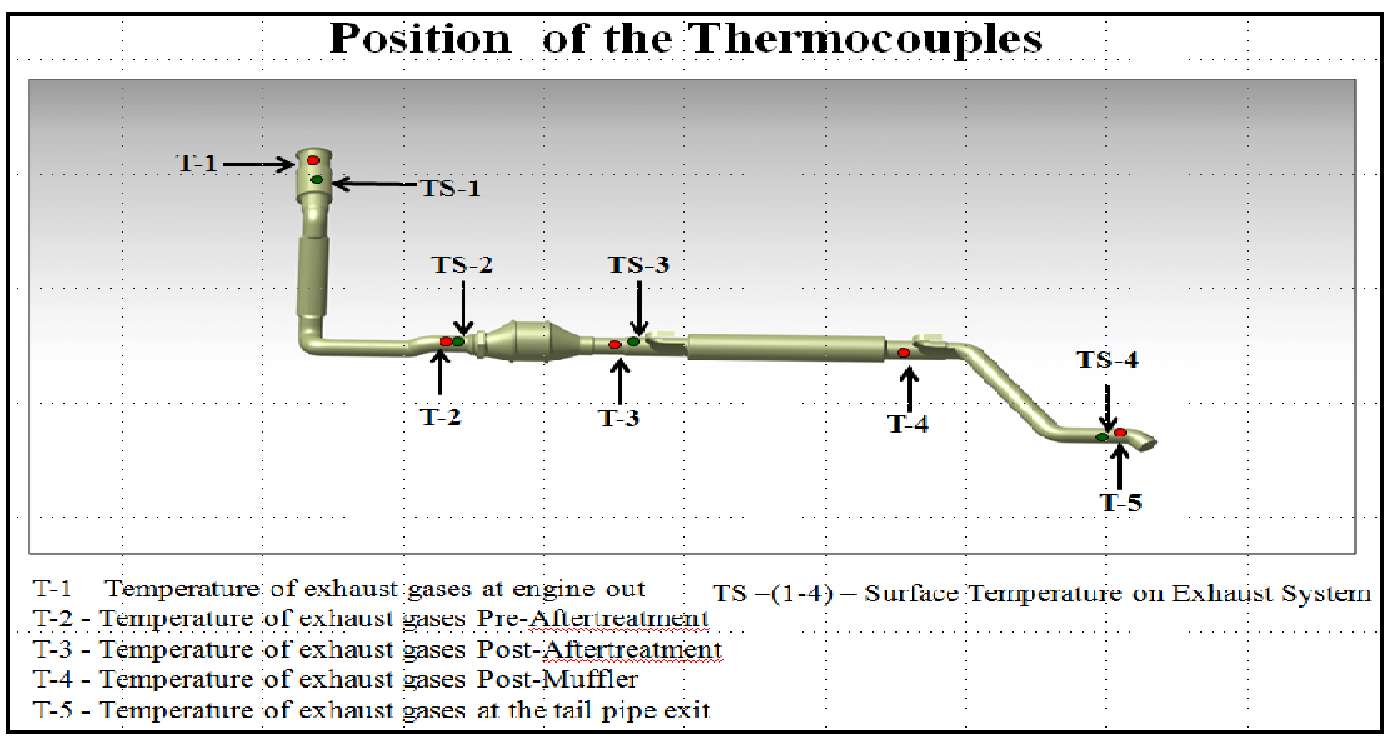

Figure 34 Location of thermocouples to measure temperature of exhaust gases and surface temperature of the exhaust system

Figure 35 shows the location of the thermocouples for the vehicle underbody. The thermocouples are located on the surface of vehicle underbody just above the exhaust system at the locations shown in Figure 35. The surface thermocouples are glued to the surface using a thermal paste. Four thermocouples are used to measure the temperature of the surface of the vehicle underbody at different locations. The floor temperature of the cabin is measured from the inside of the vehicle.

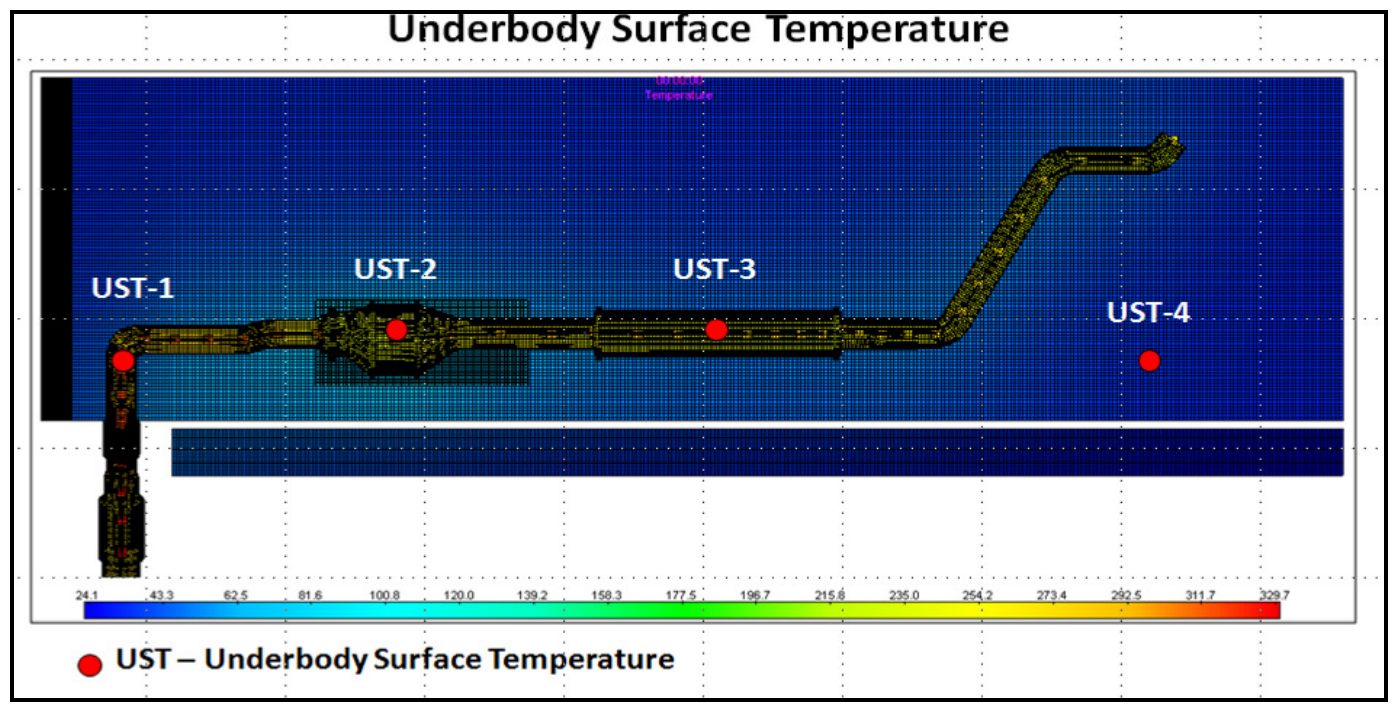

Figure 35 Location of Underbody Surface Temperature (UST) thermocouples 
In total 14 thermocouples were used to measure temperature at different locations in the HMMWV. Table 8 gives a brief description of the location of all the thermocouples.

Table 8 List of Thermocouples and Description of Location

\begin{tabular}{|c|c|c|}
\hline $\begin{array}{l}\text { Srl. } \\
\text { No. }\end{array}$ & $\begin{array}{l}\text { Thermocou- } \\
\text { ple Number }\end{array}$ & Description of Location \\
\hline 1. & $\mathrm{~T}-1$ & Temperature of the exhaust gases at the engine out \\
\hline 2. & $\mathrm{~T}-2$ & Temperature of the exhaust gases Pre-Aftertreatment \\
\hline 3. & T-3 & Temperature of the exhaust gases Post-Aftertreatment \\
\hline 4. & T-4 & Temperature of the exhaust gases Post-Muffler \\
\hline 5. & T-5 & Temperature of the exhaust gases at the tail pipe \\
\hline 6. & TS-1 & Temperature at the surface of the flexible joint \\
\hline 7. & TS-2 & $\begin{array}{l}\text { Temperature at the surface of the exhaust system Pre- } \\
\text { Aftertreatment }\end{array}$ \\
\hline 8. & TS-3 & $\begin{array}{l}\text { Temperature at the surface of the exhaust system in } \\
\text { between the aftertreatment and the muffler. }\end{array}$ \\
\hline 9. & TS-4 & $\begin{array}{l}\text { Temperature at the surface of the exhaust system at the } \\
\text { end of the tail pipe. }\end{array}$ \\
\hline 10. & UST-1 & $\begin{array}{l}\text { HMMWV Underbody surface temperature at the start of } \\
\text { the horizontal surface above the exhaust system. }\end{array}$ \\
\hline 11. & UST-2 & $\begin{array}{l}\text { HMMWV Underbody surface temperature above the } \\
\text { aftertreatment }\end{array}$ \\
\hline 12. & UST-3 & $\begin{array}{l}\text { HMMWV Underbody surface temperature above the } \\
\text { center of the muffler. }\end{array}$ \\
\hline 13. & UST-4 & $\begin{array}{l}\text { HMMWV Underbody surface temperature at the far end } \\
\text { of the vehicle. }\end{array}$ \\
\hline 14. & FCT & Cabin Floor temperature just above the aftertreatment \\
\hline
\end{tabular}

UNCLASSIFIED - Distribution Statement A. Approved for public release. Page 47 of 64 
Figure 36 and 37 shows the underbody of the vehicle after all the thermocouples have been installed.

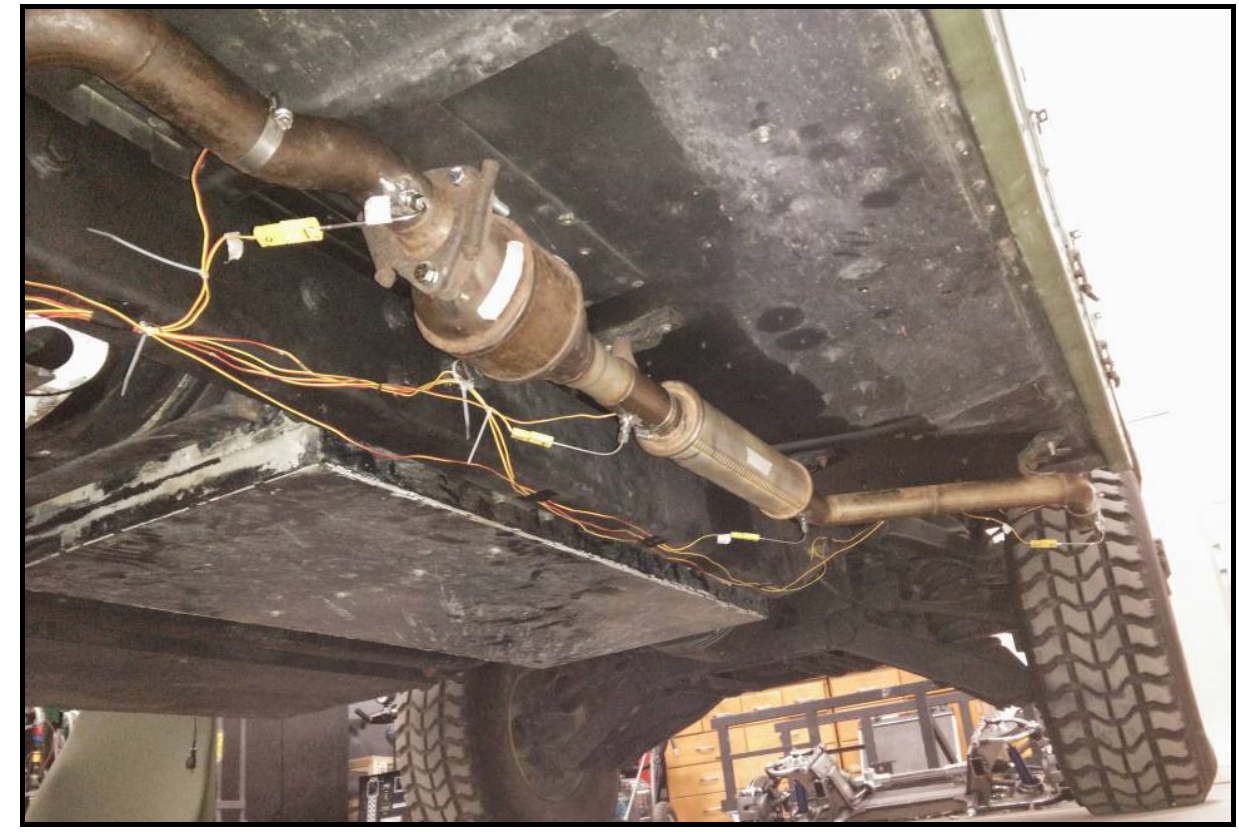

Figure 36 Vehicle Underbody after installation of thermocouple

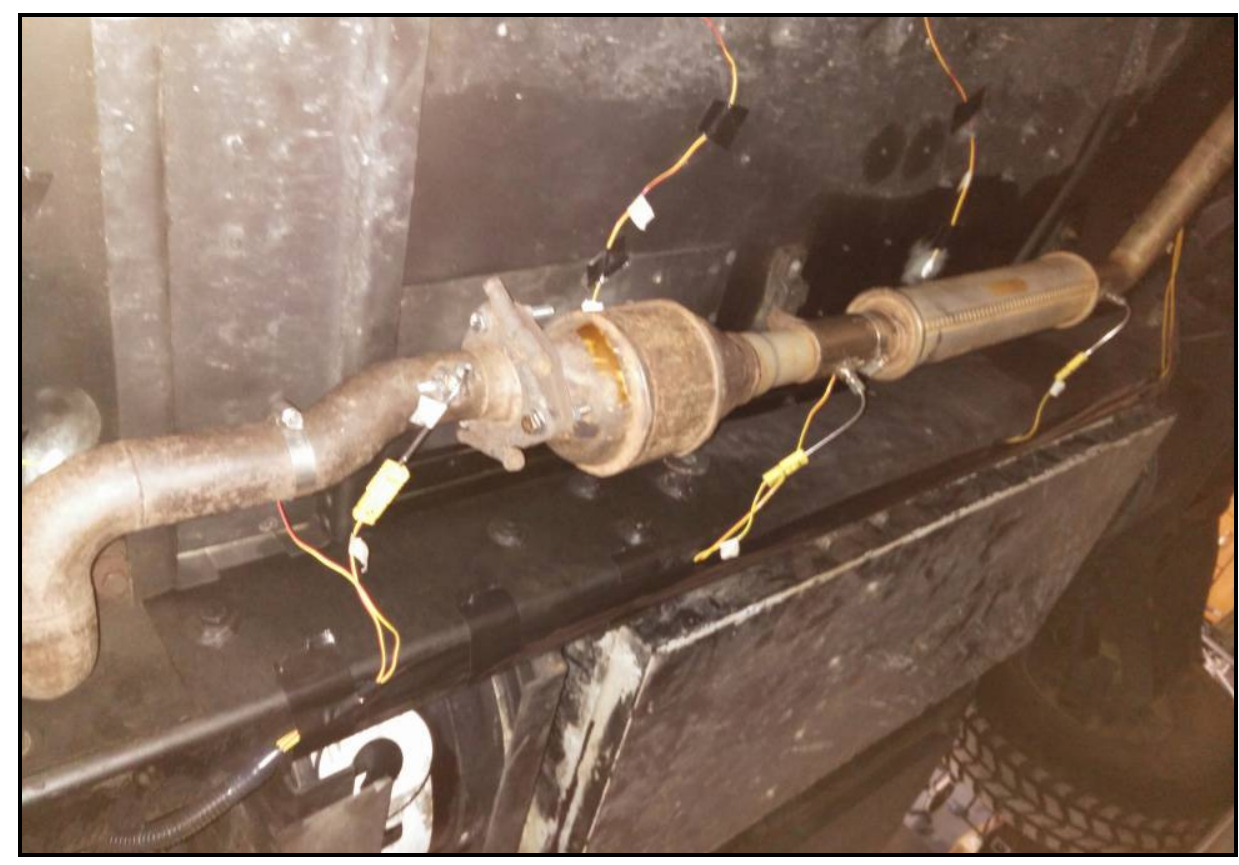

Figure 37 Vehicle Underbody after installation of thermocouple 
Figure 38 shows the thermocouple for measuring in-cabin floor temperature

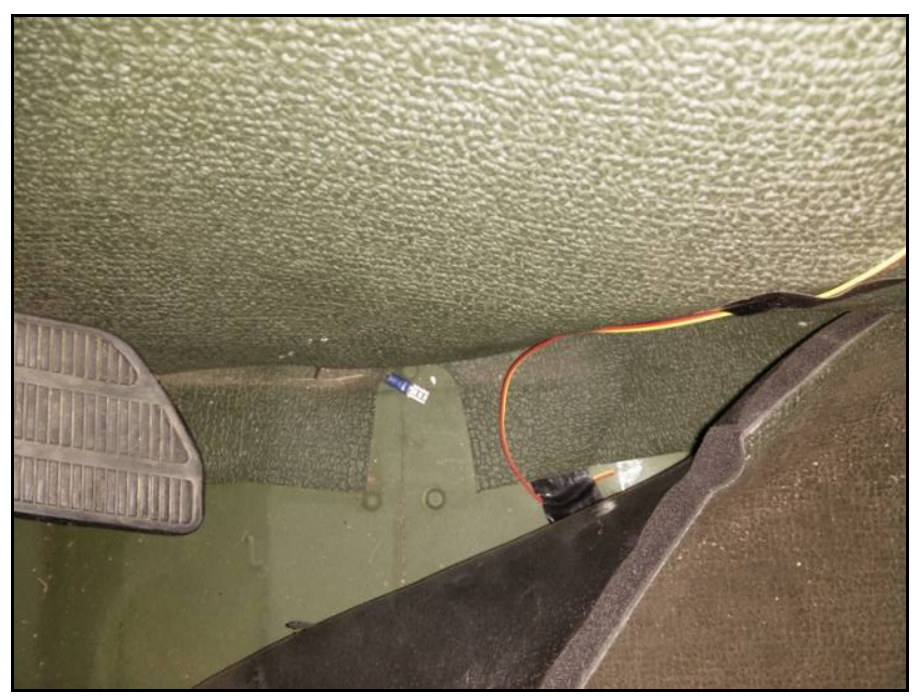

Figure 38 In-Cabin Floor Thermocouple

\subsubsection{Surface Properties for the Outer Surface of Exhaust System}

The surface properties for the exhaust system were measured using the Directional Hemispherical Reflectometer, SOC410 built by Surface Optics Corporation. This device is used for measuring the thermal emissivity and solar absorptivity values for the surfaces of objects. Table 9 lists the radiation heat transfer surface properties of the exhaust system. Figure 39 shows the various locations where the surface properties are measured.

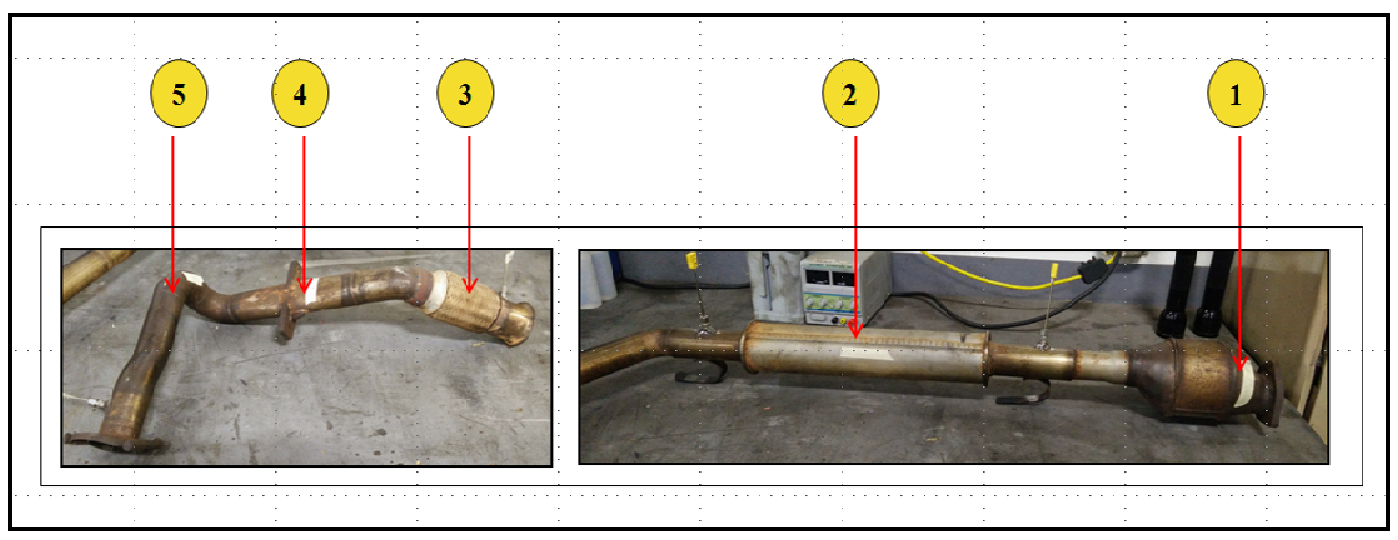

Figure 39 Surface Properties of the Exhaust System 
Table 9 Radiation heat transfer properties for the outer surface of Exhaust Pipe

\begin{tabular}{|c|c|c|c|c|}
\hline $\begin{array}{l}\text { Srl. } \\
\text { No. }\end{array}$ & Component & $\begin{array}{l}\text { Thermal } \\
\text { Emissivity }\end{array}$ & $\begin{array}{c}\text { Solar } \\
\text { Absorptivity }\end{array}$ & IMAGES \\
\hline 1 & $\begin{array}{c}\text { Catalytic } \\
\text { Converter - } \\
\text { Dark }\end{array}$ & 0.897 & 0.738 & \\
\hline 2 & $\begin{array}{l}\text { Muffler - } \\
\text { Silver }\end{array}$ & 0.714 & 0.416 & \\
\hline 3 & $\begin{array}{l}\text { Header } \\
\text { Pipe } \\
\text { Flexible } \\
\text { Section }\end{array}$ & 0.791 & 0.649 & \\
\hline 4 & $\begin{array}{c}\text { Header } \\
\text { Pipe - Shiny }\end{array}$ & 0.776 & 0.318 & \\
\hline 5 & $\begin{array}{c}\text { Header } \\
\text { pipe - Dark }\end{array}$ & 0.883 & 0.823 & \\
\hline 6 & $\begin{array}{c}\text { Vehicle } \\
\text { Underbody }\end{array}$ & 0.96 & 0.941 & \\
\hline
\end{tabular}




\subsubsection{Data Acquisition (DAQ) System}

To continuously log the temperatures from all locations (as well as various vehicle parameters on the CAN bus), a data acquisition tool was developed using National Instruments hardware and National Instruments LabView as the interfacing software. Temperatures for the fourteen locations were measured using the analog input module and a Virtual Instrument (VI) was built in LabView to display and record all the temperatures. Table 10 lists all the National Instruments hardware that were used.

Table 10 List of NI Hardware Used

\begin{tabular}{|c|c|c|}
\hline Description & Part No. & \multicolumn{2}{|c|}{ Image } \\
\hline Chassis & cDAQ 9174 & \\
\hline CAN Module & NI 9862 & \\
\hline $\begin{array}{c}\text { Thermocouple } \\
\text { Module }\end{array}$ & NI 9213 \\
\hline
\end{tabular}


Figure 40 shows the LabView interface to monitor the temperatures and different engine parameters. It also shows the engine speed and current state of charge (SOC) for the battery.

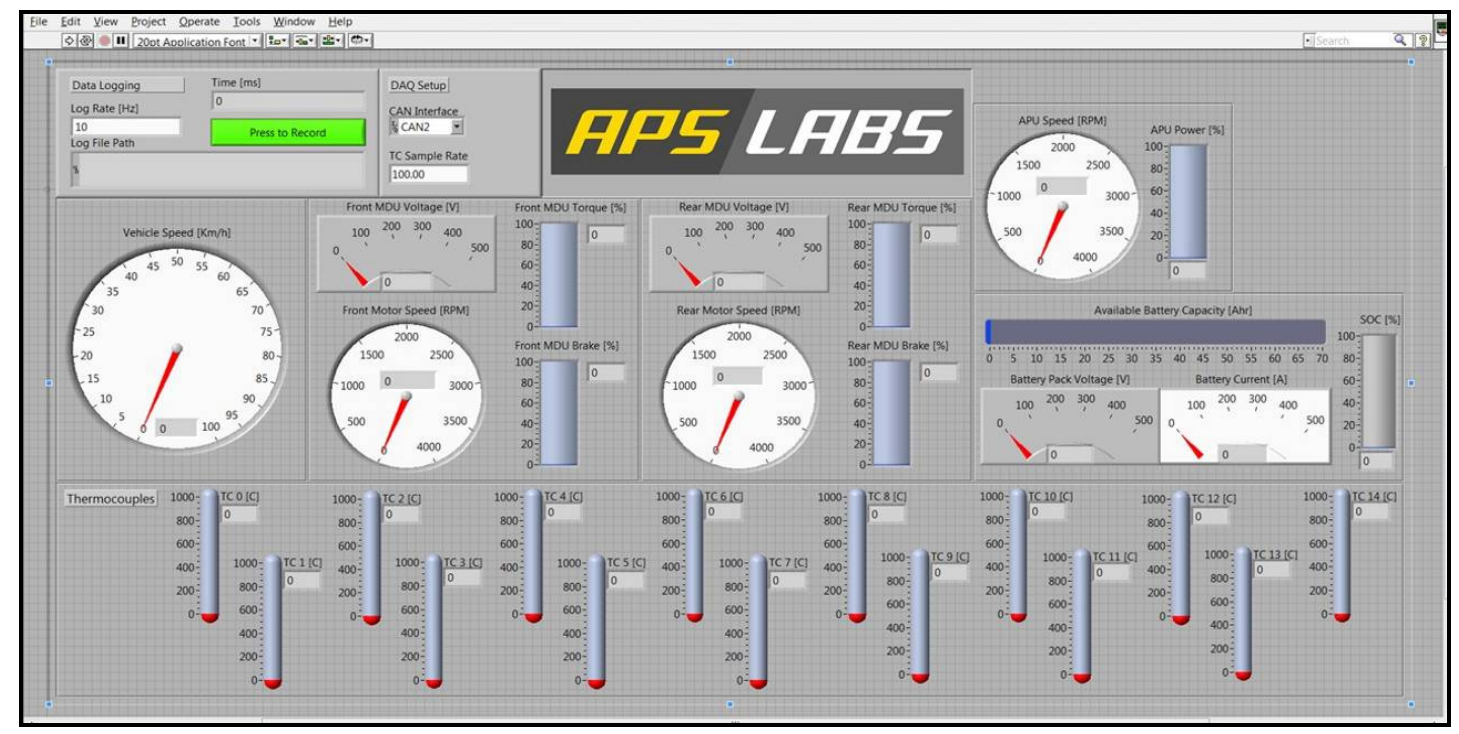

Figure $\mathbf{4 0}$ LabView interface to monitor temperature and engine parameters

Figure 41 shows the onboard Data Acquisition (DAQ) system used in the HMMWV.

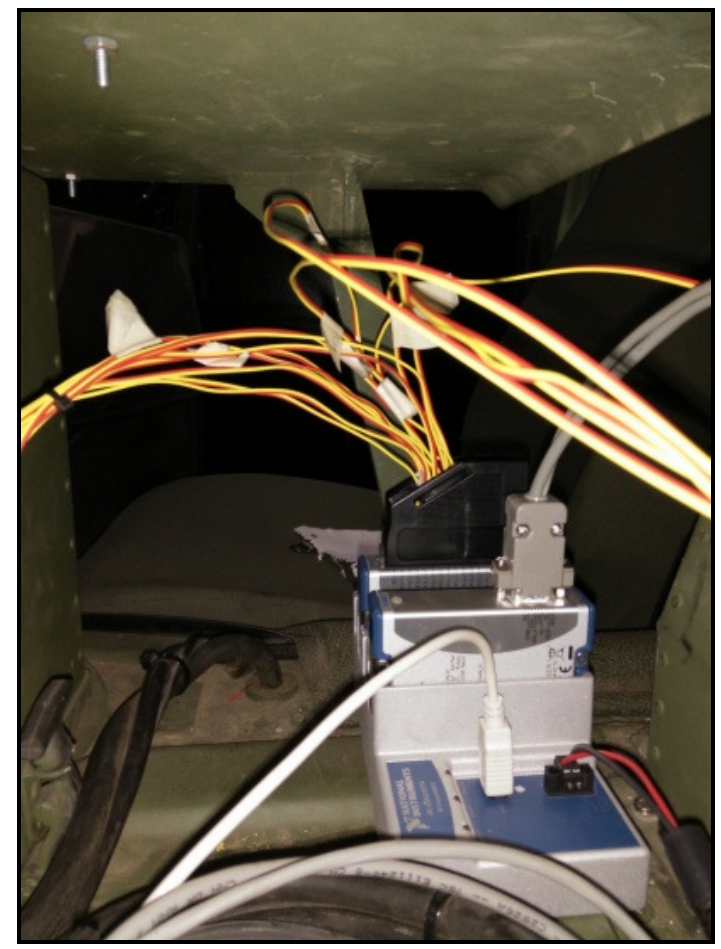

Figure 41 Onboard Data Acquisition (DAQ) system 


\subsection{Model Calibration}

This objective of this research work was to develop a model for the exhaust system of the HMMWV in RadTherm and validate the results with the experimental data obtained from testing. The RadTherm model developed for the exhaust system was for a steady state condition. As a result, the transient behavior of the system was not considered and the validation of the model was also done at the timestamp where the exhaust system and the engine had attained a thermally stable state.

The engine operating load was continuously monitored through the percent APU throughout the cycle and the model was validated when the engine operation stabilized. Figure 42 shows a graph between the Battery SOC and the Exhaust Gas Temperature with respect to time. From the graph it can observed that when the state of charge (SOC) of the battery was low (around 50\%) the engine was operating at a higher load (and thus higher Exhaust Gas Temperature) in order to charge the battery quickly. Once the SOC of the battery reaches the optimum value, the exhaust temperature remains constant for some time and then starts decreasing further indicating further decrease in engine load.

Since the RadTherm model was developed for steady state analysis, the results were validated after the engine and the exhaust system had reached a steady state. Case II shows the (shown in Figure 42 and Figure 43) timestamps where the model is calibrated and CASE-I shows the timestamp where the model is validated.

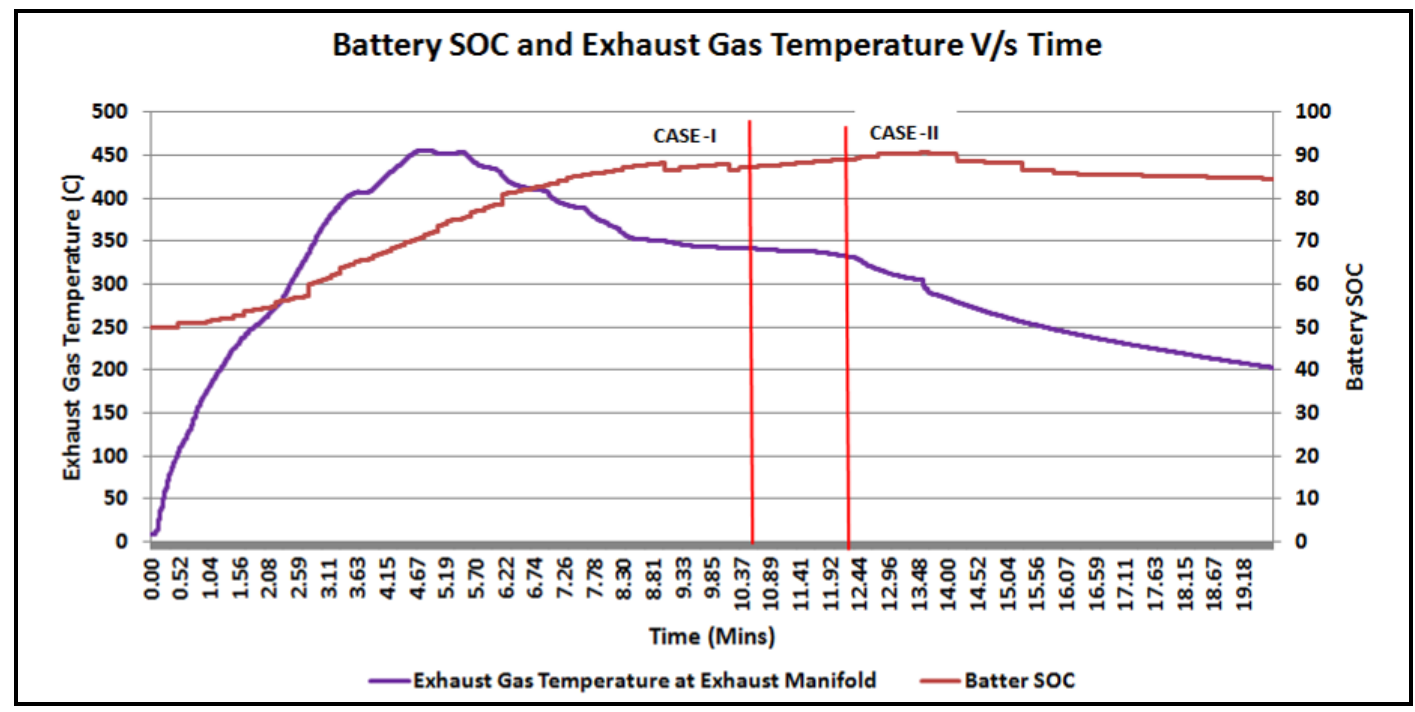

Figure 42 Battery SOC and the Exhaust Gas Temperature with respect to Time 


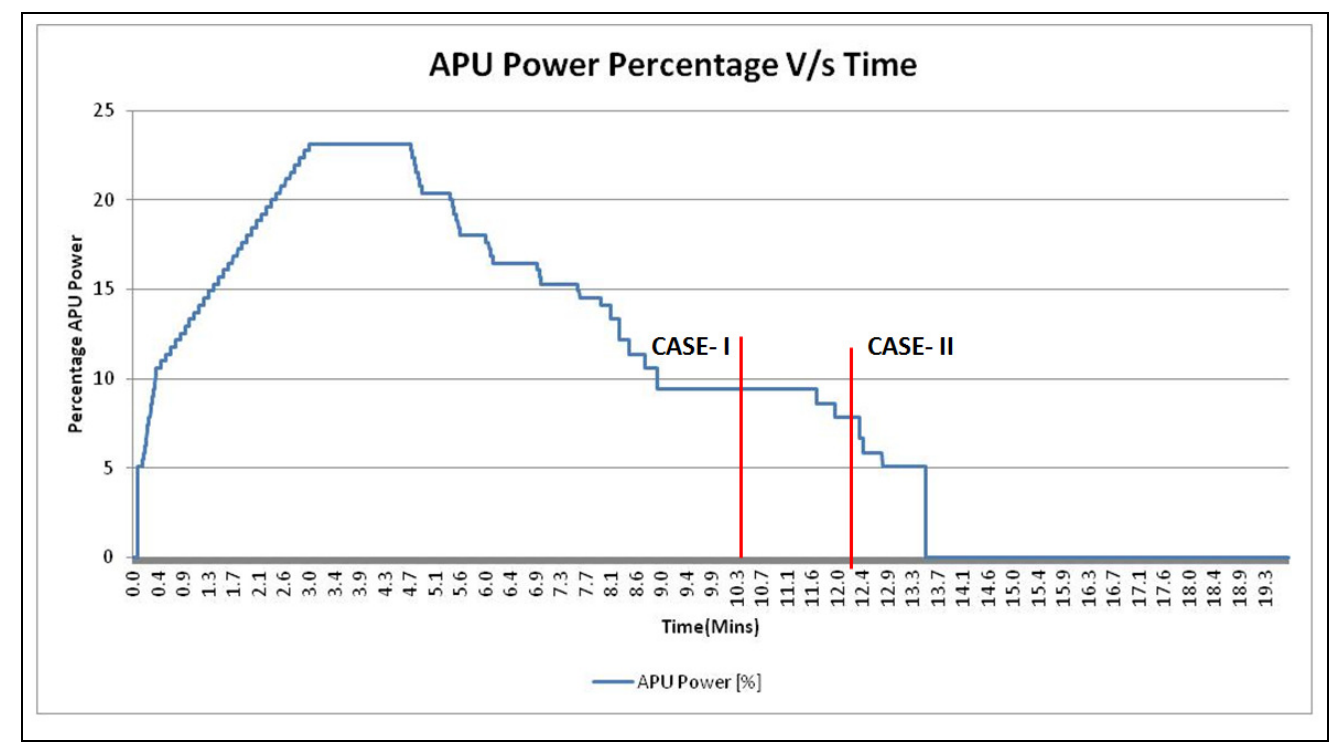

Figure 43 Percentage APU Power with respect to Time

Table 11 Validation and Calibration Points for Steady State Analysis

\begin{tabular}{|c|c|c|c|c|c|}
\hline CASE & Type & $\begin{array}{c}\text { Timestamp } \\
\text { (Mins) }\end{array}$ & $\begin{array}{c}\text { Exhaust Gas } \\
\text { Temp. (T1) C }\end{array}$ & $\begin{array}{c}\text { Percentage } \\
\text { APU Power } \\
\text { (\% APU } \\
\text { Power) }\end{array}$ & $\begin{array}{c}\text { Mass Flow Rate } \\
\text { of the Exhaust } \\
\text { Gases (g/sec) }\end{array}$ \\
\hline CASE I & $\begin{array}{c}\text { Validation } \\
\text { Point }\end{array}$ & 10.4 & 341 & $9.41 \%$ & 36.5 \\
\hline CASE II & $\begin{array}{c}\text { Calibration } \\
\text { Point }\end{array}$ & 12.2 & 332 & $7.84 \%$ & 29.7 \\
\hline
\end{tabular}

For accurately modeling the exhaust system, a heat generation element was introduced at the after-treatment. This was done to account for the heat released in the after-treatment due to the exothermic reaction. The amount of heat generated is calculated based on the principles of the IC engines and the final value is calibrated using the experimental results. 


\section{Calculations of heat addition at after-treatment}

Comparing the results from the RadTherm model with the experimental results it was found that the temperature profile for the Upstream exhaust gases as predicted by the model accurately matches with the experimental results but the temperature predicted by the RadTherm for the Downstream exhaust gases were lower than the experimental results. This indicated that the RadTherm model required some parameters to be calibrated to match the experimental results. From the results, it was concluded that the heat was required to be added in the RadTherm model at the after-treatment to account for the exothermic reactions.

The prototype HMMWV has a Auxiliary Power Unit (APU) which consists of the Engine and the Generator together. The experimental data obtained from the HMMWV over the CAN had a parameter known as the APU Power percent (APU \%). The APU percent is assumed to be the percent electrical output of the generator.

From the experimental data for CASE II at 12.2 mins,

APU Power $\%=7.84$

Rated Output of Generator [3] $=85 \mathrm{~kW}$

Actual Output Power of the generator $=\frac{\text { Rated Output of Generator } \times \text { APU Power } \%}{100}$

$$
\begin{aligned}
& =\frac{85 \times 7.84}{100} \\
& =6.65 \mathrm{~kW}
\end{aligned}
$$

Generator efficiency $[3]=90 \%$

Therefore,

Generator Input Power

$$
\begin{aligned}
& =\frac{\text { Actual Output Power of the generator }}{\text { Generator Efficiency }} \\
& =\frac{6.65}{0.9} \mathrm{~kW} \\
& =7.4 \mathrm{~kW}
\end{aligned}
$$


This is the power output from the engine to the generator

Engine Output Power = Generator Input Power

Rated Output of Engine $\quad=100 \mathrm{~kW}$

Engine Load

$$
\begin{aligned}
& =\frac{\text { Engine Output Power }}{\text { Rated Output of Engine }} \times 100 \\
& =\frac{7.4}{100} \times 100 \\
& =7.4 \%
\end{aligned}
$$

Thermal efficiency of the engine( $\left.\eta_{t}\right)$ [Appendix 6.1] $=30 \%$

Engine Input Fuel Power

$$
\begin{aligned}
& =\frac{\text { Engine Output Power }}{\text { Thermal Efficiency of the engine }} \\
& =\frac{7.4}{0.3} \\
& =25 \mathrm{~kW}
\end{aligned}
$$

Lower Heating Value of Diesel [4] $=43.2 \mathrm{MJ} / \mathrm{Kg}$

Mass flow rate of fuel $\left(m_{f u e l}\right)=\frac{\text { Fuel Input Power to Engine } \times 10^{3}}{\text { LHV of diesel } \times 10^{6}} \mathrm{~kg} / \mathrm{sec}$

$$
\begin{aligned}
& =\frac{25 \times 10^{3}}{43.2 \times 10^{6}} \mathrm{~kg} / \mathrm{sec} \\
& =0.0005787 \mathrm{~kg} / \mathrm{sec} \\
& =0.5787 \mathrm{gm} / \mathrm{sec}
\end{aligned}
$$

Combustion efficiency used for the engine is $99 \%$ [4], therefore, only $1 \%$ of the fuel escapes to the after-treatment. This is the amount of chemical energy escaping to the after-treatment.

Mass of diesel escaping to after-treatment $=1 \%$ of the mass flow rate of the fuel 


$$
\begin{aligned}
& =\frac{1}{100} \times 0.5787 \\
& =0.005787 \mathrm{gm} / \mathrm{sec}
\end{aligned}
$$

Based on the conversion efficiency of the after-treatment as 99\% [7], the amount of heat released at the after-treatment due to the oxidation process can be calculated.

Amount heat released in the after-treatment $=$ Mass of diesel escaping to after treatment $x$

$$
\begin{aligned}
& =\frac{0.005787 \times 43.2 \times 10^{6}}{10^{3}} \\
& =250 \text { Watts }
\end{aligned}
$$

After calibration of the RadTherm model with the experimental results, the heat generated at the after-treatment was set at 300 Watts.

\section{Calculations of Mass Flow rate of the exhaust gases}

Mass flow rate of the exhaust gases can be calculated using Equation 4.

$$
\begin{aligned}
& m_{\text {exhaust }}=m_{\text {int ake_air }}+m_{\text {fuel }} \\
& \text { where, } \\
& \cdot m_{\text {exhaust }}=\text { Mass flow rate of exhaust } \\
& \cdot m_{\text {int } a k e_{-} \text {air }=\text { Mass flow rate of intake air }} \\
& \cdot m_{\text {fuel }=\text { Mass flow rate of fuel }}
\end{aligned}
$$

\section{Case II at 12.2 mins}

As calculated before, 
Mass flow rate of the fuel $\left(m_{\text {fuel }}\right)=0.5787 \mathrm{gm} / \mathrm{sec}$

Mass flow rate of the intake air is calculated using Equation 5

$$
P V=m R T
$$

where,

$\mathrm{P}=$ Pressure in $\mathrm{Pa}=($ Standard atmospheric pressure $101325 \mathrm{~Pa})$

$V=$ Volume Flow rate obtained from the Calibration Curve in $\mathrm{m}^{3} / \mathrm{sec}$

$\mathrm{R}=$ Universal Gas Constant for air $=287.058 \mathrm{~J} / \mathrm{Kg} / \mathrm{K}$

$\mathrm{T}=$ temperature in Kelvin $=293 \mathrm{~K}$

$\mathrm{m}=$ Mass flow rate of the air in $\mathrm{Kg} / \mathrm{s}$

Pressure drop measured across manometer $=2.1 \mathrm{cms}$

From the Air Flow Rate V/s Pressure drop Calibration Curve (Figure 27)

Volume Air Flow Rate in CFM = 51.5 CFM

Volume Air Flow Rate of intake air (V) $=0.0243 \mathrm{~m}^{3} / \mathrm{sec}$

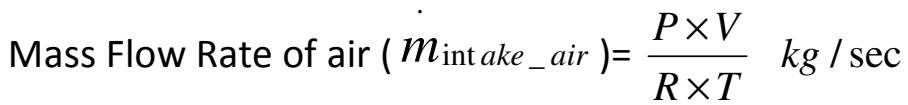

$$
\begin{aligned}
& =\frac{101325 \times 0.0243}{287 \times 293} \mathrm{~kg} / \mathrm{sec} \\
& =0.0292 \mathrm{~kg} / \mathrm{sec} \\
& =29.2 \mathrm{gm} / \mathrm{sec}
\end{aligned}
$$

Therefore, Mass flow rate of the exhaust gases

$$
\begin{gathered}
\dot{m}_{\text {exhaust }}=\dot{m}_{\text {int } \text { ake_air }_{-}+\dot{m}_{\text {fuel }}} \\
\dot{m}_{\text {exhaust }}=29.2+0.5787=29.7 \mathrm{gm} / \mathrm{sec}
\end{gathered}
$$




\section{Convective Augmentation Factor (CAF)}

The convective heat transfer coefficient has a considerable effect on the rate of heat transfer through convection. The pulsating and turbulent nature of flow also contributes to the value of heat transfer coefficient which in turn affects the overall heat transfer rates. Therefore, it was important to set this parameter correctly. Before calibrating the CAF, it was observed that the temperature of the exhaust gases as predicted by RadTherm model were much higher than the experimental values and the surface temperature of the exhaust system in the model were lower than the experimental values. This difference could be because of either the linear curve fit used for the calibration of the mass flow rate for the intake air or it could be also due to the exhaust gases were not transferring the heat to the exhaust system because of lower convective heat transfer coefficient in RadTherm. In order to account for this and match the experimental results, a Convective Augmentation Factor was introduced in the RadTherm model.

The convective heat transfer coefficient for any flow depends on relation between the three parameters namely the Nusselt Number(Nu), the PrandtI Number(Pr) and Reynolds Number(Re) [5]. For flow through pipes these parameters depend on a number of other parameters like flow velocity, wall surface roughness of the pipe, diameter of pipe and length to diameter ratio (l/d). The correlations [5] between these factors are as follows:

$$
\begin{aligned}
& N u_{\text {ideal }}=0.027 \operatorname{Re}^{4 / 5} \operatorname{Pr}^{1 / 3}\left(\frac{\mu}{\mu_{s}}\right)^{0.14} C_{\text {entr }} \\
& C_{\text {entr }}=0.892+\frac{2.02}{L / d} \\
& N u_{\text {actual }}=(C A F) 0.027 \operatorname{Re}^{4 / 5} \operatorname{Pr}^{1 / 3}\left(\frac{\mu}{\mu_{s}}\right)^{0.14} C_{\text {entr }} \\
& \text { Where, } \\
& C A F=\frac{N u_{\text {actual }}}{N u_{\text {ideal }}}
\end{aligned}
$$

In general, the value of CAF ranges from 2 to 3 [5]. The value of CAF in RadTherm model was tuned and set to 2 to match the experimental results. 


\section{Results And Discusion}

A RadTherm model for the exhaust system of HMMWV XM-1124 was developed for thermal analysis. After calibration of the CAF and the heat addition in the aftertreatment, the model was validated by comparing the results with the experiment results. The results were validated at the timestamp of 10.4 mins (CASE I) while the model was calibrated at timestamp of 12.2 mins (CASE II).

\subsection{Exhaust Gas Temperature Profile}

The temperature of the exhaust gases as they flow through the exhaust system were measured using thermocouples. This temperature profile was then compared with the temperature profile predicted by RadTherm. Figure 44 plots the exhaust gas temperature as it flows through the exhaust system for both the experimental and simulation cases. The $\mathrm{x}$-axis represents the location of the 5 thermocouples (T-1 to T5) along the length of exhaust system. As expected, it can be seen that the temperature of the exhaust gases as predicted by RadTherm decreases as the gases flow through the exhaust system due to heat is lost to the environment and vehicle underbody. With a second order polyfit for data points It can also be observed that the simulation results from RadTherm matches the experimental results with $95 \%$ accuracy.

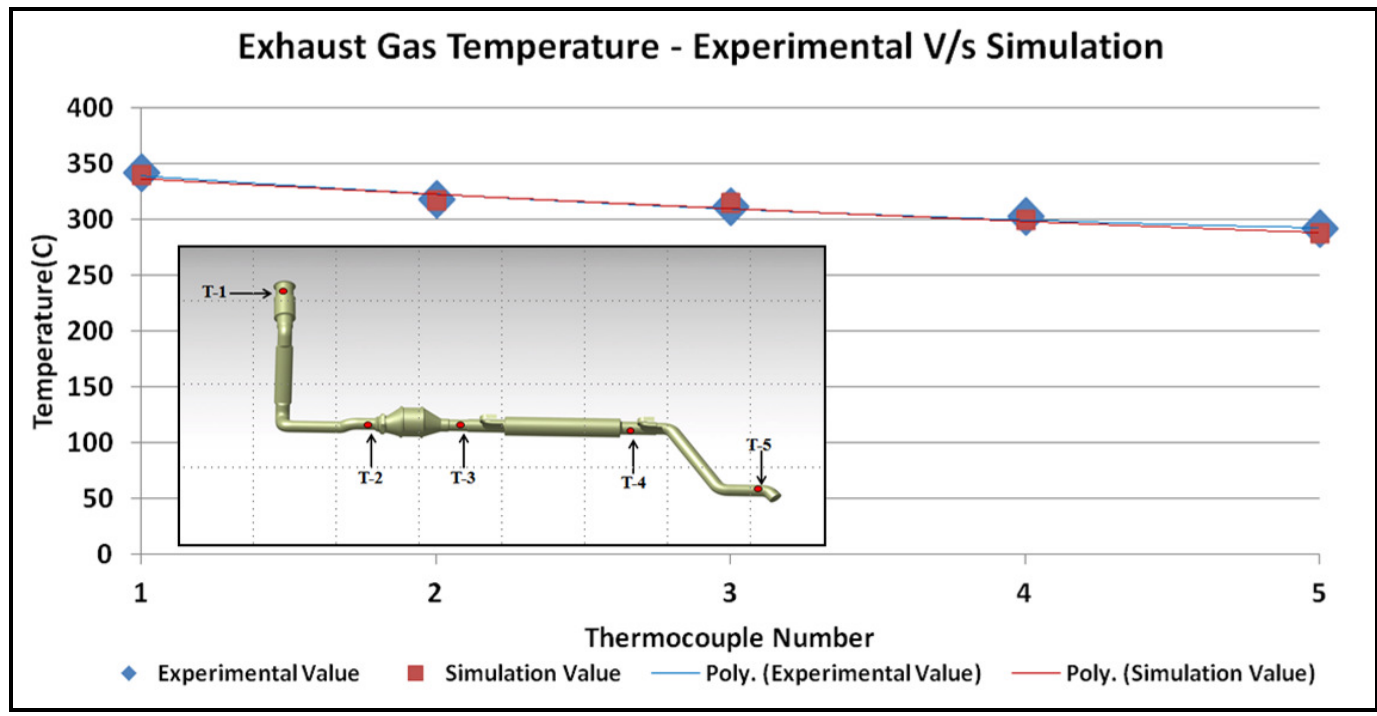

Figure 44 Exhaust Gas Temperature profile through the exhaust system for experimental and simulation results 


\subsection{Surface Temperature Profile for the Exhaust System}

The temperature profile for the surface of the exhaust system along the length was measured using thermocouples. The temperature profile obtained from the RadTherm simulation was compared with the actual temperature profile. Figure 45 plots the surface temperature for the exhaust system for both the experimental and simulation cases. The $x$-axis of the graph represents the location of the 4 thermocouples (TS-1 to TS-4) on the surface of the exhaust system along its length. It can be seen that the temperature of the exhaust gases as predicted by RadTherm matches closely with the actual temperatures measured on the HMMWV. The temperatures predicted by RadTherm were $7 \%$ higher than the actual temperatures measured on the HMMWV.

The difference in the results between experimental and actual values can be due to the following reasons:

1. Difference in the value of convective heat transfer coefficient ( $h$ ) on the outer surface of the exhaust pipe as calculated by RadTherm and the actual value.

2. It could be possible that when the temperatures were measured the system was still in transient state and may not have attained steady state completely. This explains why the experimental values are lower than the simulation values as the system was still heating up.

3. The ambient temperature for heat loss to surrounding was considered to be $20^{\circ} \mathrm{C}$ but in actual the floor temperature was likely colder than $20^{\circ} \mathrm{C}$. This could result in higher heat loss to the floor resulting in lower temperature for the surface of the exhaust system. 


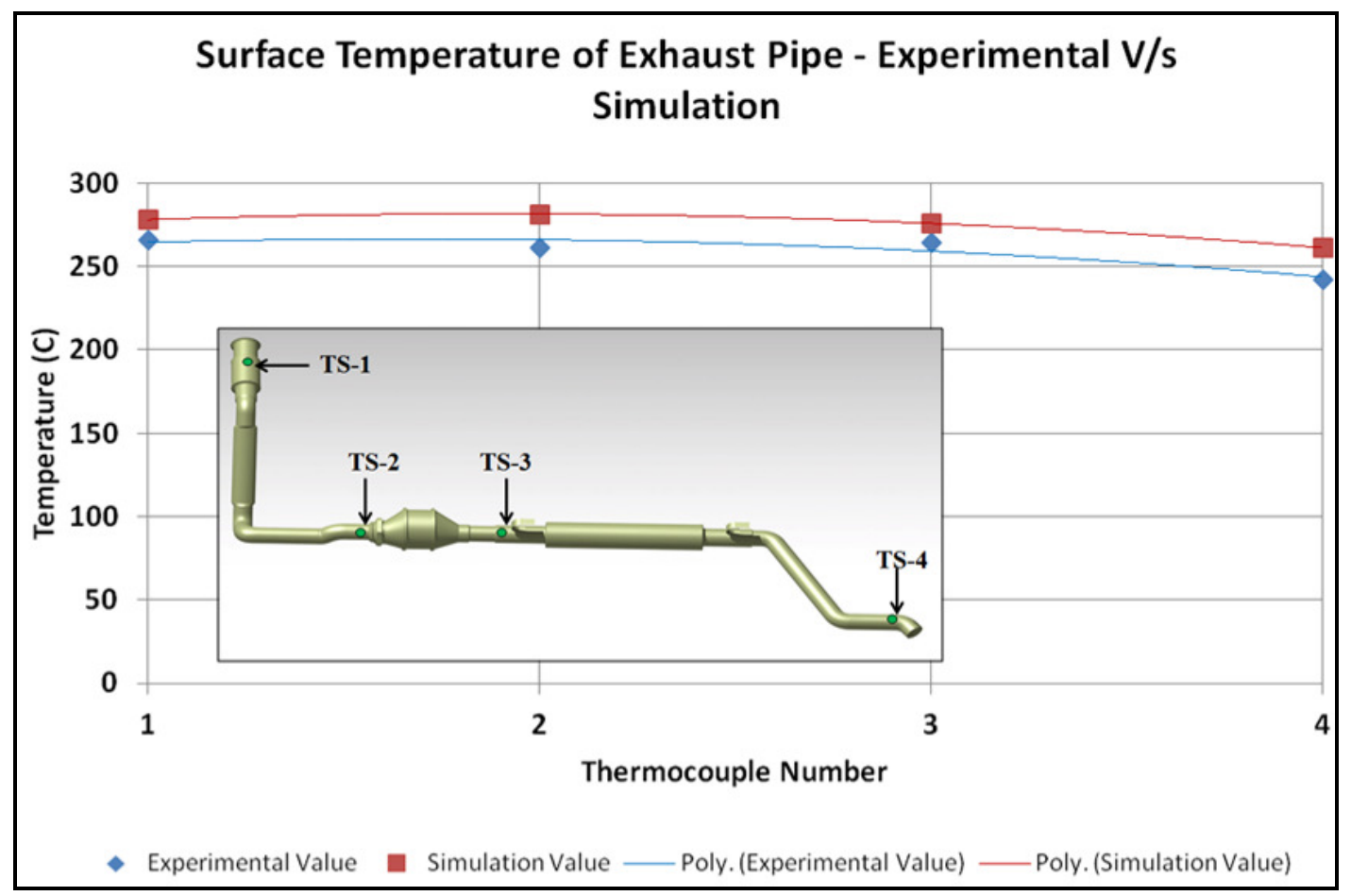

Figure 45 Surface Temperature Profile for Exhaust system for experimental and simulation results

\subsection{Surface Temperature for the Underbody of HMMWV}

To validate the RadTherm model of the exhaust system completely the underbody surface temperature of the HMMWV was compared with the temperatures as predicted by RadTherm. It was found that the temperatures predicted by RadTherm are within $5-6{ }^{\circ} \mathrm{C}$ to the actual temperatures measured on the vehicle. Figure 46 shows the comparison between the actual underbody temperatures and the values predicted by RadTherm. The x-axis of the plot represents the location of the thermocouples (UST-1 to UST-4. Refer to Table - 7 and Figure 35). It can be observed that except at UST - 4, the temperature at other locations are close to the simulation value. The location of the thermocouple at UST-4 was farthest from the exhaust system. This location was selected to verify one of anticipated the cold spots on the vehicle underbody.

The difference in the results could be attributed to the difference in the wind velocity which was considered in RadTherm. This factor affects the rate at which heat is lost to the environment and the amount of heat transferred to the vehicle underbody. 


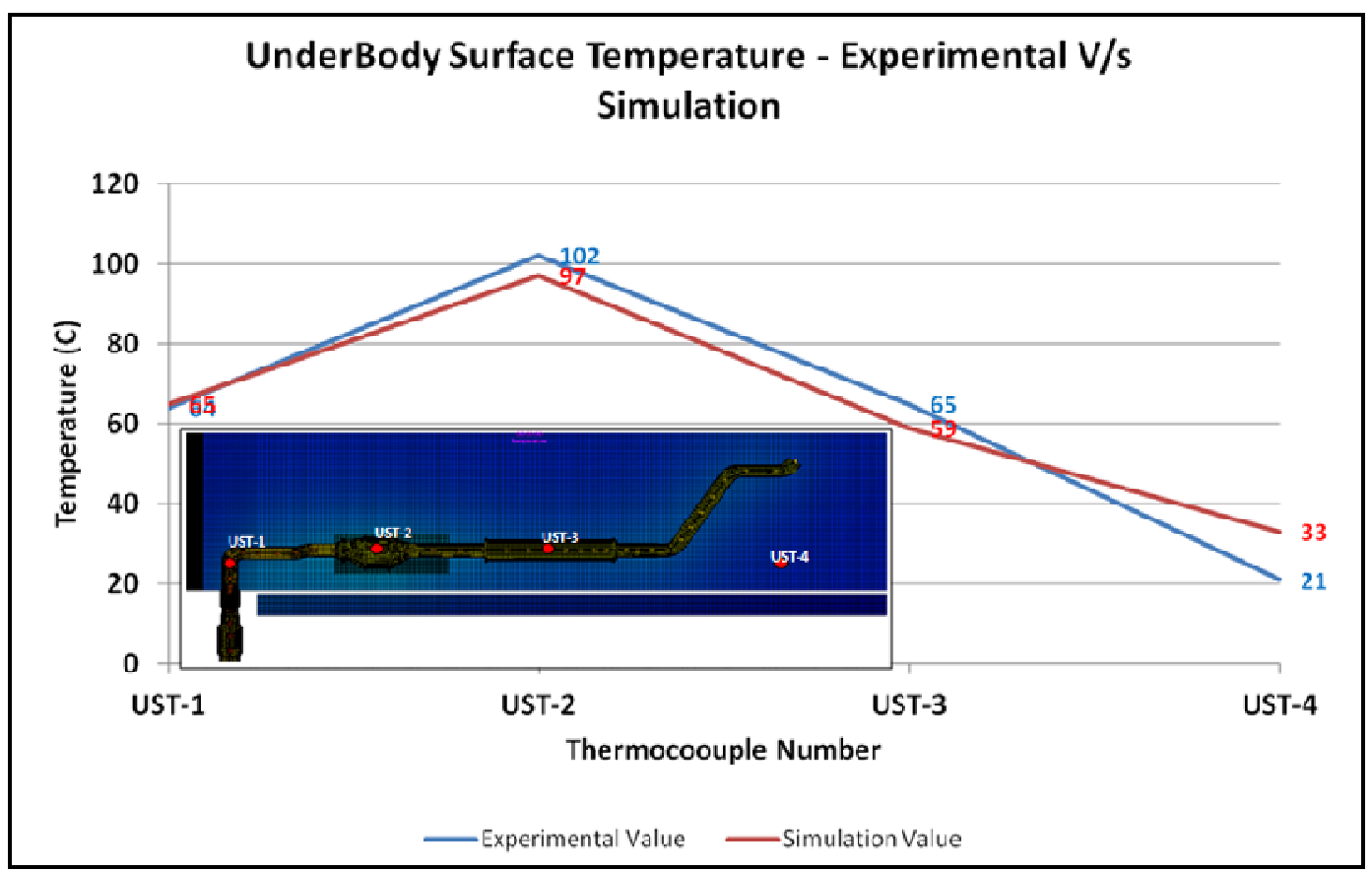

Figure 46 Surface Temperature for the Underbody of HMMWV for experimental and simulation results

\subsection{In-Cabin Floor Temperature of HMMWV}

The in-cabin floor temperature as obtained from the RadTherm model was close to the actual temperature measured on the vehicle. RadTherm model predicted the incabin floor temperature as $58^{\circ} \mathrm{C}$ as against the actual value of $52^{\circ} \mathrm{C}$. 


\section{Conclusion}

A RadTherm model for predicting the behavior of the exhaust system was successfully developed. After calibration, the RadTherm model closely matches the experimental results. Now that it is calibrated and validated, the simulation can be used as a predictive tool to identify hot spots in the exhaust system and the vehicle underbody and design appropriate heat shielding to prevent heat transfer into the cabin. This report also discussed the various methods for obtaining the mass flow rate of the exhaust system and how the temperature profile for the exhaust system and the vehicle underbody were measured and recorded.

The current RadTherm model simulates the exhaust system of the HMMVW under steady state operation. This is because one of the applications of this prototype HMMVW is to operate in a steady state condition and export electrical power to a small camp. Different engine operating load under steady state condition can be simulated by changing the inlet temperature and mass flow rate of the exhaust gases leaving the engine and entering the exhaust system. In the future, this model can be modified to predict the behavior of transient engine operation by providing a time dependent temperature profile for the exhaust gases at the inlet of the exhaust system.

This research work was also included in the MEEM 5296 Advanced Propulsion Systems for HEV Lab class as an assignment for the SPRING 2015 semester. This assignment provided students with a balance exposure to simulation and validation of simulation results with experimental data. 


\section{Appendix}

\subsection{Energy conversion efficiencies for different powerplants}

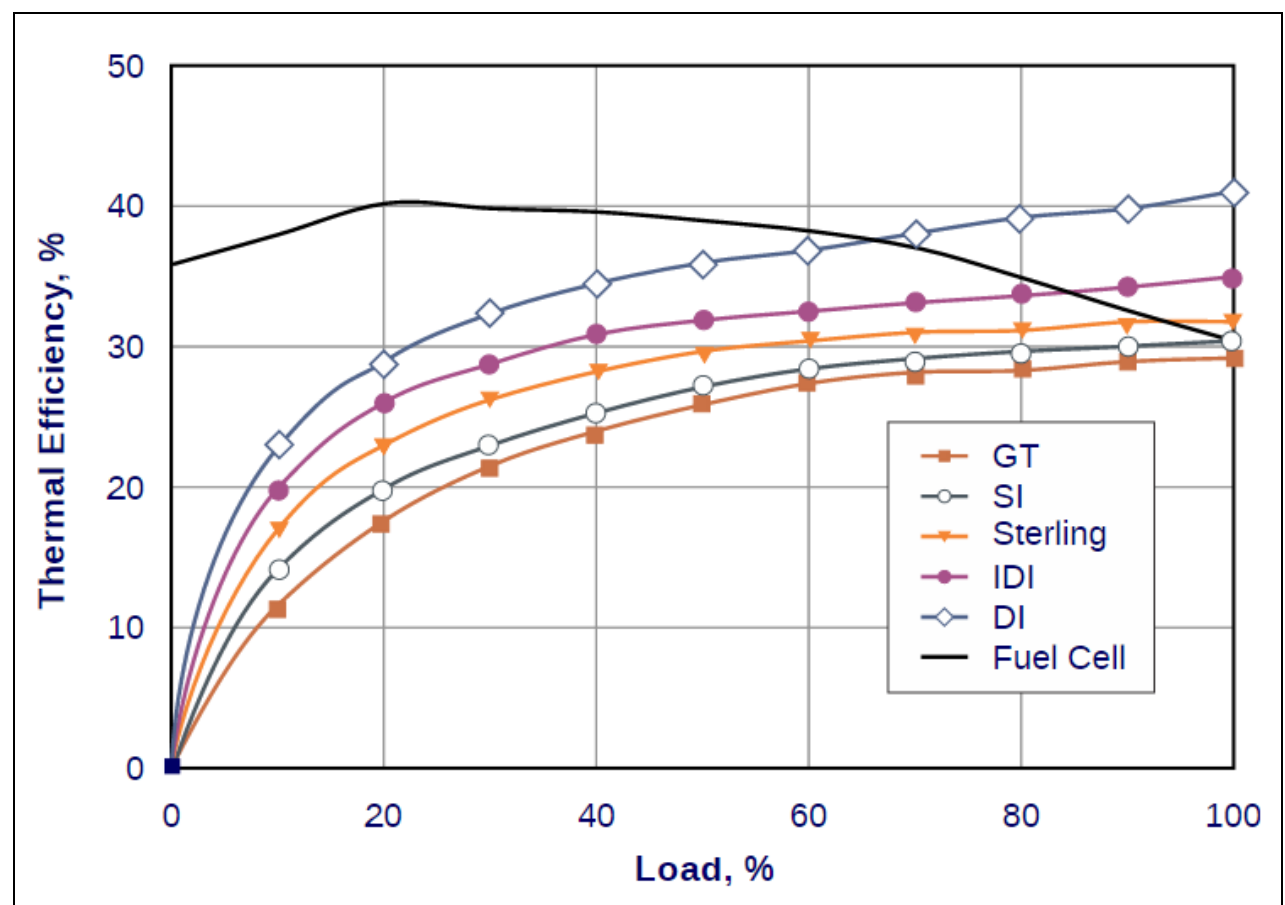

Figure 47 Energy conversion efficiencies for different powerplants [source: https://www.dieselnet.com/tech/diesel_powerplants.php] 


\section{References}

1. Training Manual for BOSCH EDC $15 C 2$ HDI SYSTEM (High pressure Diesel Injection)

2. Sensors for Engine Management, TecDoc Web Catalog - Certified Data Supplier

3. UQM Technologies PowerPhase 100 Traction System - For Electric, Hybrid Electric, and Fuel Cell Powered Vehicles

4. Internal Combustion Engine Fundamental by John B. Heywood

5. Depcik, C. and Assanis, D., "A Universal Heat Transfer Correlation for Intake and Exhaust Flows in an Spark-Ignition Internal Combustion Engine," SAE Technical Paper 2002-01-0372, 2002, doi:10.4271/2002-01-0372.

6. RadTherm User Manual Version: 11.3.0

7. Watling, T., Ahmadinejad, M., Juţuianu, M., Johansson, Å. et al., "Development and Validation of a Pt-Pd Diesel Oxidation Catalyst Model," SAE Int. J. Engines 5(3):14201442, 2012, doi:10.4271/2012-01-1286. 